2. To: (Receiving Organization) Distribution

5. Proj./Prog./Dept./Div.:

Hanford Defined Waste

Model/Waste

Management/M\&I/Process

Engineering

8. Originator Remarks:

This document is being released into the supporting document system for retrievabijity purposes.

11. Receiver Remarks: 11A. Design Baseline Document? [] Yes [X] No For release.

3. From: (originating Organization)
Models and Inventory
Engr.:

R. W. Harmsen
6. Design Authority/ Design Agent/Cog.
4. Related EDT No.:

$\mathrm{N} / \mathrm{A}$.

7. Purchase Order No.:

$N / A$

9. Equip./Component No.:

$\mathrm{N} / \mathrm{A}$

10. System/Bldg./Facility: $\mathrm{N} / \mathrm{A}$

12. Major Assm. Dwg: No.: $N / A$

13. Permit/Permit Application No.: $\mathrm{N} / \mathrm{A}$

14. Required Response Date: $10 / 27 / 98$

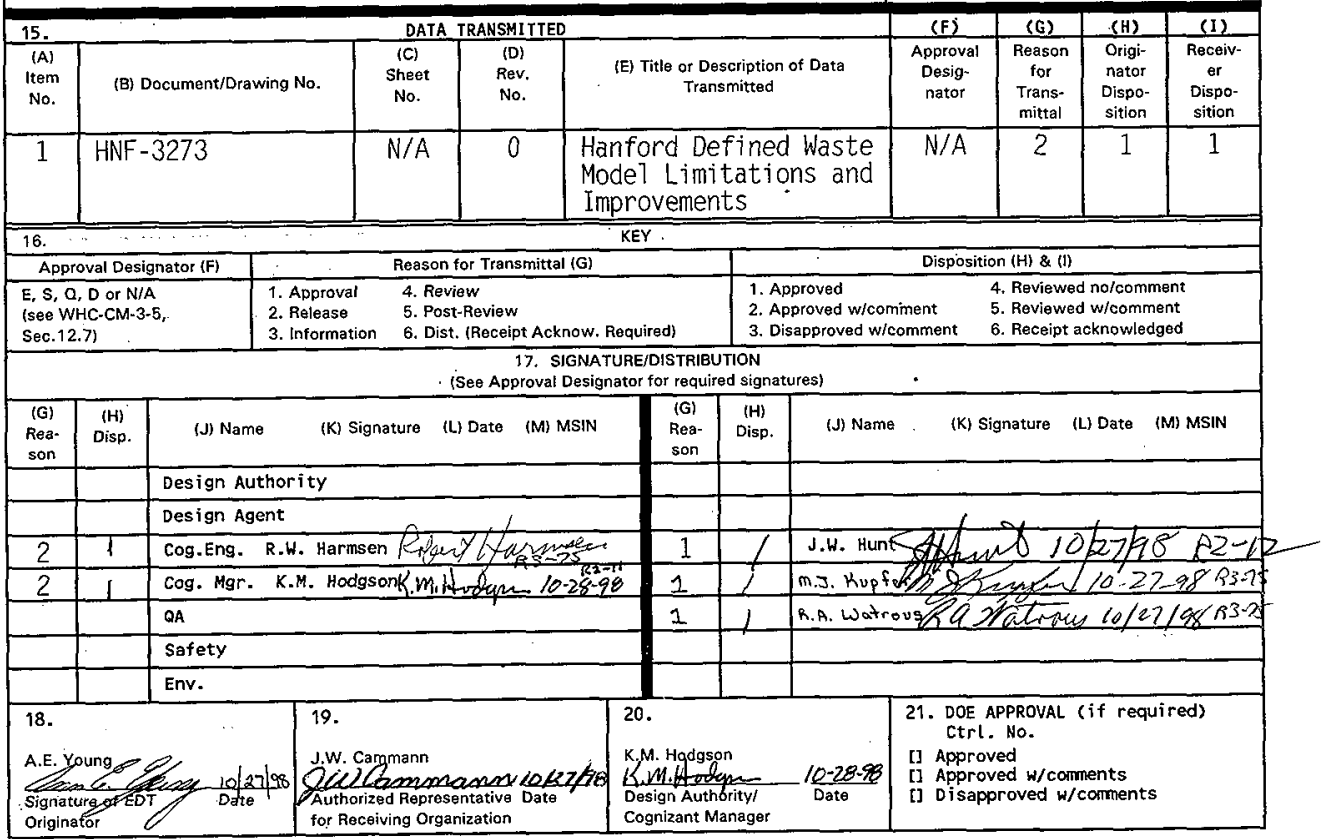

BD-7400-172-2 (05/96) GEF097 


\section{Hanford Defined Waste Model Limitations and Improvements}

R.W. Harmsen, J.W. Cammann, M.J. Kupfer, R.A. Watrous, and S.L. Lambert (COGEMA) Lockheed Martin Hanford, Corp., Richland, WA 99352

U.S. Department of Energy Contract DE-AC06-96RL13200

EDT/ECN: EDT-622490

Org Code: 74840

B\&R Code: EW 3120074
UC: 2070

Charge Code: CACN 102238/COA EI00

Key Words: DNFSB 93-5 Committment 5.6.3.1.i, Hanford Defined Waste Rev. 4. HDW, Limitations, Recommendations

Abstract: Recommendation 93-5 Implementation Plan, Milestone 5.6.3.1.i requires issuance of this report which addresses "updates to the tank contents model". This report summarizes the review of the Hanford Defined Waste, Revision 4, model limitations and provides conclusions and recommendations for potential updates to the model.

TRADEMARK DISCLAIMER. Reference herein to any specific commercial product, process, or service by trade name, tradenark, manufacturer, or otherwise, does not necessarily constitute or imply its endorsement, recommendation, or favoring by the United States Government or any agency thereof or its contractors or subcontractors.

Printed in the United States of America. To obtain copies of this document, contact: Document Control Services, P.0. 80x 950, Mailstop H6-08, Richland WA 99352, Phone (509) 372-2420; Fax (509) 376-4989.

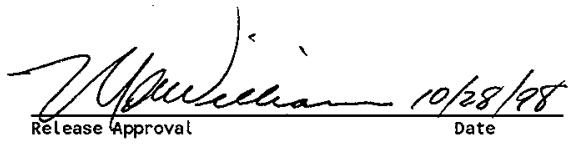

Approved for Public Release 
HNF-3273

Revision 0

\title{
HANFORD DEFINED WASTE MODEL LIMITATIONS AND IMPROVEMENTS
}

October 1998

\author{
R. W. Harmsen \\ R. A. Watrous \\ J. W. Cammann \\ M. J. Kupfer \\ Lockheed Martin Hanford Corporation \\ Richland, Washington \\ S. L. Lambert \\ Cogema \\ Richland, Washington \\ Prepared for \\ U.S. Department of Energy \\ Richland, Washington
}


HNF-3273

Revision 0

This page intentionally left blank. 
HNF-3273

Revision 0

CONTENTS

1.0 INTRODUCTION

1.1 BACKGROUND: RECOMMENDATION 93-5 IMPLEMENTATION PLAN5

1.2 WASTE CHARACTERIZATION AND SAFETY STRATEGY ...............6

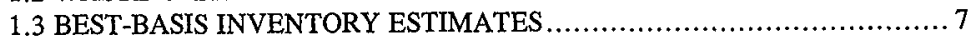

1.4 EVALUATION OF THE TANK CONTENTS MODEL $\ldots \ldots \ldots \ldots \ldots \ldots \ldots \ldots \ldots . \ldots \ldots$

1.5 USE OF THE TANK CONTENTS MODEL: HDW MODEL (REV. 4),.....8

2.0 HANFORD DEFINED WASTE MODEL DEVELOPMENT ....................11

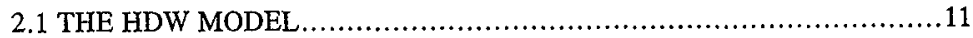

2.1.1 HDW Model - Rev. 0 .............................................. 11

2.1.2 HDW Model - Rev. 1 .............................................12

2.1.3 HDW Model - Rev. 2 .............................................12

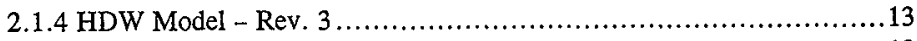

2.1.5 HDW Model - Rev. 4 ...............................................13

2.2 HDW MODEL (REVISION 4) USER INTERFACE .......................14

3.0 LIMITATIONS AND ACCURACY OF HDW MODEL - RADIONUCLIDES...17

3.1 UNCERTAINTIES AFFECTING GLOBAL INVENTORY MODELING.....17

3.2 UNCERTAINTIES AFFECTING INDIVIDUAL TANK INVENTORY

MODELING .......................................................20

3.2.1 Sixty Tank Broad Comparison ..........................................20

3.2.2 Uncertainties Due To Solubility and Partitioning Factors................21

3.2.3 Uncertainties Due to Waste Transaction Data Base Errors ...............22

3.2.4 Uncertainties Due to Model Methodology (Waste Averaging) ...........22

4.0 SUMMARY AND RECOMMENDATIONS …...................................25

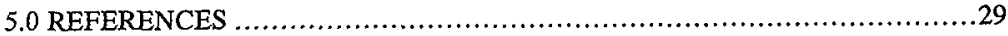

\section{LIST OF TABLES}

Table 3-1. Uncertainty in Global Inventory Values....................................15 
HNF-3273

Revision 0

\section{LIST OF TERMS}

$\begin{array}{ll}\text { BBI } & \text { Best-Basis Inventory } \\ \text { DBP } & \text { Dibutyl phosphate } \\ \text { DKPRO } & \text { Computer code for radioactive decay and separations processing } \\ \text { DNFSB } & \text { Defense Nuclear Facilities Safety Board } \\ \text { DOE } & \text { U.S. Department of Energy } \\ \text { DQO } & \text { Data quality objective } \\ \text { DST } & \text { Double-shell tank } \\ \text { EDTA } & \text { Ethylenediaminetetracetic acid } \\ \text { FY } & \text { Fiscal year } \\ \text { HDW } & \text { Hanford Defined Waste } \\ \text { HEDTA } & \text { Hydroxyethylethylenediaminetriacetic acid } \\ \text { HTCE } & \text { Historical Tank Content Estimates } \\ \text { ORIGEN2 } & \text { Oak Ridge Isotope Generation (computer code) } \\ \text { PUREX } & \text { Plutonium-uranium extraction (fuel separation process) } \\ \text { REDOX } & \text { Reduction and oxidation (fuel separation process } \\ \text { RSD } & \text { Relative standard deviation } \\ \text { SMM } & \text { Supernatant Mixing Model } \\ \text { SST } & \text { Single-shell tank } \\ \text { TLM } & \text { Tank Layering Model } \\ \text { TOC } & \text { Total organic carbon } \\ \text { TWRS } & \text { Tank Waste Remediation System } \\ \text { WSTRS } & \text { Waste Status and Transaction Record Summary } \\ & \end{array}$


HNF-3273

Revision 0

\section{HANFORD DEFINED WASTE MODEL LIMITATIONS AND IMPROVEMENTS}

\subsection{INTRODUCTION}

\subsection{BACKGROUND: RECOMMENDATION 93-5 IMPLEMENTATION PLAN}

On September 9, 1993, the U.S. Department of Energy (DOE) accepted Defense Nuclear Facilities Safety Board (DNFSB) Recommendation 93-5. Recommendation 93-5 notes that there is insufficient tank waste technical information to ensure that Hanford Site tank wastes can be safely stored, that associated operations can be safely conducted, and that future disposal data requirements can be met.

Since Recommendation 93-5 was issued, significant progress has been made in understanding tank safety-related phenomena, resolving tank safety issues, and enhancing the capabilities and efficiency of tank waste characterization operations. Accomplishments in each of these areas led to the realization that tank safety issues can not be resolved solely by accelerating tank waste sampling and analysis activities. It was decided that the key to resolving safety issues is to better understand safety- related tank waste phenomena.

A revised characterization and safety strategy was developed in May of 1996. This revised strategy, DOE/RL 94-0001, "Recommendation 93-5 Implementation Plan, Revision 1," is a multifaceted approach consisting of numerous activities. In general, the primary focus is on maintaining tanks in an interim configuration using safety measures, engineering controls, administrative procedures, and mitigative actions. Key elements of the approach include sampling of High Priority Tanks, safety screening sample analyses, qualification of rotary mode core sampling, determination of flammable gas concentrations and the presence of organic solvents.

Section 5.6 and Appendix J of the Recommendation 93-5 Implementation Plan discuss completion of tank waste sampling and analysis in accordance with the Tank Characterization Technical Sampling Basis (Brown et al. 1998). Sampling and analysis plans focus on providing the highest priority tank waste information by imposing a multitude of Tank Waste Remediation System (TWRS) Data Quality Objectives (DQOs).

Section 5.6.3.1 of the Recommendation 93-5 Implementation Plan lists milestones for addressing DNFSB concerns regarding tank waste characterization and safety. One of the milestones, 5.6.3.1.i, requires issuance of this report addressing "Updates to the Tank Contents Model or Define Limitations of the Model." Other related DNFSB milestones that have been completed in prior fiscal years include 5.6.3.1.d, "Update 
HNF-3273

Revision 0

Historical Tank Content Estimates (HTCEs)" and 5.6.3.1.f, "Provide Standard Inventory Estimates for all Tanks."

\subsection{WASTE CHARACTERIZATION AND SAFETY STRATEGY}

Hanford's single- and double-shell tank wastes are diverse due to numerous processing operations conducted over the past four to five decades. This diversity of processing operations, coupled with incomplete records of tank waste transfers over the years, creates a complex challenge for tank waste characterization. This situation is complicated by limited riser locations for sampling, incomplete core recovery during sampling, and spatial variability within the wastes.

A fundamental step in tank waste characterization is the development of an approach for acquiring tank waste samples and evaluating tank waste information. In an unconstrained environment, standard tank waste sampling schemes (random grids, sequential sampling, etc.) could be implemented to reduce uncertainties associated with estimating tank waste inventories. However, the tank waste sampling situation is highly constrained at the Hanford Site. As a result, a meaningful, statistically defensible picture of tank waste inventories cannot be provided through sampling alone.

Consequently, tank waste samples cannot be considered in isolation. Numerous sources of tank waste information exist, and must be considered in conjunction with sample results to develop a more thorough understanding of tank waste inventories. These sources of information include process flowsheets, chemical use records, material purchase records, waste transfer histories, surveillance measurements, numerical model predictions, and other sources of tank waste data.

Two key sources of information used in determining tank waste inventories are (1) the analytical data from samples of tank wastes, and (2) numerical model predictions of tank inventories using the Hanford Defined Waste (HDW) model. The HDW model estimates tank inventories based on historical waste processing records. Engineering assessments are also performed to determine tank waste inventories. The engineering assessments are based on process history and evaluation of samples from other tanks believed to contain similar waste types (i.e., tank groupings and associated waste type templates). Although engineering assessments utilize process history, some input assumptions (e.g., flowsheet basis) may differ from those assumed in the HDW model if the revised assumptions are believed to be a better representation of the actual situation. 
HNF-3273

Revision 0

\subsection{BEST-BASIS INVENTORY ESTIMATES}

DNFSB milestone 5.6.3.1.f, "Standard Inventory Estimates for all Tanks," was completed in August of 1997. These standard inventory estimates, more commonly referred to as the Best-Basis Inventories (BBIs), include 25 chemical analytes and 46 radionuclides. The chemical analytes and radionuclides comprising the BBIs were determined following review of applicable TWRS programmatic DQOs. The BBIs were generated on a tank-specific, as well as global basis, and represent greater than 99 percent of the chemical mass and radionuclide activity in Hanford tank wastes. The global inventory estimates include five additional chemical analytes that were introduced during fuel fabrication, fuel fission and activation, chemical process operations, and chemical impurities.

The BBIs are based on actual sample results, when the data are available and deemed reliable. In the absence of actual sample results, engineering assessments are conducted to extrapolate knowledge gained from sampled tanks to tanks believed to contain similar waste types. In the absence of reliable sample results and a basis for engineering assessment extrapolations, HDW model (Rev. 4) inventory predictions are used. During the development of the BBIs, all sources of tank inventory information (sample results, engineering assessments, and HDW model predictions) were considered and reconciled against one another to arrive at the best estimate of tank waste inventories. This methodology is discussed further in Standard Inventories of Chemicals and Radionuclides in Hanford Site Tank Wastes (Kupfer et al. 1997).

This report addresses how the information gained from the sampling and analysis of high priority tanks has resulted in updates to the HDW model. Existing limitations of the HDW model are also discussed along with proposals for additional model enhancements to improve the model's predictive capabilities, where warranted.

\subsection{EVALUATION OF THE TANK CONTENTS MODEL}

The quality of HDW model predictions must be assessed to ensure the credibility and defensibility of model-based predictions of tank waste inventories. The historical information forming the basis for the HDW model, although extensive, is still incomplete. Furthermore, certain assumptions regarding waste content and behavior are embedded within the HDW model's architecture. The resulting model-based predictions of tank waste inventories contain potential inaccuracies that need to be better understood and quantified. This report discusses the results of HDW model evaluations in each of the following areas:

Input information - evaluate source terms, solubilities, split factors, transaction records, and other key input data necessary for predicting tank waste inventories, 
HNF-3273

Revision 0

Assumptions and sensitivities - evaluate the physical and chemical constraints imposed by embedded modeling assumptions and determine if the model introduces, dampens, or exacerbates variability in the tank waste inventory estimates.

Output comparisons and uncertainties - compare sampling data and model predictions to examine model accuracy, and evaluate uncertainties associated with process and analyte solubility variations.

In addition to these areas of evaluation, a Historical Model Evaluation Data Requirements (Simpson and McCain 1997) document was prepared in support of tank waste sampling activities. This DQO is being used to obtain information through selective tank waste sampling to refine waste type templates and quantify uncertainties in tank waste inventory predictions.

\subsection{USE OF THE TANK CONTENTS MODEL: HDW MODEL (REV. 4)}

It is generally preferable to base tank waste inventories on actual sample results when the data is available and deemed reliable. This includes template-based extrapolations of sample results from sampled to unsampled tanks if the process history and waste transaction records suggest that the tanks contain similar waste types. In the absence of reliable sample results and a sound technical basis for extrapolating sample results from one tank to another, the HDW model provides a process history-based prediction of tank waste inventories.

Although sample-based inventories are desired, engineering assessment-based inventories provide an important verification function. It is possible for sample-based inventories to be biased as a result of limited sampling locations, poor sample recovery, and spatial heterogeneities within the waste. Engineering assessment-based inventories provide a process flowsheet-based comparison to determine if sample-based inventories are the best representation of tank contents.

Comparison of sample-based and engineering assessment-based inventories with the HDW model predictions can be useful. Major differences in the inventories predicted by the various methods could result from biases in the sample results, variations in assumed process flowsheets, or invalid assumptions used by the HDW model. Experience has shown that some defined waste compositions used by the HDW model differ from those derived from engineering assessments or indicated from sample data. Also, assumptions in the HDW model regarding component solubilities often differ significantly from those assumed in engineering assessments or indicated from sample data. A separate task was completed during fiscal year 1997 to document deficiencies in the HDW model. These deficiencies are discussed in this report.

For the 25 chemical analytes comprising the BBI, sufficient analytical information is usually obtained during tank waste sampling or can be extrapolated from engineering 
HNF-3273

\section{Revision 0}

assessments of tanks containing similar waste types, to support sample-based BBIs. Consequently, the HDW model is not relied upon for estimates of chemical analyte inventories and is used primarily in a comparative mode only. Conversely, the HDW model is relied upon heavily for predicting the inventories of the 46 radionuclides comprising the BBIs. This is due largely to the lack of analytical data for the majority of the radionuclides. Therefore, the model updates and limitations discussed in this report focus primarily on the radionuclide prediction capabilities of the HDW model.

A representative database for chemical analytes contained in the tanks has been developed as a result of extensive core sampling in roughly 100 Hanford Site singleshell tanks (SSTs) and double-shell tanks (DSTs). This chemical analyte database has been used to construct templates that represent the composition of common waste types found in the tanks. Since the information used by the HDW model to predict chemical and radionuclide inventories is based on the same set of historical records, it is possible to test the validity of the HDW model for various groups of tanks. The objective would be to not only test the validity of the HDW model, but also identify areas where chemical analyte inventory predictions could be improved and used for better radionuclide inventory estimates (i.e., chemical analogs that mimic radionuclide behavior). This is discussed further in Appendix $\mathrm{E}$ of this report. 
HNF-3273

Revision 0

This page intentionally left blank. 
HNF-3273

Revision 0

\subsection{HANFORD DEFINED WASTE MODEL DEVELOPMENT}

\subsection{THE HDW MODEL}

An insightful first step in the characterization of tank waste is the compilation and evaluation of historical information regarding the waste-generating processes and the transfer of waste materials to and from tanks. This historical information provides a sound basis for a "first approximation" of tank contents that can be compared to actual tank waste sample results.

A more complete model of tank contents was developed from historical records (Historical Tank Content Estimates, [HTCEs]) to meet DNFSB milestone 5.6.3.1.d. The HTCEs included all contributing waste streams for each tank to predict an overall tank waste inventory.

In order to prepare the HTCEs, the following major tasks were completed:

- Chemical compositions for $\mathbf{4 8}$ process waste streams from four separations plants, several different radionuclide recovery operations, and eight different evaporator campaigns were defined (HDW, Agnew et al. 1996).

- Fifty years of process history and more than 40,000 documented transactions were organized into a structured database (WSTRS, Agnew et al. 1995a).

- Volumes and locations of the various process wastes in the tank farms were estimated (Tank Layering Model [TLM], Agnew et al. 1995b).

- Compositions of concentrated and non-concentrated supernatant mixtures were calculated (Supernatant Mixing Model [SMM], Agnew et al. 1996).

These four task areas were integrated into a model for estimating the chemical and radionuclide compositions of the 149 SSTs and 28 DSTs. This fully integrated model is referred to as the HDW model.

\subsubsection{HDW Model - Rev. 0}

The HDW model was first used to predict chemical and radionuclide inventories in Northeast and Southwest quadrant tanks in June of 1994 (Rev. 0). The Northeast quadrant includes tanks in 241-A, - AX, -B, -BX, -BY, and -C tank farms. The 
Southwest quadrant includes tanks in $241-\mathrm{S},-\mathrm{SX}$, and $-\mathrm{U}$ tank farms. Revision 0 of the HDW model assumed single waste types for saltcake and salt slurry.

\subsubsection{HDW Model - Rev. 1}

In the Fall of 1994, Revision 1 of the HDW model was used to predict the chemical and radionuclide inventories for all SSTs (Northeast, Northwest, and Southwest quadrants). Chemical and radionuclide inventories in the double-shell tanks (Southeast quadrant) were estimated in March of 1995.

The major difference between Revision 0 and Revision 1 was the addition of process vessel corrosion source terms ( $\mathrm{Fe}, \mathrm{Cr}$, and $\mathrm{Ni}$ ) and a source term for hard water $(\mathrm{Ca})$. Revision 1 also blended all evaporator campaigns into multi-year composites. The evaporator blends were an improvement over the single waste types for saltcake and salt slurry assumed in Revision 0 . The evaporator blends provided good representations of the total waste generated during a campaign and overall waste volume reduction. However, one of the problems with Revision 1 was that it calculated ${ }^{137} \mathrm{Cs}$ and ${ }^{90} \mathrm{Sr}$ inventories roughly 20 percent higher than would be expected.

\subsubsection{HDW Model - Rev. 2}

Revision 2 of the HDW model was issued in the Winter of 1995 (Agnew et al. 1995c). The five later evaporator campaigns were expressed on a tank-by-tank basis using the Supernatant Mixing Model (SMM) to predict waste concentration histories through each of the evaporator campaigns.

A Revision 2.1 was issued to correct problems with the calculation of water content and total organic carbon (TOC). Revision 2, and its successor Revision 2.1, improved the ${ }^{137} \mathrm{Cs}$ and ${ }^{90} \mathrm{Sr}$ inventory calculation deficiencies inherent in Revision 1 . Revision 2.1 also included chloride and potassium source terms that are affected by sodium hydroxide additions. Several other changes were made including the addition of a mercury source term for the fuel decladding process, slight adjustments to the wastes generated by the uranium recovery process, and realignment of the first- and second-cycle bismuth phosphate process waste campaigns.

Revision 2 also reduced the process vessel corrosion source terms for early bismuth phosphate wastes and decladding wastes. This reduction in corrosion source terms was consistent with the fact that bismuth phosphate and decladding waste processes were much less corrosive than either the reduction and oxidation (REDOX) or plutonium-uranium extraction (PUREX) processes.

Despite improvements made in Revision 2 and Revision 2.1, problems still existed as a result of incomplete waste transaction records for later evaporator campaigns and 
resultant impacts on the distribution of waste concentrates. Most notable were problems with chemically impossible over concentration (e.g., Na in excess of $16 \mathrm{~mol} / \mathrm{L}$ ) while slurry receivers were more dilute than expected.

\subsubsection{HDW Model - Rev. 3}

Revision 3 of the HDW model was issued in May of 1996 (Agnew et al. 1996). Extensive modifications of the WSTRS dataset occurred as a result of adjusting evaporator transactions to blend on a quarterly, or even finer time scale. Improvements in the transaction records were possible through the discovery and incorporation of new evaporator logbook datasets. An extensive set of reports addressing 242-S and 242-A evaporator operations were also uncovered and incorporated. Unfortunately, detailed information regarding $242-\mathrm{T}$ evaporator operations was lacking.

The analyte list included 4 radionuclides $\left({ }^{137} \mathrm{Cs},{ }^{90} \mathrm{Sr},{ }^{239} \mathrm{Pu}\right.$, and $\left.{ }^{238} \mathrm{U}\right)$ and 33 nonradioactive chemical species ( $\mathrm{Na}, \mathrm{Al}, \mathrm{Fe}, \mathrm{Cr}, \mathrm{Bi}, \mathrm{La}, \mathrm{Hg}, \mathrm{Zr}, \mathrm{Pb}, \mathrm{Ni}, \mathrm{Sr}$ (stable), $\mathrm{Mn}, \mathrm{Ca}, \mathrm{K}, \mathrm{OH}$, nitrate, nitrite, carbonate, phosphate, sulfate, silicate, $\mathrm{F}, \mathrm{Cl}$, citrate, ethylenediaminetetracetic acid [EDTA], hydroxyethylethylenediaminetriacetic acid [HEDTA], glycolate, acetate, oxalate, dibutyl phosphate [DBP], butanol, ammonia, and ferrocyanide). Five waste properties are also included (density, wt\% water, wt\% TOC, sludge void fraction, and heat load).

Analyte inventories change very little from previous versions of the model. Most notable were changes in $\mathrm{Pb}, \mathrm{Mn}$, and oxalate inventories. The $\mathrm{Pb}$ inventories increased by almost two orders of magnitude due to the inclusion of the $\mathrm{Pb}$ coating that covered each fuel slug. An error was discovered in the Mn concentration in PUREX organic wash wastes during the 1963 to 1967 time period. The correction of this error reduced the $\mathrm{Mn}$ inventory by a factor of five. The oxalate inventory increased by a factor of three as a result of a decrease in the assumed solubility limit.

\subsubsection{HDW Model - Rev. 4}

The current version of the HDW model, Revision 4, was issued in January of 1997 (Agnew et al. 1997). Two primary modifications were made in this version of the model. First, the number of radionuclides with predicted inventories was expanded from four to 46. Secondly, calculations of analyte variabilities for each tank based on process and solubility uncertainties were included.

The historical Fuel Activity Data File generated by the DKPRO ${ }^{1}$ computer code is the HDW model's primary radionuclide source term. This file determines the activity,

${ }^{1}$ DKPRO is a computer code for radioactive decay and separations processing. 
in terms of curies, for the 46 radionuclides in each of 1,276 batches of Hanford reactor fuel processed through the separations plants from 1944 through 1989. The DKPRO calculations of radionuclide activity are based on ORIGEN $2^{2}$ computer runs that predict discharged fuel activity for a series of fuel exposure levels and fuel types. The output from the DKPRO computer code is expressed in terms of curies per metric ton of uranium (Ci/MTU). Revision 4 represents the first attempt at carrying radionuclides through reprocessing for uranium recovery and B-Plant $\mathrm{Sr} / \mathrm{Cs}$ campaigns.

Revision 4 also addresses two sources of uncertainty resulting from process and solubility variations. The variation of 33 processes is calculated at $+/-1.00$ Relative Standard Deviation (RSD) to generate two scenarios. Two separate scenarios are also calculated for 24 analyte solubilities that are varied as a group by $+/-1.00$ RSD, along with 16 analyte solubilities that are varied independently for 32 additional scenarios. In all, 36 scenarios of the $48 \mathrm{HDW}$ provide 1,728 variations for each analyte in each tank at $+/-1.00$ RSD. Maximum and minimum variations are selected from this set to represent $+/-1.00 \mathrm{RSD}$ (67 percent confidence interval). Another 1,728 variations are calculated for the $+/-1.96 \mathrm{RSD}$. Their maximum and minimum variations then determine the $+/-1.96$ RSD (95 percent confidence interval).

\subsection{HDW MODEL (REVISION 4) USER INTERFACE}

The HDW model is a valuable tool for predicting the chemical and radionuclide inventories in tanks where no sampling results exist or a basis for engineering assessment extrapolations from similar tanks is not possible. In an effort to maximize the flexibility of the HDW model and easily accommodate changes in model input parameters and assumptions, a HDW model user interface was developed during Fiscal Year (FY) 1998.

The user interface provides on-line interaction with the HDW model. It is written in Visual Basic ${ }^{3}$ for Applications, the standard macro programming language for all Microsoft Office ${ }^{4}$ applications. Three Microsoft Excel ${ }^{5}$ workbooks and one dynamic link library file were developed to facilitate access to, and manipulation of, HDW model input parameters and assumptions.

Once the user interface is accessed, a series of tabs are provided to make changes in the HDW model input parameters and assumptions. A "General" tab includes options for automatically adjusting the fraction precipitated in the HDW model, establish the run date for inventory estimates, check for values exceeding user-definable

\footnotetext{
${ }^{2}$ ORIGEN2 (Oak Ridge Isotope Generation) is a computer code.

${ }^{3}$ Visual Basic is a trademark of Microsoft Corporation.

${ }^{4}$ Microsoft Office is a trademark of Microsoft Corporation.

${ }^{5}$ Microsoft Excel is a trademark of Microsoft Corporation.
} 
limits, and generate a log file of changes to the HDW model input parameters and assumptions.

A "Solubility Limits" tab enables changes to solubility limits in one of two ways. First, solubility limits can be set for a given chemical analyte. Secondly, the fraction precipitated for each HDW waste type can be set individually. When a chemical analyte or HDW waste type is selected, the corresponding values for the species are displayed for the supernatant and sludge concentrations. The fraction precipitated can be adjusted automatically as changes are saved if this option is selected under the "General" tab.

A "Process Chemicals" tab allows determination of chemical and radionuclide concentrations for each HDW waste type. Chemicals can be added to each of the HDW waste types. If a chemical and associated waste type is calculated by spreadsheets embedded within the HDW model, then a message will be displayed indicating that the value cannot be changed.

A "WSTRS Transaction" tab includes options for editing, inserting, and deleting transactions from the WSTRS dataset. Waste transactions are displayed on a quarterly basis for a given tank and year. If a particular waste transaction is labeled as a "send" or "receive", then the corresponding tank's waste transactions will be displayed with the send/receive transaction highlighted. Although a great deal of flexibility and freedom are provided with respect to changing WSTRS transactions, there are certain restrictions based on transaction type and whether it is an edit, insertion, or deletion. For example, the volume percent solids and solids type can only be accessed for the addition of primary wastes from a processing plant (xin, always positive) or a transfer from another tank (rec, always positive). This tab also contains the option to create a "virtual leak tank" to track all transactions designated as tank leaks. 
HNF-3273

Revision 0

This page intentionally left blank. 


\subsection{LIMITATIONS AND ACCURACY OF HDW MODEL - RADIONUCLIDES.}

The HDW Rev, 4 model and it's supporting codes, DKPRO and ORIGEN2 were used to predict tank-by-tank inventories for 46 key radionuclides as well as "global" inventories for all 177 tanks. These predictions contain various degrees of error in the form of (1) general biases deriving from the calculation of curies per ton of uranium fuel, and (2) tank specific errors related to the difficulty of modeling in-tank chemistry and tank-to-tank waste transfers. The following sections are presented to describe the magnitude of uncertainties in the HDW (Rev. 4) model's prediction of global and individual tank inventories. A major objective is to identify the degree of model improvement that could be gained by various modifications to the model.

\subsection{UNCERTAINTIES AFFECTING GLOBAL INVENTORY MODELING}

The current degree of bias in Rev. 4 global values has been evaluated via a sensitivity study in which individual input parameters, used in the supporting ORIGEN2 code, were updated. ORIGEN2 code input parameters were adjusted to account for recently updated data libraries defining (1) nuclear cross sections, (2) the time variability of certain uranium fuel impurities which serve as target nuclides for activation product generation, (3) radionuclide half-lives, and 4) fission product yield factors. These four parameters all affect the ORIGEN2 code's prediction of radionuclide activity in fuel that entered Hanford separations plants. Appendix D gives details describing the results of individual parameter adjustments.

HDW model Rev. 4 global inventory values also contain uncertainties related to fractional losses of certain radionuclides that occurred during fuel separations operations (i.e., losses to atmosphere, process condensate, and product streams). In the HDW model many of these loss effects are (conservatively) neglected. For the extracted "product" elements (U, Pu, Np) the model has used loss factors containing uncertainties, which really cannot be characterized until additional tanks are sampled and analyzed.

Table 3-1 summarizes "bias factors" for 46 key radionuclides associated with the composite effect of adjusting the four ORIGEN2 input parameters. The bias factors express the ratio of the global curie inventory as calculated with updated input parameters to the original curie inventory as calculated by the HDW model (Rev. 4). For example, the bias factor for ${ }^{14} \mathrm{C}$ means that the updated curie inventory for ${ }^{14} \mathrm{C}$ is 80 percent of the value predicted by the HDW model (Rev. 4). Comments in the "Other Factors" column indicate that there are additional sources of uncertainty in the global inventory related to processing losses and decay calculation limitations. 
HNF-3273

\section{Revision 0}

Table 3-1. Uncertainty in Global Inventory Values.

\begin{tabular}{|c|c|c|}
\hline & $\begin{array}{c}\text { Composite } \\
\text { bias }{ }^{(a)}\end{array}$ & Other uncertainty factors \\
\hline $\mathrm{H} 3$ & 0.99 & $\begin{array}{l}\text { The HDW model assumes } 100 \% \text { of tritium in fuel is } \\
\text { routed to tank waste. Due to losses to atmosphere and } \\
\text { condensate, actual tank inventories are significantly less. }\end{array}$ \\
\hline $\mathrm{C} 14$ & 0.80 & $\begin{array}{l}\text { Additional uncertainty may exist, associated with losses of } \\
\text { C-14 to atmospheric emissions. }\end{array}$ \\
\hline $\mathrm{CO} 60$ & 2.75 & \\
\hline NI59 & 1.18 & \\
\hline NI63 & 1.35 & \\
\hline SE79 & $\begin{array}{c}0.042- \\
0.092\end{array}$ & - L _ Cran mav he hiased low \\
\hline SR90 & 0.99 & $\begin{array}{l}\text { The HDW global inventory for Sr-90 may be biased low } \\
\text { by } 14 \% \text { due to internal assumptions accounting for the } \\
\text { quantity of Sr-90 separated in B-Plant and routed to } \\
\text { capsules, offsite, plant residuals and solid wastes. }\end{array}$ \\
\hline $\mathrm{Y} 90$ & 0.99 & \\
\hline ZR93 & 1.00 & \\
\hline NB93m & 1.00 & \\
\hline TC99 & 1.00 & $\begin{array}{l}\text { The HDW global inventory for }{ }^{99} \mathrm{Tc} \text { may be biased high by } \\
\text { about } 32 \% \text { due to it's not accounting for the fractional } \\
\text { separation of Tc (to the uranium product stream) in TBP, } \\
\text { PUREX and REDOX processes. }\end{array}$ \\
\hline RU106. & 1.00 & \\
\hline $\begin{array}{c}\mathrm{CD} 113 \\
\mathrm{~m}\end{array}$ & 0.66 & \\
\hline SN126 & $0.26-0.32$ & \\
\hline SB125 & 0.85 & \\
\hline I129 & 0.76 & $\begin{array}{l}\text { Additional uncertainty may exist, associated with losses of } \\
{ }^{129} \mathrm{I} \text { to atmospheric emissions from fuel dissolution } \\
\text { operations. The HDW model assumes } 100 \% \text { is routed to } \\
\text { tank waste. }\end{array}$ \\
\hline CS134 & 1.00 & \\
\hline CS137 & 1.00 & $\begin{array}{l}\text { The HDW global inventory for }{ }^{137} \mathrm{Cs} \text { may be biased } \\
\text { slightly high (less than } 2 \% \text { ) due to internal assumptions } \\
\text { accounting for the quantity of }{ }^{137} \mathrm{Cs} \text { separated in B-Plant } \\
\text { and routed to capsules, offsite, plant residuals and solid } \\
\text { wastes. }\end{array}$ \\
\hline \multirow[t]{2}{*}{$\begin{array}{c}\mathrm{BA} 137 \\
\mathrm{~m}\end{array}$} & 1.00 & \\
\hline & 1.06 & \\
\hline
\end{tabular}




\section{Revision 0}

Table 3-1. Uncertainty in Global Inventory Values.

\begin{tabular}{|c|c|c|}
\hline & $\begin{array}{l}\text { Composite } \\
\text { bias }^{\left({ }^{2}\right)}\end{array}$ & Other uncertainty factors \\
\hline \multicolumn{3}{|l|}{ SM151 } \\
\hline EU152 & 0.91 & \\
\hline EU154 & 0.89 & \\
\hline EU155 & 0.97 & \\
\hline RA226 & 1.00 & $\begin{array}{l}\text { The HDW global inventory for }{ }^{226} \mathrm{Ra} \text { is biased (see note a) } \\
\text { by factors of } 0.03-1.0 \text { due to decay calculation } \\
\text { limitations and depending on waste type. }\end{array}$ \\
\hline RA228 & 1.00 & $\begin{array}{l}\text { The HDW global inventory for }{ }^{228} \mathrm{Ra} \text { is biased by factors } \\
\text { of } 0.02-1.0 \text { due to decay calculation limitations and } \\
\text { depending on waste type. }\end{array}$ \\
\hline $\mathrm{AC} 227$ & 1.00 & $\begin{array}{l}\text { The HDW global inventory for }{ }^{227} \mathrm{Ac} \text { is biased by factors } \\
\text { of } 0.03-1.0 \text { due to decay calculation limitations and } \\
\text { depending on waste type. }\end{array}$ \\
\hline TH229 & 1.00 & $\begin{array}{l}\text { The HDW global inventory for }{ }^{229} \mathrm{Th} \text { is biased by factors } \\
\text { of } 0.14-1.0 \text { due to decay calculation limitations and } \\
\text { depending on waste type. }\end{array}$ \\
\hline TH232 & 1.00 & $\begin{array}{l}\text { The HDW global inventory for }{ }^{232} \mathrm{Th} \text { is biased by factors } \\
\text { of } 0.01-1.0 \text { due to decay calculation limitations and } \\
\text { depending on waste type. }\end{array}$ \\
\hline $\mathrm{U} 232$ & 1.00 & $\begin{array}{l}\text { The HDW global inventory for uranium may be } \\
\text { significantly uncertain due to the use of approximate } \\
\text { factors, which account for extraction losses and } \\
\text { assumptions related to the efficiency of U recovery from } \\
\text { Metal Waste sludges. }\end{array}$ \\
\hline $\mathrm{U} 233$ & 1.00 & " \\
\hline $\mathrm{U} 234$ & 1.00 & “ \\
\hline $\mathrm{U} 235$ & 1.00 & " \\
\hline $\mathrm{U} 236$ & 1.15 & " \\
\hline $\mathrm{U} 238$ & 1.00 & 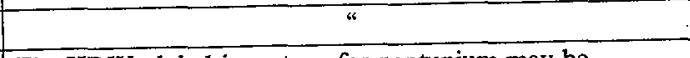 \\
\hline NP237 & 0.72 & $\begin{array}{l}\text { The HDW global inventory for neptunium may be } \\
\text { significantly uncertain due to the use of approximate } \\
\text { factors, which account for extraction losses. }\end{array}$ \\
\hline PU238 & 0.95 & $\begin{array}{l}\text { The HDW global inventory for plutonium may be } \\
\text { significantly uncertain due to the use of approximate } \\
\text { factors, which account for extraction losses. }\end{array}$ \\
\hline PU239 & 0.99 & “ \\
\hline PU240 & 1.36 & “ \\
\hline PU241 & 1.13 & $"$ \\
\hline
\end{tabular}


HNF-3273

Revision 0

Table 3-1. Uncertainty in Global Inventory Values.

\begin{tabular}{|l|c|c|}
\hline & $\begin{array}{c}\text { Composite } \\
\text { bias }^{(2)}\end{array}$ & Other uncertainty factors \\
\hline PU242 & 1.27 & \\
\hline AM241 & 1.18 & \\
\hline AM243 & 1.07 & \\
\hline CM242 & 1.00 & \\
\hline CM243 & 1.01 & \\
\hline CM244 & 1.01 & \\
\hline
\end{tabular}

parameters)/(Inventory with original ORIGEN2 parameters).

\subsection{UNCERTAINTIES AFFECTING INDIVIDUAL TANK INVENTORY MODELING}

This study assesses uncertainties in tank by tank inventory predictions in three ways: (1) by analyzing the broad comparison between model predictions and analytical values for a set of 60 sampled and measured tanks, (2) by systematically adjusting various parameters in the HDW model (such as chemical and radionuclide solubility factors) to test the degree of match between model and predictions and measured inventory for selected tanks, and (3) by comparison to independent calculations. The tank selection includes 47 core sampled SSTs and 13 DSTs with sample values as of 1994, the last transaction date in the model. The second assessment uses systematic adjustments of various parameters in the HDW model to improve the match between model predictions and measured (analytical) values for particular problem or "outlier" tanks. The third assessment evaluates the degree of tank prediction error resulting from the HDW model's method of waste concentration averaging. Results from assessment (1) define the overall-model-versus-sample error. Results from assessments (2) and (3) identify certain sources of error in the model and their contribution to the overall error.

\subsubsection{Sixty Tank Broad Comparison}

The analysis shows the degree of mismatch between the Rev. 4 model (Agnew 1997, Appendix E) and measured results for key radionuclides. In this discussion, measured tank inventory values are assumed to be the more valid. These comparisons have been evaluated by simple "scatter plots" in Appendix A. The scatter plot for ${ }^{137} \mathrm{Cs}$ indicates a relatively good match between model and measured inventory for Hanford's highest inventory tanks (such as 241-AZ-101 and -102); mode1/measurement ratios vary from 0.4 to 2 . For lower inventory tanks, however, (tanks containing less than about $100,000 \mathrm{Ci}$ of ${ }^{137} \mathrm{Cs}$ ) the model versus measurement uncertainty becomes 
HNF-3273

Revision 0

relatively large; model/measurement ratios vary from 0.015 to 50 . The average model prediction for these 60 tanks appears to be biased 20 percent lower than the average of measured values.

The scatter plot for ${ }^{90} \mathrm{Sr}$, which is considered to be an insoluble fission product, indicates good agreement for the isolated, aging waste tanks (241-AZ-101 and -102), but even greater scatter (than for ${ }^{137} \mathrm{Cs}$ ) for other tanks containing less than about 6 million curies. The average model prediction for these tanks appears to be biased 33 percent lower than the average of the measured values.

The scatter plot for ${ }^{241} \mathrm{Am}$, an insoluble actinide and major alpha emitting radionuclide, indicates a relatively poor match between model and sample measurements with a strong bias toward low predictions; a significant number of predictions were found to be an order of magnitude low.

Scatter plots are also provided for ${ }^{60} \mathrm{Co},{ }^{99} \mathrm{Tc}$, and ${ }^{239} \mathrm{Pu}$ (see Appendix A). Other radionuclides either have not been measured or too few measurements have been obtained for a meaningful comparison. Thus, predictions for other radionuclides can only be inferred from the scatter observed for ${ }^{90} \mathrm{Sr},{ }^{137} \mathrm{Cs}$ and ${ }^{241} \mathrm{Am}$.

There are certain reasons for the observed mismatch between model and samplebased estimates. For ${ }^{90} \mathrm{Sr}$ and ${ }^{137} \mathrm{Cs}$, the mismatch can be traced to deficiencies in the HDW model's solubility parameters, radionuclide split factors (i.e., fractions leaving fuel processing plants in different waste streams), solids carryover fractions in tank cascades, and the WSTRS data file (historical waste transfer records). The data scatter for ${ }^{241} \mathrm{Am}$ and the associated bias can be traced to additional factors--the "Defined Waste Concentration" averaging error (see Section 3.2.4) and perhaps to analytical accuracy. [Note that the model's bias toward low predictions may be only partially explained by the use of outdated cross section data (see Appendix D).]

\subsubsection{Uncertainties Due To Solubility and Partitioning Factors.}

A sensitivity study was performed to identify the cause of certain errors and improve model performance related to the modeling of radionuclide chemistry in the tank environment. As described in Appendix B, solubility or fraction precipitated solids parameters were modified to better reflect the ${ }^{90} \mathrm{Sr}$ and ${ }^{137} \mathrm{Cs}$ chemistry for each HDW type. The model was updated with these parameters and the results were compared with sample values for 60 tanks. The ${ }^{90} \mathrm{Sr}$ predictions were improved 50 percent while the overall accuracy of ${ }^{137} \mathrm{Cs}$ predictions did not change. While these modifications did not provide as much improvement as expected, they did reveal that most of the problems seem to be associated with Bismuth Phosphate Process Waste and Cladding Waste. 
To investigate the potential for improving tank-by-tank inventory predictions, the HDW Model was compared to sample based estimates for bismuth and ${ }^{90} \mathrm{Sr}$ (see Appendix E for details). The bismuth trial included 30 SSTs with a sample-based inventory of at least 500 kilograms of bismuth each. These tanks collectively contain about 70 percent of the total bismuth inventory at Hanford. The HDW Model was modified as necessary to improve the fit between model and sample based estimates for these tanks. The revised HDW Model provided estimates within $+/-50$ percent of the sample inventory for 73 percent of the tanks, and estimates within $+/-100$ percent of the sample inventory for 93 percent of the tanks. A similar study was also performed for 47 single-shell tanks with sample derived ${ }^{90} \mathrm{Sr}$ inventories (Best-Basis Inventories). The results show that the revised HDW Model provided estimates within +/100 percent of the sample estimate for 66 percent of the tanks, and estimates within $+/$ 200 percent of the sample estimate for 80 percent of the tanks (38 out of 47 tanks in the sample were high, these deviations clearly exceeded the 95 percent confidence intervals defined in the HDW Model. In other words, the 95 percent $\mathrm{CI}$ in the HDW Model does not truly represent the wide range of variability found in the ${ }^{90} \mathrm{Sr}$ tank population

\subsubsection{Uncertainties Due to Waste Transaction Data Base Errors}

Based on the results of solubility sensitivity studies described in Section 3.2.2 (i.e., prediction errors for ${ }^{137} \mathrm{Cs}$ do not appear to be caused by solubility effects), it is believed that the Waste Transaction Data Base (WSTRS file) may be a major cause of modeling inaccuracies (Appendix D). However, funding during FY 1998 has not permitted this hypothesis to be directly tested. To do so would have required an extensive effort to research historical waste handling records in order to improve the completeness of the WSTRS file.

\subsubsection{Uncertainties Due to Model Methodology (Waste Averaging)}

One source of uncertainty in tank-by-tank inventory predictions is associated with the method used in the HDW model to generate its defined waste compositions. In this method, the detailed historical fuel batch activity file (giving curies in batches of fuel for periods of one month or less) is summed over time spans of many years and divided by the corresponding volume of waste generated over this time span to calculate an "average defined waste concentration." The use of this average concentration in calculating the curies added to individual tanks leads to modeling errors, which are the result of two effects:

1) Over a period of several years fuel exposures were increased significantly (specific fuel activity in curies per MTU increased), and

2) Over the same operating period separation plant flowsheets were improved to significantly reduce the volumes of waste generated per MTU (liters per MTU decreased). 
HNF-3273

Revision 0

The combination of these two effects means that actual waste composition values (Ci/liter) have changed significantly over a period of years. The error occurs because the HDW model assumes a constant average waste type composition for the period. Tanks filled early in the period have their curie additions overestimated, while tanks filled late in the period are underestimated.

An analysis by Wootan (1998) characterizes the magnitude of these errors present in the HDW model's estimate of curie inventory for various waste types and particularly for those tanks which were filled very early or very late in the "average waste" time period. Note, that this analysis has been developed to the point of bracketing the generic error for the most highly affected time periods (quarters), but not to the point of identifying specific tanks filled during those time periods.

Results, detailed in Appendix $\mathrm{C}$, vary by waste type and by radionuclide half-life. For example:

- Most longer lived radionuclide inventories estimated by the HDW model to be in Bismuth Phosphate waste receiver tanks could be overpredicted by a factor of $1.9(1 / 0.53=1.9)$ or underpredicted by as much as a factor of 5 , depending on when during the period 1950 to 1956 the tank was filled. Because of its relatively short half-life, the error range for ${ }^{106} \mathrm{Ru}$ is even larger.

- Model estimates for tanks filled with REDOX waste generated from 1952 to 1957 could be overpredicting the longer half-lived radionuclides by a factor of $2.2(1 / 0.45=2.2)$ or underpredicting them by a factor of 2.4 . $\left({ }^{24} \mathrm{Am}\right.$ and ${ }^{244} \mathrm{Cm}$ are exceptions in REDOX waste tanks where the inventories could be overpredicted by factors of 20 or greater and underpredicted by factors of up to 4.6 , depending on when the tank was filled.

- Tanks receiving P2 waste during the period 1963 to 1967 could be overpredicted by factors of 6 and underpredicted by factors of 2 , depending on when the tanks were filled. The ${ }^{244} \mathrm{Cm}$ in these same tanks could be overpredicted by up to a factor of 50 ! 
HNF-3273

Revision 0

These uncertainty ranges are presented as an example of the degree of uncertainty present in model predictions for all waste types. For any single waste type, some tanks will receive waste that is predicted erroneously low; some tanks will receive waste that is predicted erroneously high; while some tanks will surely receive waste where the "average" concentration is representative of the true concentration. 


\subsection{SUMMARY AND RECOMMENDATIONS}

DNFSB milestone 5.6.3.1.f, "Standard Inventory Estimates for all Tanks," was completed in August of 1997. These standard inventory estimates, more commonly referred to as the BBIs, include 25 chemical analytes and 46 radionuclides. The BBIs were generated on a tank-specific, as well as global basis, and represent greater than 99 percent of the chemical mass and radionuclide activity in Hanford tank wastes. During the development of the BBIs, all sources of tank inventory information (sample results, engineering assessments and inventory predictions from the HDW Model, Rev. 4) are considered and reconciled against one another to arrive at the best estimate of tank waste inventories.

Section 5.6.3.1 of the Recommendation 93-5 Implementation Plan_lists the milestone 5.6.3.1.i, which requires issuance of this report addressing "Updates to the Tank Contents Model or Define Limitations of the Model." Validation and review of the HDW Model, Rev. 4, bases were part of the BBI effort in FY 1996 and 1997. This Section summarizes the results of the review and provides the conclusions and recommendations for potential future updates to the model.

DNFSB Milestone 5.6.3.1.i requires that the quality of HDW model predictions be assessed to ensure the credibility and defensibility of model-based predictions of tank waste inventories. The resulting model-based predictions of tank waste inventories contain potential inaccuracies and limitations that need to be better understood and quantified. The HDW model evaluations focused on each of the following areas:

- Input information-evaluation of HDW model source terms, solubilities, split factors, transaction records, and other key input data necessary for predicting tank waste inventories.

- Output comparisons and uncertainties-comparison of sampling data and model predictions to examine model accuracy and evaluation of uncertainties associated with process and analyte solubility variations.

Several limitations of the HDW model have been identified-some will require only simple modifications to the model and others may require significant time to optimize parameter adjustments.

Part of a major update for use in a revised HDW model was accomplished in FY 1998. The DKPRO code was run to create an updated Fuel Activity File. This file accounts for: (1) improved cross section data sets, (2) improved half-life data for ${ }^{79} \mathrm{Se}$, ${ }^{93 \mathrm{~m}} \mathrm{Nb}$, and ${ }^{126} \mathrm{Sn}$, (3) time variation of fuel impurity levels, important to the calculation of activation products, and (4) improved fission yield factors. 
HNF-3273

Revision 0

With minimal additional effort, the DKPRO and ORIGEN2 codes could be rerun to improve the calculation of fuel activity at very low exposure levels.

Further potential improvements to the accuracy of the HDW model for chemicals and radionuclides are discussed in Sections 2.0 and 3.0 and in additional detail in Appendices B through $\mathrm{E}$. The following summarizes key modifications expected to provide the most benefit.

- Updating the model with improved solubility parameters

- Updating the model with improved radionuclide split factors

- Updating the model with adjusted solids carryover factors for cascaded tanks

- Adding decay correction calculations for ${ }^{233} U$ and ${ }^{238} \mathrm{Pu}$ to the HDW model. Other second order decay daughters $\left({ }^{226} \mathrm{Ra},{ }^{227} \mathrm{Ac},{ }^{228} \mathrm{Ra},{ }^{229} \mathrm{Th}\right.$, and ${ }^{231} \mathrm{~Pa}$ ) could be deleted from the model as a practical alternative to the task of adding decay correction modifications

- Adding a new radionuclide to the model-activation product ${ }^{36} \mathrm{Cl}$

- Correcting the apparent error in the model's prediction of ${ }^{243} \mathrm{Am}$

- Modifying the model to generate defined waste compositions (for radionuclides) which more closely account for month-by-month variations in fuel specific activity

- Correcting the WSTRS file to improve the accuracy of historical waste transfer records (when model results are inconsistent with the sample data). In addition, this effort would update the WSTRS file to account for missing transaction records principally related to evaporator operations. In addition, the WSTRS file should be extended to account for waste transactions that have occurred since the file was frozen as of January 1, 1994. (This task will likely require considerable effort.)

- Verification/updating model tank layering profiles based on core sample profiles from tanks that have been core sampled

- Modifying the HDW model to generate tank specific estimates that more closely match sample results for key radionuclides

- Calibrating the model with key radionuclides or chemical surrogates to generate more reliable distribution profiles for radionuclides that are not currently in our sample population 
HNF-3273

Revision 0

With part or all of the model modifications listed above, the HDW model will be upgraded to Rev. 5. It is envisioned that a Rev. 5 version of the HDW model will be useful in providing the basis for estimating the composition of analytes (primarily radionuclides) identified in high-level and low-activity feed specifications for waste vitrification operations. Rev. 5 could also be used to predict the compositions of analytes that may be identified in the future as being important for waste form performance assessments or for feed specification compliance for waste vitrification. Such an improved model will also provide the basis for judging the consistency of sample analytical data from tanks with common waste types. Finally, the model can aid in the development of tank waste composition uncertainty estimates, based on sample data from common sludge layers or from common supernates. 
HNF-3273

Revision 0

This page intentionally left blank. 
HNF-3273

Revision 0

\subsection{REFERENCES}

Agnew, S. F., R. A. Corbin, T. B. Duran, K. A. Jurgensen, T. P. Ortiz, and B. L. Young, 1995a, Waste Status and Transaction Record Summary (WSTRS Rev. 2), WHC-SD-WM-TI-615, -614, -669, -689, Rev. 2, Los Alamos National Laboratory, Los Alamos, New Mexico.

Agnew, S. F., P. Baca, R. Corbin, K. Jurgensen, and B. Young, 1995b, Tank Layer Model, LA-UR-94-4269, Rev. 1, Los Alamos National Laboratory, Los Alamos, New Mexico.

Agnew, S. F., 1995c, Hanford Defined Wastes: Chemical and Radionuclide Compositions, WHC-SD-WM-TI-632, Rev. 2, (LA-UR-94-2657, Rev. 2), Los Alamos National Laboratory, Los Alamos, New Mexico.

Agnew, S. F., J. Boyer, R. A. Corbin, T. B. Duran, J. R. FitzPatrick, K. A. Jurgensen, T. P. Ortiz, and B. L. Young, 1996, Hanford Tank Chemical and Radionuclide Inventories: HDW Model Rev. 3, LA-UR-96-858, Los Alamos National Laboratory, Los Alamos, New Mexico.

Agnew, S. F., J. Boyer, R. A. Corbin, T. B. Duran, J. R. FitzPatrick, K. A. Jurgensen, T. P. Ortiz, and B. L. Young, 1997, Hanford Tank Chemical and Radionuclide Inventories: HDW Model Rev. 4, LA-UR-96-3860, Los Alamos National Laboratory, Los Alamos, New Mexico.

Brown, T. M., J. W. Hunt, and L. J. Fergestrom, 1998, Tank Characterization Technical Sampling Basis, HNF-SD-WM-TA-164, Rev. 4, Lockheed Martin Hanford Corporation, Richland, Washington.

Kupfer, M. J., A. L. Boldt, K. M. Hodgson, L. W. Shelton, B. C. Simpson, and R. A. Watrous (LMHC); B. A. Higley and R. M. Orme (NHC); M. D. LeClair (SAIC); G. L. Borsheim (Borsheim Associates); R. T. Winward (Meier Associates); N. G. Colton (PNNL); S. L. Lambert and D. E. Place (Cogema); and W. W. Schulz (W ${ }^{2}$ S Corporation), 1998, Standard Inventories of Chemicals and Radionuclides in Hanford Site Tank Wastes, HNF-SD-WM-TI-740, Rev. OB, Lockheed Martin Hanford Corporation, Richland, Washington.

Simpson, B. C., and D. J. McCain, 1997, Historical Model Evaluation Data Requirements, HNF-SD-WM-DQO-018, Rev. 2, Lockheed Martin Hanford Corporation, Richland, Washington. 
HNF-3273

Revision 0

This page intentionally left blank. 
HNF-3273

Revision 0

\section{APPENDIX A}

\section{ASSESSMENT OF UNCERTAINTIES OF INDIVIDUAL TANK INVENTORY PREDICTIONS}


HNF-3273

Revision 0

This page intentionally left blank. 
HNF-3273

Revision 0

\section{APPENDIX A}

\section{ASSESSMENT OF UNCERTAINTIES OF INDIVIDUAL TANK INVENTORY}

This study assesses Hanford Defined Waste (HDW) model uncertainties in tankby-tank inventory predictions. A broad comparison is made between model predictions and analytical values for waste from 60 sampled and analyzed tanks. The tank selection includes 47 core sampled SSTs and 13 DSTs with sample values as of 1994, the last transaction date in the model. This assessment uses systematic adjustment of various parameters in the HDW model to improve the match between model predictions and measured (analytical) values for certain tanks.

Scatter plots are presented in Figures A-1 through A-6 showing HDW Rev. 4 predictions for key nuclides $\left({ }^{60} \mathrm{Co},{ }^{90} \mathrm{Sr},{ }^{99} \mathrm{Tc},{ }^{137} \mathrm{Cs},{ }^{239} \mathrm{Pu},{ }^{241} \mathrm{Am}\right)$. These plots are used to show the relationship between the HDW Rev. 4 prediction and the sample value for the 60 sampled tanks. The tank inventory prediction (in curies) is shown on the horizontal axis while the sample value (in curies) is shown on the vertical axis. Separate plots are provided for six representative radionuclides.

This analysis shows the degree of mismatch between the HDW Rev. 4 model (Agnew et al. 1997, Appendix E) and measured results for key radionuclides; in most cases, measured tank inventory values are assumed to be the more correct value.

\section{A1.0 COMPARISON OF HDW REV. 4 TO SAMPLE ESTMMATES FOR STRONTIUM-90}

Figure A-1 compares the model to sample estimates for ${ }^{90} \mathrm{Sr}$. To interpret the plot, one must compare data points to the $1: 1$ a diagonal line. This line represents a perfect fit between samples and model predictions for all sampled tanks. Most tanks are clustered near the diagonal line, but three or four tank clusters are clearly displaced from the diagonal indicating room for improved ${ }^{90} \mathrm{Sr}$ predictions.

The scatter plot for ${ }^{90} \mathrm{Sr}$, which is an insoluble fission product, indicates good agreement for the isolated, aging waste tanks (241-AZ-101 and 102), but more scatter (than for ${ }^{137} \mathrm{Cs}$ ) for tanks containing less than about 6 million curies. The average model prediction for these tanks appears to be biased 33 percent lower than the average of the measured values. 
HNF-3273

Revision 0

Figure A-1. HDW Model Rev. $4{ }^{90} \mathrm{Sr}$ Inventory Prediction Versus Sample Value.

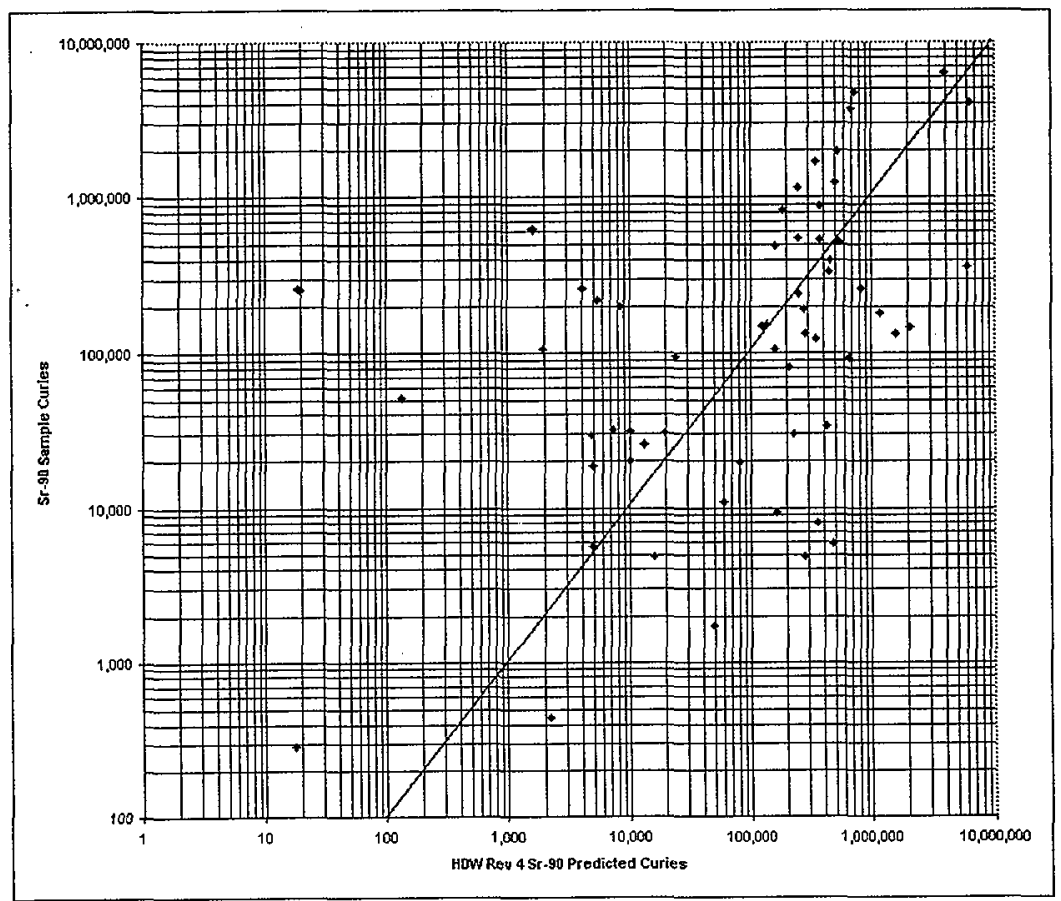


HNF-3273

Revision 0

Figure A-2. HDW Model Rev. $4{ }^{137}$ Cs Inventory Prediction Versus Sample Value.

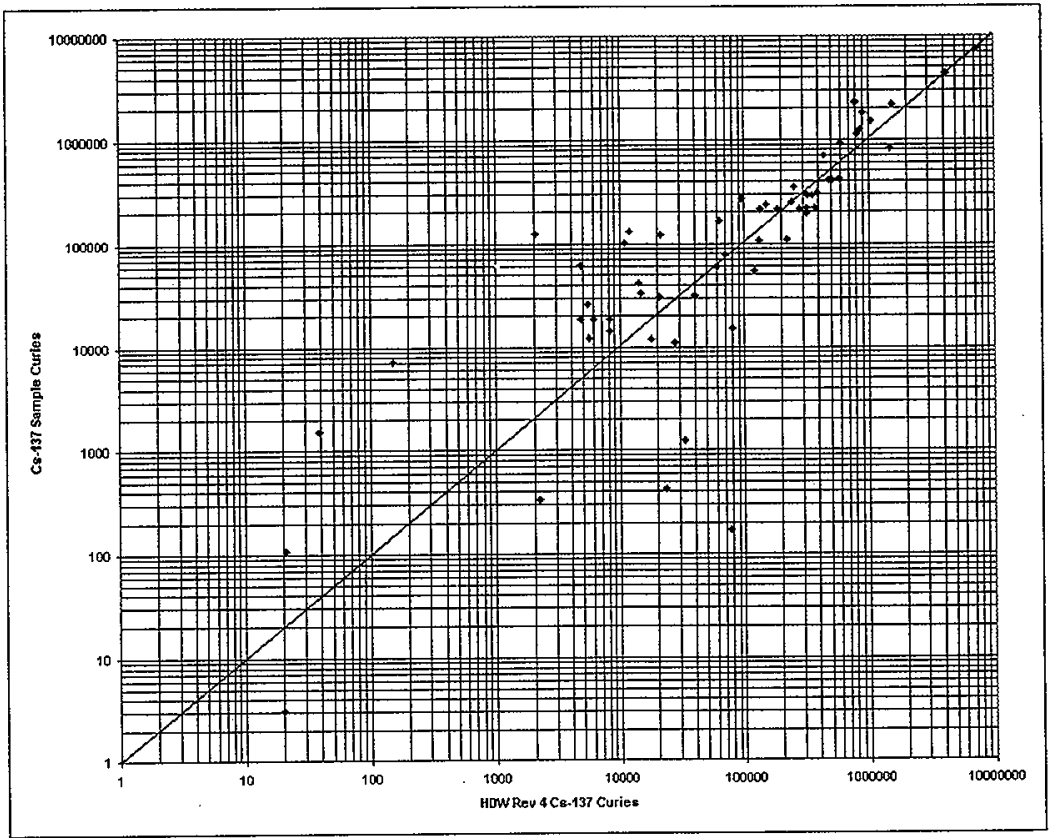


HNF-3273

Revision 0

Figure A-3. HDW Rev. $4{ }^{60}$ Co Prediction Versus Sample (or Best-Basis Inventory).

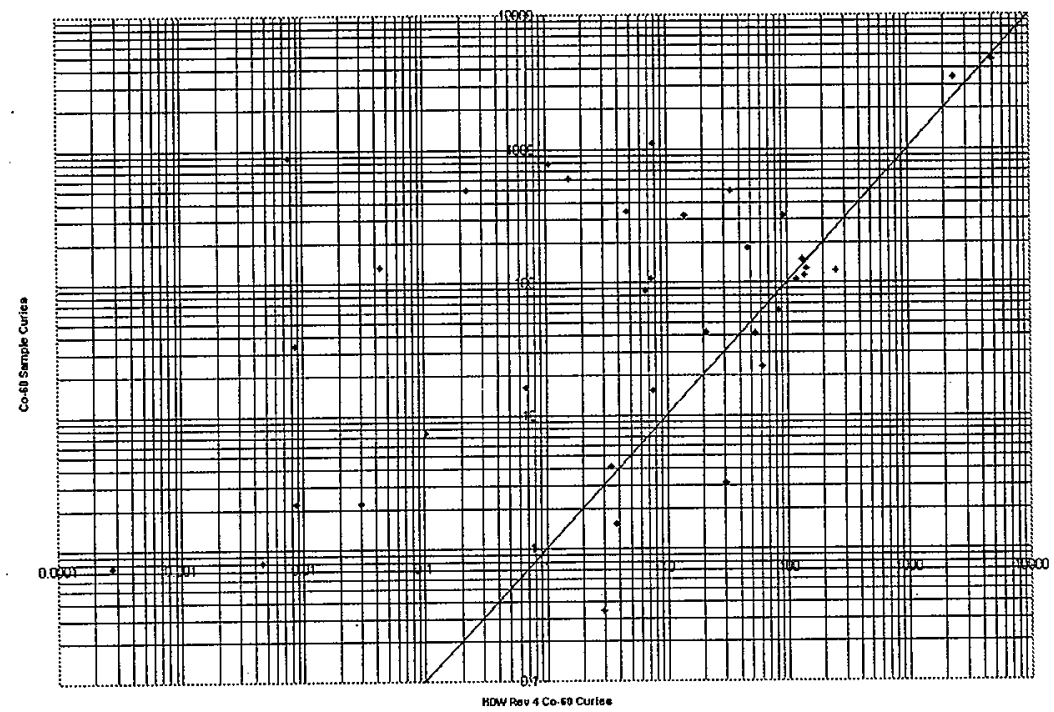


HNF-3273

Revision 0

Figure A-4. HDW Rev. $4{ }^{99}$ Tc Predicted Inventory Versus Sample (or Best-Basis Inventory).

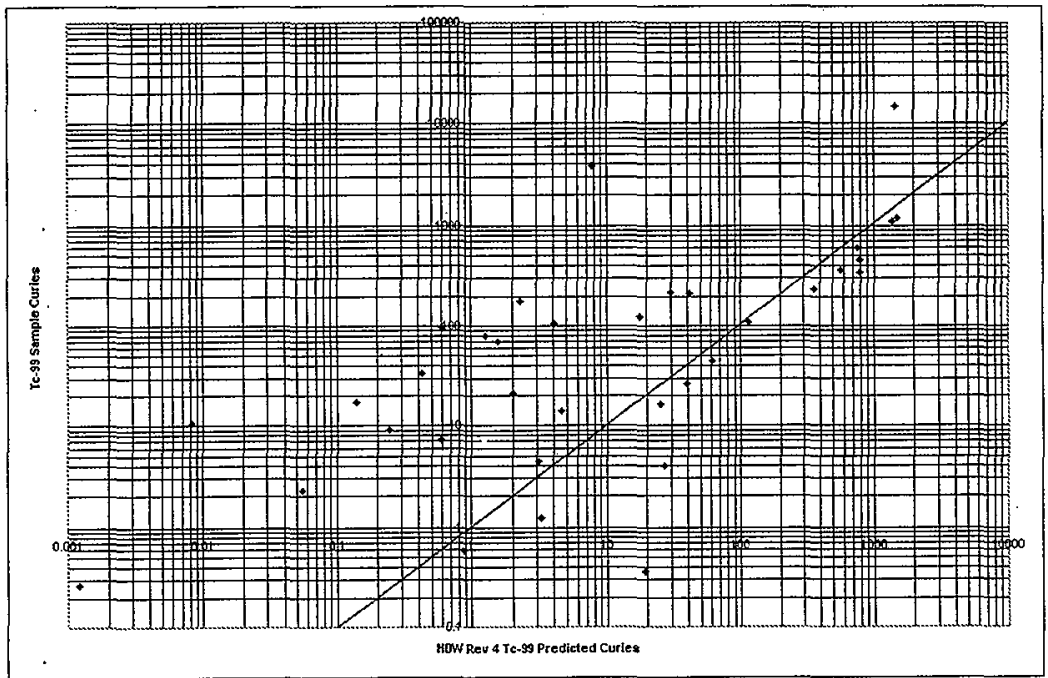


HNF-3273

Revision 0

Figure A-5. HDW Rev. $4{ }^{239}$ Pu Prediction Versus Sample (or Best-Basis Inventory).

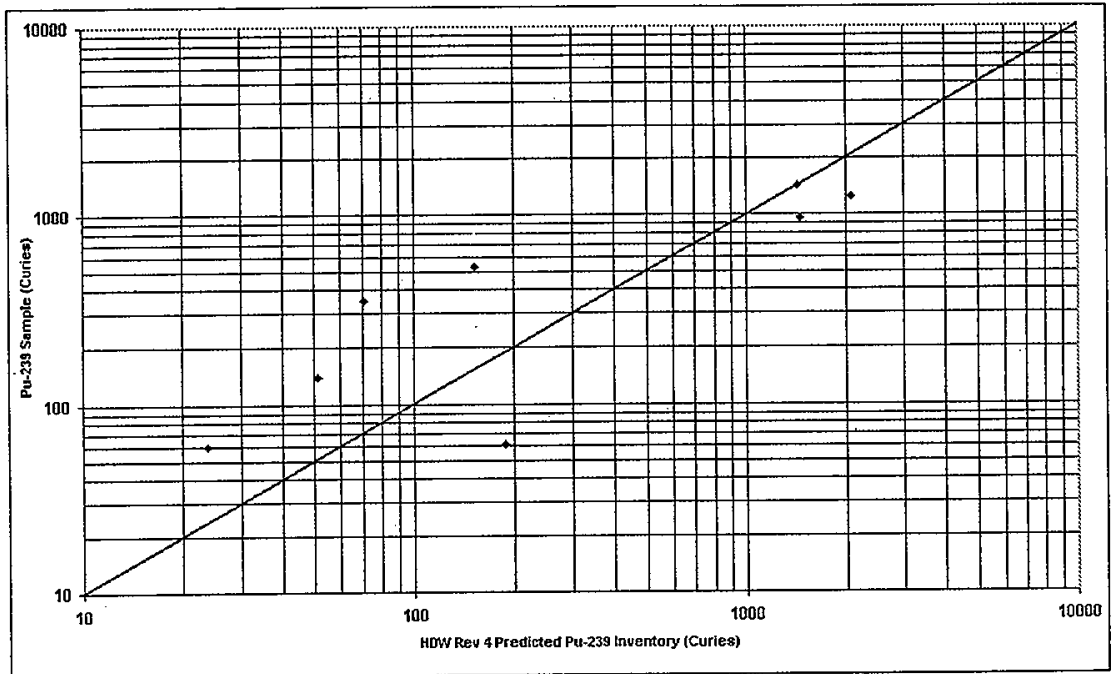


HNF-3273

Revision 0

Figure A-6. HDW Rev. $4^{241}$ Am Prediction Versus Sample (or Best-Basis Inventory).

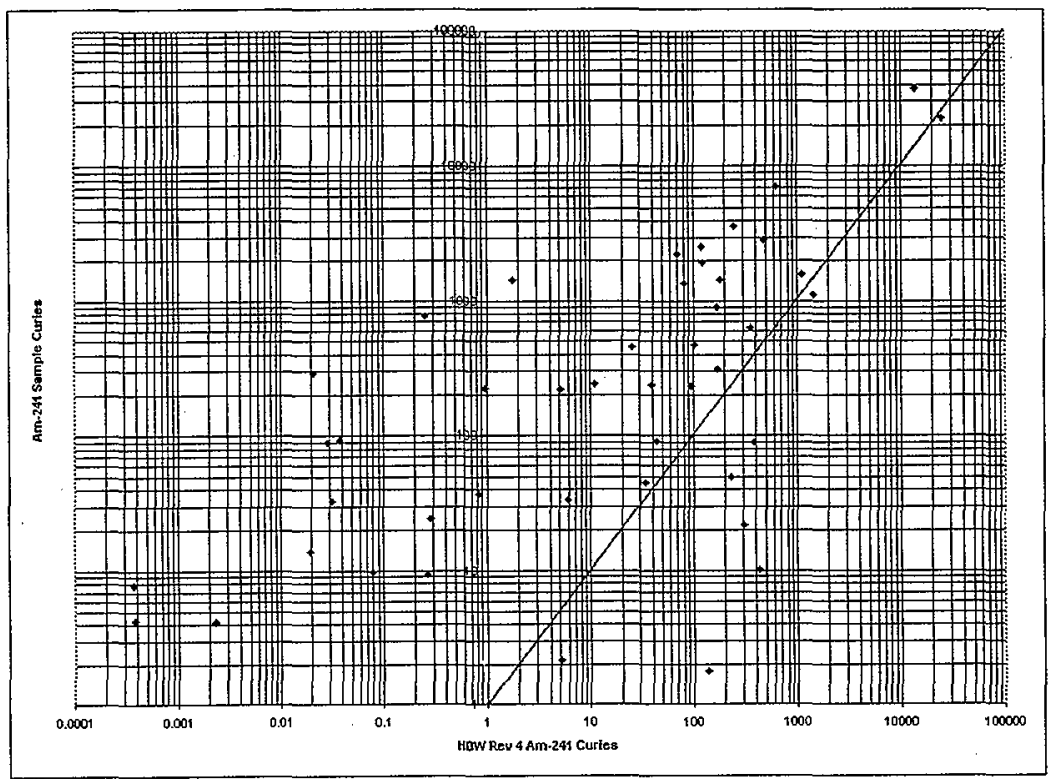


HNF-3273

Revision 0

\section{A2.0 COMPARISON OF HDW REV. 4 TO SAMPLE ESTIMATES FOR CESIUM-137}

Figure A-2 compares the model to sample estimates for ${ }^{137} \mathrm{Cs}$. Cesium-137 is a very soluble radionuclide. The scatter plot for ${ }^{137} \mathrm{Cs}$ indicates a relatively good match between model and measured inventory for Hanford's highest inventory tanks (241-AZ-101 and -102), where model/measurement ratios varied from 0.4 to 2 . For lower inventory tanks, however, (tanks containing less than about $100,000 \mathrm{Ci}$ of ${ }^{137} \mathrm{Cs}$ ) the model versus measurement uncertainty becomes relatively large, with model/measurement ratios varying from 0.015 to 50 . The average model prediction for these 60 tanks appears to be biased 20 percent lower than the average of measured values. The compressed scatter relative to ${ }^{90} \mathrm{Sr}$ seems to indicate that soluble radionuclides such as ${ }^{137} \mathrm{Cs}$ may be predicted more accurately than less soluble radionuclides like ${ }^{90} \mathrm{Sr}$.

\section{A3.0 OTHER RADIONUCLIDE COMPARISONS}

Other comparisons were also generated for ${ }^{60} \mathrm{Co},{ }^{99} \mathrm{Tc},{ }^{239} \mathrm{Pu}$, and ${ }^{241} \mathrm{Am}$. These comparisons are presented in Figures A-3 through A-6, respectively. On these plots, the numbers on the diagonal represent a match between the BBI and HDW Rev. 4 predictions. For ${ }^{60} \mathrm{Co}$, nearly all the off-diagonal points are above the diagonal indicating the model's predictions are biased significantly low relative to sample values. For ${ }^{99} \mathrm{Tc}$, a highly soluble radionuclide, the predictions are also biased low. For ${ }^{239} \mathrm{Pu}$, many of the tanks in the sample population have no sample or BBI values. These are indicated by the points along the bottom of the plot. Only eight of the remaining tanks are off the diagonal and are evenly divided between high and low values. Finally, for ${ }^{241} \mathrm{Am}$, a strong bias toward low predictions is indicated with a significant number of model values being an order of magnitude low.

\section{A4.0 SUMMARY OF MODEL TO SAMPLE COMPARISONS}

Evidence of excessive randomness and/or bias is evident from the HDW model predictions for ${ }^{90} \mathrm{Sr}$ and ${ }^{137} \mathrm{Cs}$. The ${ }^{90} \mathrm{Sr}$ mean is biased 33 percent low and the log ratio root mean square (RMS) value is 0.97 , indicating a prediction uncertainty of nine times the sample. The ${ }^{137} \mathrm{Cs}$ mean is biased 20 percent low and the log ratio RMS value is 0.71 , showing a prediction uncertainty of five times the sample. Evidence of excessive randomness and/or bias is even more evident for other radionuclides. The ${ }^{60} \mathrm{Co}$ mean is 
HNF-3273

Revision 0

biased 80 percent low and has a log ratio RMS value of 1.4 ; the ${ }^{99} \mathrm{Tc}$ mean is biased 60 percent low and has a RMS value of 1.0 ; the ${ }^{239} \mathrm{Pu}$ mean is biased 160 percent high and has a RMS value of 2.4 ; and the ${ }^{241} \mathrm{Am}$ mean is biased 90 percent low and has a RMS value of 1.7 . The ${ }^{239} \mathrm{Pu}$ prediction is biased high because the best-basis inventory values for many of the tanks were set to zero. The RMS values are significant in that all represent prediction uncertainties that are 10 times larger than the sample values.

There are certain reasons for the observed difference between the model and analytical measurements. For ${ }^{90} \mathrm{Sr}$ and ${ }^{137} \mathrm{Cs}$, the deficiencies can be traced to the HDW model's solubility parameters, radionuclide split factors (i.e., fractions leaving fuel processing plants in different waste streams), solids carryover fractions in tank cascades, and the Waste Status Transaction Record Summary (WSTRS) data file (historical waste transfer records). The scatter for ${ }^{241} \mathrm{Am}$ and large biases can be traced to other factors, including analytical uncertainty. [Note that the model's bias toward low predictions is only partially due to the use of poor cross section data (see Table D-3).] Appendix B evaluates the effects of adjusting the HDW model solubility parameters on the predictive capabilities of the model.

\section{A5.0 REFERENCES}

Agnew, S. F., J. Boyer, R. A. Corbin, T. B. Duran, J. R. FitzPatrick, K. A. Jurgensen, T. P. Ortiz, and B. L. Young, 1997, Hanford Tank Chemical and Radionuclide Inventories: HDW Model Rev. 4, LA-UR-96-3860, Los Alamos, New Mexico. 
HNF-3273

Revision 0

This page intentionally left blank. 
HNF-3273

Revision 0

\section{APPENDIX B}

\section{SOLUBILITY AND PARTITION FACTOR EFFECTS ON TANK INVENTORY PREDICTIONS}


HNF-3273

Revision 0

This page intentionally left blank.

B-2 
HNF-3273

Revision 0

APPENDIX B

\title{
SOLUBILITY AND PARTITION FACTOR EFFECTS ON TANK INVENTORY PREDICTIONS
}

\begin{abstract}
Appendix D of the Hanford Defined Waste (HDW) model (Agnew et al. 1997) provides estimates of the solids precipitated from alkaline solutions (fraction precipitated estimate) by waste type for each radionuclide and chemical component. With the goal of improving model performance, revised solubility or fraction precipitated solids estimates were derived to better reflect the Sr-90 and Cs-137 chemistry for each HDW type. The model was updated with these parameters and the results were compared with sample estimates for the 60 tanks in the sample population. The HDW Model, Rev. 4, was modified using ${ }^{137} \mathrm{Cs}$ and ${ }^{90} \mathrm{Sr}$ fraction precipitated solids estimates developed for each HDW type based on process chemistry. The model normally calculates these values from a single solubility limit defined for each species. Three different versions of the model were examined each with a different slate of fraction precipitated solids estimates (Harmsen and Schulz 1998). These versions are called Case 1, Case 2, and Case 3, which are compared to the HDW Model, Rev. 4, and tank sample data. The sample data were derived from tanks from which one or more core samples have been taken (47 SSTs and 13 DSTs). The DSTs chosen because those tanks have had stable inventories since 1994 (the final transaction date in the HDW model).
\end{abstract}

\section{B1.0 DEVELOPMENT OF PERFORMANCE MEASURES}

Performance measures were also developed to assess improvements to the HDW model. These measures were used to compare HDW Rev. 4 predictions to sample values for 60 single and double-shell tanks.

\section{B1.1 PERFORMANCE MEASURES}

Performance measures were defined to provide a basis for comparing the models. Initially, conventional scatter diagrams of model versus sample inventory values were prepared to compare the model's predictive performance. When applied to the 60 tanks, the results were inconclusive because of the high degree on randomness. A "sorted log ratio" performance measure was found to be useful for comparing several models on the same graph. The zerovalue horizontal line represents a perfect model-to-sample fit. A value of 1 represents a model prediction 10 times the sample value, while a value of -1 represents a model prediction onetenth of the sample value. Unbiased predictions produce graphs with values evenly distributed above and below the zero line. 
The mean value of the log ratio measure indicates the bias in the model's radionuclide prediction. Likewise, the root mean square (RMS) value of the log ratio measure estimates the variance or standard deviation of the scatter about the perfect prediction. These measures effectively quantify the bias and uncertainty associated with the model's predictions.

Because the log ratio is weighted equally for all tanks, an additional performance measure was developed to compare model performance by cumulative curie inventory. Tables were used to accumulate curie inventories with model-to-sample curie ratios in the following ranges: 0.5 to $2,0.25$ to $4,0.125$ to 8 , and 0.1 to 10 . These tables show the fraction of (sampled tank) inventory in each range.

\section{B1.2 SAMPLE ACCURACY}

The performance measures treat the analytical values equally regardless of the number of samples per tank. Analytical values were developed from one to eight core samples per tank. In this report, the analytical value is assumed to represent the collective inventory of all phases in the tank, including sludge, salt cake, and supernate.

\section{B2.0 COMPARISON OF SOLUBILITY FACTORS}

In the following discussion, the strontium and cesium fraction precipitated solids estimates are discussed in detail. Fraction precipitated values for ${ }^{90} \mathrm{Sr}$ were calculated by the HDW Model, Rev. 4, based on a solubility limit of $0.034 \mathrm{Ci} / \mathrm{L}$. Values for the ${ }^{137} \mathrm{Cs}$ fraction precipitated were provided as part of the model and therefore are not calculated from a solubility limit. Fraction precipitated values used in the model are shown in Table B-1. Certain groups are represented by a range of values assigned to different HDWs in the group. 
Table B-1. HDW Rev. 4 Fraction Precipitated Solids. Estimates for ${ }^{90} \mathrm{Sr}$ and ${ }^{137} \mathrm{Cs}$.

\begin{tabular}{|c|c|c|}
\hline HDW model waste types ${ }^{a}$ & $\begin{array}{c}\text { Fraction of strontium }\left({ }^{90} \mathrm{Sr}\right) \\
\text { precipitated }\end{array}$ & $\begin{array}{c}\text { Fraction of cesium }\left({ }^{137} \mathrm{Cs}\right) \\
\text { precipitated }\end{array}$ \\
\hline \multicolumn{3}{|l|}{ Process high-activity waste } \\
\hline $\mathrm{BiPO}_{4}$ process $^{b}$ & 0 & 0.01 \\
\hline Other processes ${ }^{\mathrm{c}}$ & 0 to 0.986 & 0 to 0.03 \\
\hline \multicolumn{3}{|l|}{ Claddng waste } \\
\hline Aluminum $^{d}$ & 0 & 0 \\
\hline Zircaloy $^{e}$ & 0 & 0 \\
\hline \multicolumn{3}{|l|}{ Miscellaneous waste } \\
\hline \multicolumn{3}{|l|}{ Solid waste } \\
\hline Ferrocyanide solids $^{f}$ & 0.55 to 0.98 & 0.55 to 0.97 \\
\hline Other solids ${ }^{g}$ & 0.92 & 0 \\
\hline Complexed waste & 0.64 to 0.74 & 0 \\
\hline Other liquid wastes $^{i}$ & 1 & 0 to 0.16 \\
\hline
\end{tabular}

${ }^{2} \mathrm{After}$ addition of $\mathrm{NaOH}$

'Tncludes HDW Model, Rev. 4, waste types MW1, MW2, 1C1, 1C2, 2C1, 2C2, 224, and UR

'Includes HDW Model, Rev. 4, waste types R1, R2, P1, P2, P2', Th1, Th2, P3, PL1, PL2, and Z

${ }^{\mathrm{d} I n c l u d e s}$ HDW Mode1, Rev 4, waste types CWR1, CWR2, CWP1, and CWP2

'Includes HDW Model, Rev 4, waste types CWZr1 and CWZr2

Includes HDW Model, Rev 4, waste types PFeCN1, PfeCN2, TFeCN, and 1CfeCN

${ }^{2}$ Includes HDW Model, Rev 4, waste types DE, CEM, and AR

"Includes HDW Model, Rev 4, waste types HS and SSR

includes HDW Model, Rev 4, waste types OWW1, OWW2, OWW3, NIT, BL, CSR, DW, N, PASF, and B 
Table B-2 summaries the final set (Case 3) of estimates used for the model solubility calculations. Clearly, significant changes were recommended for bismuth phosphate process and cladding wastes. The results that were produced from these modifications are discussed in Sections B2.1 through B2.3.

Table B-2. Revised Fraction Precipitated Solids Estimates for ${ }^{91} \mathrm{Sr}$ and ${ }^{137} \mathrm{Cs}$-Case 3

\begin{tabular}{|c|c|c|}
\hline HDW Model waste types ${ }^{a}$ & $\begin{array}{l}\text { Fraction of strontium }\left({ }^{\infty} \mathrm{Sr}\right) \\
\text { precipitated }\end{array}$ & $\begin{array}{c}\text { Fraction of cesium }\left({ }^{137} \mathrm{Cs}\right) \\
\text { precipitated }\end{array}$ \\
\hline \multicolumn{3}{|l|}{ Process high-activity waste } \\
\hline $\mathrm{BiPO}_{4}$ process $^{b}$ & 0.98 & 0.10 \\
\hline Other processes $^{c}$ & 0.98 & 0.10 \\
\hline \multicolumn{3}{|l|}{ Cladding waste } \\
\hline Aluminum $^{\mathrm{d}}$ & 0.98 & 0 \\
\hline Zircalloy $^{e}$ & 0.98 & 0.30 \\
\hline \multicolumn{3}{|l|}{ Miscellaneous waste } \\
\hline \multicolumn{3}{|l|}{ Solid waste } \\
\hline Ferrocyanide solids $^{f}$ & 0.0 & 0.98 \\
\hline Other solids ${ }^{8}$ & 0.98 & 0.98 \\
\hline Complexed waste ${ }^{\mathrm{h}}$ & 0.0 & 0.0 \\
\hline Other liquid waste & 0.98 & 0.0 \\
\hline
\end{tabular}

${ }^{2}$ After addition of $\mathrm{NaOH}$ and UR

'Includes HDW Model, Rev 4, waste types MW1, MW2, 1C1, 1C2, 2C1, 2C2, 224,

'Includes HDW Model, Rev 4, waste types R1, R2, P1, P2, P2', Th1, Th2, P3, PL1, PL2, and Z

'Includes HDW Model, Rev 4, waste types CWR1, CWR2, CWP1, and CWP2

${ }^{\circ}$ Includes HDW Model, Rev 4, waste types CWZr1 and CWZr2

IIncludes HDW Model, Rev 4, waste types PFeCN1, PFeCN2, TFeCN, and 1CFeCN

Includes HDW Model, Rev 4, waste types DE, CEM, and AR

hIncludes HDW Model, Rev 4, waste types HS and SSR

Includes HDW Model, Rev 4, waste types OWW1, OWW2, OWW3, NIT, BL, CSR, DW, N, PASF, and B 
HNF-3273

Revision 0

\section{B2.1 SOLUBILITY FACTOR EFFECT ON DEFINED WASTE COMPOSITIONS}

Table B-3 provides the ${ }^{137} \mathrm{Cs}$ and ${ }^{90} \mathrm{Sr}$ defined wastes compositions in the HDW model Rev. 4. Only those waste types affected by changes in the fraction precipitated solid estimates are listed. The new compositions derived from the Case 3 fraction precipitated estimates are shown in Table B-4.

Table B-3. Comparison of Hanford Defined Waste Compositions for Supernates.

\begin{tabular}{|c|c|c|c|c|}
\hline $\begin{array}{c}\text { predicted } \\
\text { supernatant } \\
\text { for.HDW: }\end{array}$ & $\begin{array}{c}\text { HDW Rev 4 } \\
\text { Sr-90 (Ci/L) }\end{array}$ & $\begin{array}{c}\text { Case 3 } \\
\text { Sr-90 (Ci/L) }\end{array}$ & $\begin{array}{c}\text { HDW Rev 4 } \\
\text { Cs-137 (Ci/L) }\end{array}$ & $\begin{array}{c}\text { Case 3 } \\
\text { Cs-137 (Ci/L) }\end{array}$ \\
\hline MW1 & 0.0050525 & 0.00010019 & 0.00569581 & 0.00508252 \\
\hline MW2 & 0.00940242 & 0.0001864 & 0.01070591 & 0.00955095 \\
\hline 1C1 & 0.01059202 & 0.00021184 & 0.01194065 & 0.01074659 \\
\hline 1C2 & 0.01847309 & 0.00036946 & 0.02103409 & 0.01893068 \\
\hline 2C1 & 0.00139551 & $2.791 \mathrm{E}-05$ & 0.0015732 & 0.00141588 \\
\hline 2C2 & 0.00133121 & $2.6624 \mathrm{E}-05$ & 0.00151576 & 0.00136419 \\
\hline 224 & 0.00019424 & $3.8849 \mathrm{E}-06$ & 0.00022035 & 0.00019831 \\
\hline UR/TBP & 0.01139909 & 0.00022798 & 0.01281264 & 0.01164785 \\
\hline PFeCN1 & 0.000228 & 0 & 0.0003883 & 0.00025886 \\
\hline PFeCN2 & 0.00022798 & 0 & 0.00038825 & 0.00025887 \\
\hline TfeCN & 0.0002248 & 0 & 0.00038285 & 0.00025523 \\
\hline 1CfeCN & 0.0080261 & 0 & 0.0091388 & 0.00040617 \\
\hline R1 & 0.0340002 & 0.0015166 & 0.0867439 & 0.07849844 \\
\hline R2 & 0.0400005 & 0.00545147 & 0.30898536 & 0.27948425 \\
\hline CWR1 & 0.00314607 & $6.2921 \mathrm{E}-05$ & 0.00361103 & 0.00361103 \\
\hline CWR2 & 0.00532037 & 0.00010641 & 0.00602604 & 0.00602604 \\
\hline P1 & 0.03400004 & 0.00568313 & 0.32770709 & 0.29493638 \\
\hline P2 & 0.03400003 & 0.01338107 & 0.77029728 & 0.69326755 \\
\hline CWP1 & 0.00302177 & $6.0435 \mathrm{E}-05$ & 0.00348366 & 0.00348366 \\
\hline CWP2 & 0.00240559 & $4.8112 \mathrm{E}-05$ & 0.00276801 & 0.00276801 \\
\hline CWZr1 & 0.00899348 & 0.00017987 & 0.01107401 & 0.00775181 \\
\hline 0.00017803 & 0.03400001 & 0.14141691 & 0.00017803 & 0.00089899 \\
\hline TH1 & 0.00768409 & 0.00015368 & 0.00706946 & 0.00636252 \\
\hline TH2 & 0.03400013 & 0.000761 & 0.03493182 & 0.03143864 \\
\hline AR & 0.03400009 & 0 & 0.31413704 & 0.00570478 \\
\hline B & 0.03400007 & 0 & 0.02647376 & 0.02647376 \\
\hline BL & 0.03399989 & 0 & 0 & 0 \\
\hline SRR & 0.13599952 & 0.40991623 & 0.20607956 & 0.42630403 \\
\hline CSR & 0.06908916 & 0 & 0.03979031 & 0.03281983 \\
\hline P3 & 0.03399987 & 0.04827926 & 2.8215743 & 2.56468857 \\
\hline CWZr2 & 0.00495661 & $9.9132 \mathrm{E}-05$ & 0.00585121 & 0.00409585 \\
\hline & & & & \\
\hline & & 0 & & \\
\hline & & 0 & & \\
\hline
\end{tabular}


HNF-3273

Revision 0

Table B-4. Comparison of Hanford Defined Waste Compositions for Sludges.

\begin{tabular}{|c|c|c|c|c|}
\hline $\begin{array}{l}\text { predicted } \\
\text { sludge for } \\
\text { HDW: }\end{array}$ & HDWRev 4 & $\mathrm{Sr}-90$ (Ci/L) & HDWRev 4 & Case 3 \\
\hline MW1 & 0.001999058 & 0.038316034 & 0.002253588 & 0.006751096 \\
\hline MW2 & 0.002475557 & 0.070059681 & 0.002818754 & 0.01128852 \\
\hline 101 & 07608907 & 0.072996491 & 0.008577711 & 0.01609945 \\
\hline $1 \mathrm{C} 2$ & 13621007 & 0.122166187 & 0.015509342 & 0.028120897 \\
\hline $2 C_{1}$ & 1074611 & 0.019818818 & 11436 & 0.003367641 \\
\hline $2 \mathrm{C} 2$ & 25626 & 0.0383 & 13042 & 0.005736975 \\
\hline 224 & 00171989 & 0.004888394 & 0.000195102 & 0.000741042 \\
\hline UR/RP & 05160514 & 0.392957596 & & 0.050786462 \\
\hline $\mathrm{PFeCI}$ & 97428261 & 0.30336246 & 0.334319039 & 0.337687761 \\
\hline PFeCN2 & 43866517 & 0.350762845 & 196936 & 0.390410786 \\
\hline $\mathrm{eCN}$ & 85911122 & 0.8017 & 03228 & 0.8922291024 \\
\hline $1 \mathrm{CFeCN}$ & 222261 & 0.370 & 04859 & 0.413701951 \\
\hline R1 & & 1.61 & & 0.231863351 \\
\hline R2 & 780871 & 13.95 & 11434 & 1.785500589 \\
\hline CWR1 & & 0.03 & & 0.002350253 \\
\hline CWR2 & 58826 & 0.178636759 & 0.004597171 & 0.004597171 \\
\hline P1 & 67524 & 12.61 & & 1.732533845 \\
\hline P2 & & 16.69 & 791 & 2.520235292 \\
\hline CWP1 & 9938 & 0.036 & 122 & 0.002905122 \\
\hline & & & & 0.002112218 \\
\hline CWZr1 & 7710032 & 0.082 & 654 & 0.037811491 \\
\hline HS & & & & 0.000739476 \\
\hline $\mathrm{T}$ & & 0.12 & 009055 & 0.018090841 \\
\hline TH2 & & & & \\
\hline AR & 772403 & & 0.260 & 8.974599481 \\
\hline$B$ & 10369777 & & 0.02238876 & 0.02238876 \\
\hline BL. & 34210599 & 13.17 & & - \\
\hline SRR & & 0.3514 & 0.17666919 & 0.365464624 \\
\hline CSR & 93 & 1.145 & 0.025611354 & 0.021120337 \\
\hline & & & 2.950553286 & 9.270208969 \\
\hline & & & & \\
\hline
\end{tabular}


HNF-3273

Revision 0

\section{B2.2 SOLUBחITY FACTOR EFFECT ON SR-90}

The ${ }^{90} \mathrm{Sr}$ predictions provided by the modified models are shown in Figure B-1, with the tanks arranged in order of increasing model/sample ratio. Fraction precipitated adjustments increased the ${ }^{90} \mathrm{Sr}$ prediction for low-inventory tanks and reduced the prediction for most high inventory tanks (tanks containing more than 100,000 curies of ${ }^{90} \mathrm{Sr}$ ).

The log ratio measure was used to compare the ${ }^{90} \mathrm{Sr}$ performance to analytical data for the modified models. Figure B-1 presents the results for HDW Rev. 4, Case 2, and Case 3 models. The Case 1 results are essentially identical to Case 3 and were not plotted to improve clarity. One goal is to have all predictions within a factor of 10 of the analytical data; points with a performance indicator between -1 and +1 meet this criterion. The left side of the graph shows that nearly all tanks with very low HDW Rev. 4 to sample data ratios now have predictions within the criterion. For very high HDW model to analytical ratios, only one tank exceeds the criterion. The mean ${ }^{90} \mathrm{Sr} \log$ ratio measure is biased 20 percent high and the RMS value is 0.66 , representing a noise level of 4.5 times the sample.

Figure B-1. Comparison of Model/Sample Ratio as a Function of Sr-90 Solubility.

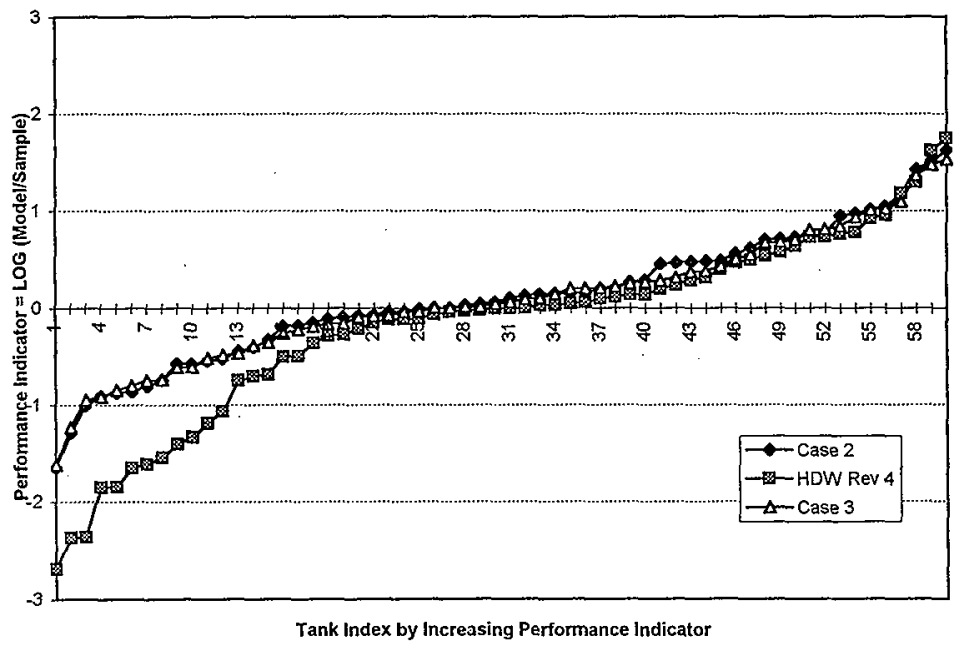


HNF-3273

Revision 0

Table B-5 compares HWD Rev. 4 and Case 3 by categorizing the ${ }^{90} \mathrm{Sr}$ predictions by proximity to sample values. The categories are model-to-sample ratio range between 0.5 and $2,0.25$ and $4,1 / 8$ and 8 , and 0.1 and 10. The results are expressed as fractions of the ${ }^{90} \mathrm{Sr}$ inventory in the sampled tank (all sampled tanks) and percent of sampled tanks. Case 3 increases from 75 to 84 percent the fraction of sampled tank inventory with predictions within a factor of four of the sample. The Case 3 model reduces the fraction of sampled tanks outside the 0.1 to 10 range from 25 percent to 12 percent. These comparisons show an overall 50 percent improvement in Sr-90 inventory predictions compared to the existing HDW model.

Table B-5. Comparison of ${ }^{90} \mathrm{Sr}$ Performance for HDW Rev. 4 and Case 3.

\begin{tabular}{|c|c|c|c|c|}
\hline \multirow[b]{2}{*}{ Model to sample ration ranges } & \multicolumn{2}{|c|}{ HDW Rev. 4} & \multicolumn{2}{|c|}{ Case 3} \\
\hline & $\begin{array}{c}\text { Fraction of } \\
\text { sampled tank } \\
\text { (Ci) inventory }\end{array}$ & $\begin{array}{c}\text { Percent of } \\
\text { sampled tanks }\end{array}$ & $\begin{array}{c}\text { Fraction of } \\
\text { sampled tank } \\
\text { inventory }(\mathrm{Ci})\end{array}$ & $\begin{array}{c}\text { Percent of } \\
\text { sampled tanks }\end{array}$ \\
\hline Model $1 / 2$ to 2 times sample & 0.629 & 43.3 & 0.636 & 45.0 \\
\hline Model $1 / 4$ to 4 times sample & 0.749 & 60.0 & 0.842 & 70.0 \\
\hline Model $1 / 8$ to 8 times sample & 0.918 & 71.7 & 0.903 & 85.0 \\
\hline $\begin{array}{l}\text { Model } 1 / 10 \text { to } 10 \text { times } \\
\text { sample }\end{array}$ & 0.920 & 75.0 & 0.916 & 88.3 \\
\hline Beyond (outlier) & 0.080 & 25.0 & 0.084 & 11.7 \\
\hline
\end{tabular}

\section{B2.3 SOLUBLITY FACTOR EFFECT ON CESIUM-137}

The ${ }^{137} \mathrm{Cs}$ predictions provided by modified models are shown in Figure B-2, with tanks arranged in order of increasing model/sample ratio. Fraction precipitated solids adjustments increase the ${ }^{137} \mathrm{Cs}$ prediction for low-inventory tanks and left the predictions unchanged for tanks with inventories of over $200,000 \mathrm{Ci}$ of ${ }^{137} \mathrm{Cs}$. In general, the Case 1 solubility parameters resulted in the greatest increase in predicted ${ }^{137} \mathrm{Cs}$ inventories. Case 2 and Case 3 produced essentially the same results.

The log ratio measure was used to compare the ${ }^{137} \mathrm{Cs}$ performance to analytical data for the modified models. Figure B-2 presents the results for HDW Rev. 4, Case 1, Case 2, and Case 3. One goal is to have all predictions within a factor of 10 of the analytical data; points with a performance indicator between -1 and +1 meet this criterion. For all modified models, the tanks with very low HDW Rey. 4 to sample ratios now have all but one or two data points within the factor of 10 criterion. Unfortunately, four tanks were pushed over the criterion at the high prediction end (see right side of Figure B-2, tank index 54 and higher). The mean 
HNF-3273

Revision 0

${ }^{137} \mathrm{Cs} \log$ ratio measure is biased 26 percent high and the RMS value is 0.72 , representing a noise level of five times the sample.

Figure B-2. Comparison of Model/Sample Ratio as a Function of ${ }^{137} \mathrm{Cs}$ Solubility.

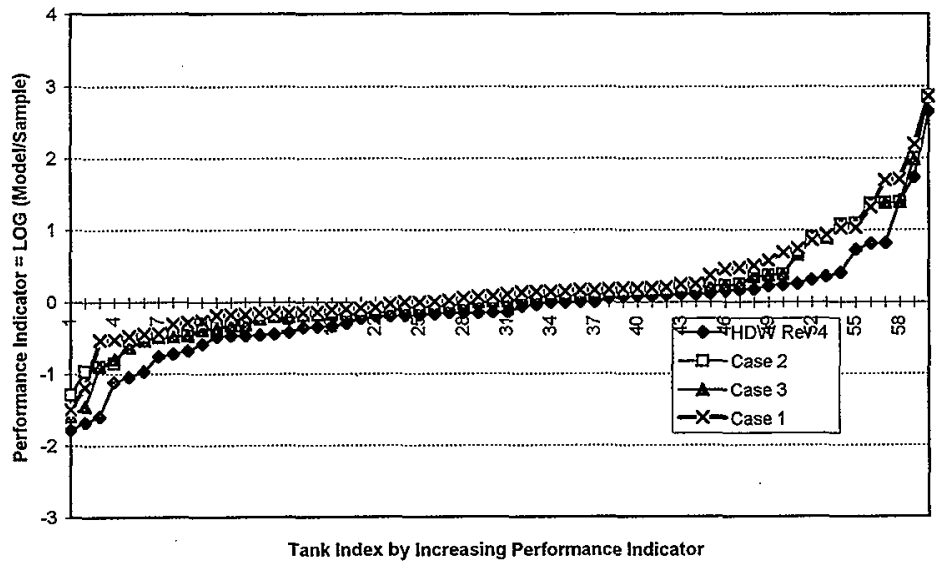


HNF-3273

Revision 0

Table B- 6 compares HWD, Rev. 4, and Case 3 by categorizing the ${ }^{137} \mathrm{Cs}$ predictions by proximity to sample values. The categories are the same as used for ${ }^{90} \mathrm{Sr}$. The results are essentially the same for HDW, Rev, 4, and Case 3 with 98 percent of the sampled tank inventory having predictions within a factor of four of the sample. Also, 87 percent of the tanks sampled have predictions within a factor of 8 of the sample estimate. Only 1 percent of the sampled tank inventory had predictions outside the $1 / 8$ to 8 model-to-sample ratio range.

The above information indicates that, unlike the predictions for ${ }^{90} \mathrm{Sr}$, little improvement in the ${ }^{137} \mathrm{Cs}$ inventory predictions was obtained by modifying the fraction precipitated estimates.

Table B-6. Comparison of ${ }^{137} \mathrm{Cs}$ Performance for HDW Rev. 4 and Case 3.

\begin{tabular}{|l|c|c|c|c|}
\hline & \multicolumn{2}{|c|}{ HDW Rev. 4 } & \multicolumn{2}{c|}{ Case 3 } \\
\hline Model to sample ratio range & $\begin{array}{c}\text { Fraction of } \\
\text { sampled tank } \\
\text { Ci inventory }\end{array}$ & $\begin{array}{c}\text { Percent of } \\
\text { sampled tanks }\end{array}$ & $\begin{array}{c}\text { Fraction of } \\
\text { sampled tank } \\
\text { Ci inventory }\end{array}$ & $\begin{array}{c}\text { Percent of } \\
\text { sampled tanks }\end{array}$ \\
\hline $\begin{array}{l}\text { Model 1/2 TO 2 times } \\
\text { sample }\end{array}$ & 0.761 & 53.3 & 0.763 & 58.3 \\
\hline $\begin{array}{l}\text { Model 1/4 TO 4 times } \\
\text { sample }\end{array}$ & 0.982 & 76.7 & 0.975 & 76.7 \\
\hline $\begin{array}{l}\text { Model 1/8 TO 8 times } \\
\text { sample }\end{array}$ & 0.99 & 86.7 & 0.99 & 86.7 \\
\hline $\begin{array}{l}\text { Model 1/10 TO 10 times } \\
\text { sample }\end{array}$ & 0.99 & 88.3 & 0.99 & 86.7 \\
\hline \begin{tabular}{l} 
Beyond (outlier) \\
\hline
\end{tabular} & 0.010 & 11.7 & 0.015 & 13.3 \\
\hline
\end{tabular}

\section{B3.0 CORRELATION OF OUTLIER TANKS TO OTHER MECHANISMS}

Tanks with HDW Rev. 4 predicted inventories over 10 times the sample value or less than $1 / 10$ th the sample value are designated as outliers. These tanks are listed in Table B-7. For ${ }^{90} \mathrm{Sr}, 16$ tanks were identified as outliers; 12 of the outliers are SSTs. For ${ }^{137} \mathrm{Cs}$, eight tanks were found to be outliers; seven of the outliers are SSTs. Of the $12{ }^{90} \mathrm{Sr}$ SST outlier tanks, 5 contain bismuth phosphate process waste and 3 contain cladding waste. Of the seven ${ }^{137} \mathrm{Cs}$ SST outlier tanks, one contains bismuth phosphate process waste and three contain cladding waste. 
HNF-3273

Revision 0

Table B-7. HDW Rev. 4 Outlier Tanks.

\begin{tabular}{|l|l|l|l|}
\hline $\begin{array}{c}\text { HDW, Rev. 4, } \\
\text { outlier tank }\end{array}$ & HDW group & $\begin{array}{c}\text { HDW, Rev. 4, }{ }^{137} \mathrm{Cs} \\
\text { outlier tank }\end{array}$ & HDW group \\
\hline TY-106 & DE & C-105 & CW \\
\hline C-105 & CW & T-102 & CW \\
\hline T-102 & CW & TY-106 & DE \\
\hline C-111 & MX & C-102 & CW \\
\hline U-110 & IC & AW-103 & CW \\
\hline C-102 & CW & TY-102 & MX \\
\hline BX-109 & UM & T-104 & IC \\
\hline TY-105 & UR & TY-101 & CN \\
\hline B-202 & 224 & & \\
\hline T-107 & IC & & \\
\hline B-201 & 224 & & \\
\hline BX-105 & MW & & \\
\hline AW-101 & CW & & \\
\hline AN-105 & SA & & \\
\hline AP-102 & MX & & \\
\hline AN-103 & SA & & \\
\hline
\end{tabular}

$\mathrm{CN}$ - Ferrocyanide solids

$\mathrm{DE}$ - other solids

$\mathrm{CW}$ - cladding waste

$\mathrm{MX}$ - mixed types

1C, 2C, 224, MW, UR - bismuth phosphate process

UM - mixture of $1 \mathrm{C} 2$ and UR/TBP types

SA - DST supernatants composed primarily of R1, AR, CWP2, Z, BL, SRR, CSR and DW types

Table B-8 provides a list of outlier tanks identified by Case 3. Case 3 reduces the number of ${ }^{90} \mathrm{Sr}$ outlier tanks from 16 to 8,5 of which are SSTs. This also model reduces the number of ${ }^{137} \mathrm{Cs}$ outlier tanks, all SSTs, to nine. Of the five ${ }^{90} \mathrm{Sr}$ SST outliers, four contain bismuth phosphate process waste. Of the nine ${ }^{137} \mathrm{Cs}$ SST outlier tanks, three contain bismuth phosphate process waste and two contain cladding waste. 
HNF-3273

Revision 0

Table B-8. Case 3 Outlier Tánks.

\begin{tabular}{|c|c|c|c|}
\hline Case $3{ }^{90}$ Sr outlier tank & HDW groups & $\begin{array}{c}\text { Case } 3{ }^{137} \mathrm{Cs} \text { outlier } \\
\operatorname{tank}\end{array}$ & HDW groups \\
\hline C-111 & MX & T-102 & $\mathrm{CW}$ \\
\hline C-107 & $1 \mathrm{C}$ & C- -105 & $\mathrm{CW}$ \\
\hline $\mathrm{AN}-105$ & SA & C-103 & $\mathrm{MX}$ \\
\hline $\mathrm{C}-110$ & $1 \mathrm{C}$ & $\mathrm{C}-106$ & $\mathrm{MX}$ \\
\hline $\mathrm{BX}-112$ & $1 \mathrm{C}$ & TY-102 & $\mathrm{MX}$ \\
\hline AP-102 & $\mathrm{MX}$ & $\mathrm{T}-111$ & $2 \mathrm{C}$ \\
\hline T-104 & $1 \mathrm{C}$ & B-202 & 224 \\
\hline \multirow{2}{*}{ AN-103 } & SA & T-104 & $1 \mathrm{C}$ \\
\hline & & TY-101 & $\mathrm{CN}$ \\
\hline
\end{tabular}

Potential Improvements. By reducing the number of ${ }^{90} \mathrm{Sr}$ outlier tanks, the Case 3 set of estimates represents a significant improvement to the model. The ${ }^{90} \mathrm{Sr}$ cladding waste tank outliers were eliminated and the ${ }^{137} \mathrm{Cs}$ cladding waste outliers were reduced 50 percent. Unfortunately, the improvement for the bismuth phosphate process waste is not as encouraging. The numbers of bismuth phosphate outlier tanks was reduced from five to four for ${ }^{90} \mathrm{Sr}$, while the number of bismuth phosphate outlier tanks increased from one to three for ${ }^{137} \mathrm{Cs}$. The opportunity for the largest further reduction in outlier tanks is with enhancements to the bismuth phosphate process model. These results might be improved by modifying the fraction precipitated estimates and waste stream split factions (radionuclide partition fractions) for bismuth phosphate wastes.

\section{B4.0 SOLUBILITY ADJUSTMENT CONCLUSIONS}

Improvements in model predictions are most pronounced for insoluble radionuclides. For ${ }^{90} \mathrm{Sr}$, the prediction bias was improved from being 33 percent low to 20 percent high. The noise level was reduced from 0.97 to 0.66 , which translates to a 50 percent reduction in scatter. The number of tanks with ${ }^{90} \mathrm{Sr}$ predictions outside the 0.1-to-10-times-sample range was reduced from 16 to 8 . Eighty-four percent of the sampled ${ }^{90} \mathrm{Sr}$ inventory is predicted within a factor of four of the sample; and 90 percent is predicted within a factor of eight of the sample.

Little impact is seen in the model predictions for highly soluble radionuclides. For ${ }^{137} \mathrm{Cs}$, the prediction bias changed from being 20 percent low to 26 percent high. The noise measure was essentially unchanged. The number of outlier tanks increased by one. For ${ }^{137} \mathrm{Cs}$, 
HNF-3273

Revision 0

76 percent of the sampled inventories were predicted within a factor of two of the sample; and 90 percent were predicted within a factor of four of the sample.

Prediction biases shifting from low to high indicate that an over-correction has occurred and further improvements are possible with better choices of fraction precipitated solids values. A reasonable goal might be to further adjust the fraction precipitated solids estimates to reduce the number of ${ }^{90} \mathrm{Sr}$ or ${ }^{137} \mathrm{Cs}$ outliers.

\section{B5.0 SEPARATIONS PLANTS PARTTTION FACTORS}

Because a large fraction of the outlier tanks contained bismuth phosphate process waste, an effort was made to improve predictions by adjusting the model's waste stream radionuclide "splits" for the bismuth phosphate process. These splits are called "radionuclide partition fractions" in the HDW model. The original and modified values are shown in Table B-9. The results from this effort are summarized in Figure B-3. The tanks that are mostly affected by the revised split factors are the tanks with a significant inventory of ${ }^{90} \mathrm{Sr}$. Two tanks with notable improvements are 241-BX-112 and 241-T-104, both with $1 \mathrm{C} 1 / 1 \mathrm{C} 2$ waste. The high ${ }^{90} \mathrm{Sr}$ inventory in tank, 241-B-201, suggests that the split for type 224 waste may be set too high.

Significantly, the mean prediction is now biased just 3 percent low (compared to 20 percent high with Case 3 ). Clearly, certain improvements can be made with better modeling of the radionuclide split factors. 
HNF-3273

Revision 0

Figure B-3. ${ }^{90}$ Sr Predictions Based on Modified Bismuth Phosphate.

Process Waste Splits.

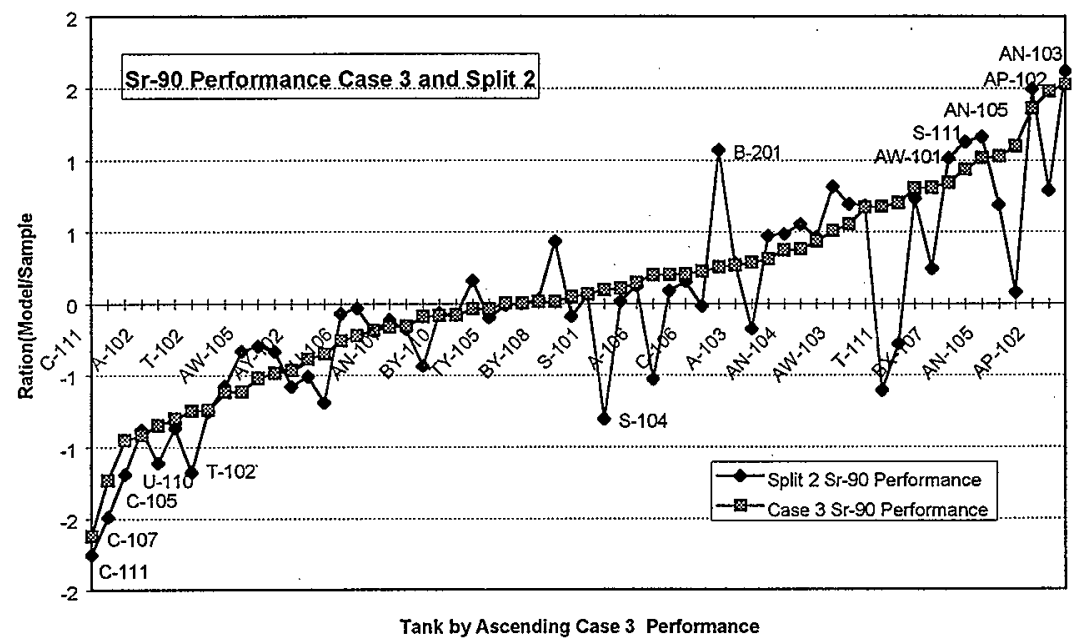

\section{B6.0 REFERENCES}

Agnew, S. F. Boyer, R. A. Corbin, T. B. Duran, J. R. Fitzpatrick, D. A. Jurgensen, T. P. Ortiz, and B. L. Young, 1997, Hanford Tank Chemical and Radiochemical Inventories: HDW Model Rev. 4, LA-UR-96-3860, Los Alamos National Laboratory, Los Alamos, New Mexico.

Harmsen, R. W., and W. W. Schulz, 1998, Best-Basis Estimates of Solubility of Selected Radionuclides in Hanford Single-Shell Tank Sludge, HNF-3271, Rev. 0, Lockheed Martin Hanford Corporation, Richland, Washington. 
HNF-3273

Revision 0

\section{APPENDIX C}

\section{UNCERTAINTY FROM WASTE COMPOSITION AVERAGING METHOD}


HNF-3273

Revision 0

This page intentionally left blank.

C-2 
HNF-3273

Revision 0

APPENDIX C

\section{UNCERTAINTY FROM WASTE COMPOSITION AVERAGING METHOD}

One source of uncertainty in tank-by-tank inventory predictions is associated with the method used in the Hanford Defined Waste (HDW) model (Agnew et al. 1997) to generate its defined waste compositions. In this method, the detailed historical fuel batch activity file (giving curies in batches of fuel for periods of one month or less) is summed over time spans of many years and divided by the corresponding volume of waste generated over this time span to calculate an "average defined waste concentration." The use of this average concentration in calculating the curies added to individual tanks leads to modeling errors, which are the result of two effects:

1. Over a period of several years fuel exposures were increased significantly (specific fuel activity in curies per MTU increased), and

2. Over the same operating period separation plant flowsheets were improved to significantly reduce the volumes of waste generated per MTU (liters per MTU decreased).

The combination of these two effects means that actual waste composition values (Ci/liter) have changed significantly over a period of years. The error occurs because the HDW model assumes a constant average waste type composition for the period. Tanks filled early in the period have their curie additions overestimated, while tanks filled late in the period are underestimated.

The objective of this section is to evaluate the degree of error present in the current HDW model due to these effects.

\section{C1.0 EVALUATION METHOD}

To evaluate the errors caused by the HDW model's method of "waste concentration averaging," this study first prepared a spreadsheet listing plant discharge volumes by quarter. These data were extracted from the Waste Status and Transaction Record Summary (WSTRS) database (part of the HDW model).

Second, using this starter sheet, Fluor Daniel Northwest (FDNW) personnel derived fuel activity data for the 46 key radionuclides and consolidated these curie values into quarterly and annual sub-totals, matching the time periods given by the WSTRS file. 
HNF-3273

Revision 0

The combined spreadsheet then calculated quarterly and annual radionuclide concentrations $(\mathrm{Ci} / \mathrm{l})$ in discharged waste by dividing the DKPRO curie sub-totals by the WSTRS volumes. These quarterly and annual concentrations are reported in Wootan (1998), and illustrate the time variability of actual waste concentrations in comparison to the HDW model's constant average concentration. This analysis then calculated ratios of high and low quarterly concentration values to the HDW model's assumed average concentration. These high, low ratios serve as an indication of the magnitude of errors present in the HDW model's estimate of curie inventory for various waste types and particularly for those tanks which were filled very early or very late in the "average waste" time period. Note, that this analysis has been developed to the point of bracketing the generic error for the most highly time periods (year or quarter), but not to the point of identifying specific tanks filled during those periods.

\section{C2.0 RESULTS OF "AVERAGING" ERROR EVALUATION}

Concentration ratio values (the ratio of true waste stream concentration to the HDW model's "average" concentration) are summarized in Table C-1. The table lists results for three typical waste types - First Cycle Bismuth Phosphate process waste generated 1950 to 1956 (1C2), REDOX high-level waste generated 1952 to 1957 (R1), and PUREX high-level waste generated 1963 to 1967 (P2). For each waste type, two concentration ratio values are given--the Quarterly Low ratio (QL) and the Quarterly High ratio $(\mathrm{QH})$. The table shows these ratio results for a selected listing of radionuclides-typically short half-lived fission products and activation products (these suffer from greater error), selected actinides, and "all other" longer-lived fission products (these have nearly constant low or high ratios). 
HNF-3273

Revision 0

Table C-1. Summary of "Waste Concentration Averaging" Error [Ratio: (True Concentration) / (Average Concentration)]

\begin{tabular}{|l|c|c|c|c|c|c|}
\hline \multirow{2}{*}{} & \multicolumn{2}{|c|}{$1 \mathrm{C2}$} & \multicolumn{2}{c|}{$\begin{array}{c}\text { REDOX, (R1) } \\
1952-1957\end{array}$} & \multicolumn{2}{c|}{$\begin{array}{c}\text { PUREX (P2) } \\
1963-1967\end{array}$} \\
\cline { 2 - 7 } & QL & QH & QL & QH & QL & QH \\
\hline${ }^{{ }^{00} \mathrm{Co}}$ & 0.45 & 5.9 & 0.3 & 3.2 & 0.17 & 2.0 \\
\hline${ }^{106} \mathrm{Ru}$ & 0.19 & 8.8 & 0.02 & 8.3 & 0.09 & 3.7 \\
\hline${ }^{125} \mathrm{Sb}$ & 0.38 & 6.5 & 0.19 & 4.1 & 0.19 & 2.3 \\
\hline${ }^{134} \mathrm{Cs}$ & 0.3 & 2.2 & 0.07 & 4.7 & 0.15 & 3.7 \\
\hline${ }^{155} \mathrm{Eu}$ & 0.42 & 6.7 & 0.29 & 3.3 & 0.18 & 2.1 \\
\hline $\begin{array}{l}\text { Other } \\
\text { FPs, APs }\end{array}$ & 0.53 & 5.3 & 0.45 & 2.4 & 0.16 & 2.0 \\
\hline${ }^{238} \mathrm{U}$ & 0.35 & 9.4 & 0.45 & 1.6 & 0.16 & 2.7 \\
\hline${ }^{237} \mathrm{~Np}$ & 0.56 & 4.8 & 0.42 & 2.2 & 0.15 & 2.3 \\
\hline${ }^{239} \mathrm{Pu}$ & 0.57 & 5.8 & 2.6 & 2.3 & 0.35 & 2.3 \\
\hline${ }^{241} \mathrm{Am}$ & 0.76 & 2.2 & 0.05 & 4.6 & 0.10 & 3.7 \\
\hline${ }^{244} \mathrm{Cm}$ & 0.44 & 2.0 & 0.01 & 3.7 & 0.02 & 16 \\
\hline
\end{tabular}

$\mathrm{AP}=$ Activation products

FP $=$ Fission products

PUREX = Plutonium-Uranium Extraction

$\mathrm{QH}=$ Quarterly High ratio

$\mathrm{QL}=$ Quarterly Low ratio

REDOX $=$ Reduction-oxidation.

As seen from Table C-1 most longer lived radionuclide inventories estimated by the HDW model to be in Bismuth Phosphate waste receiver tanks could be overpredicted by a factor of $1.9(1 / 0.53=1.9)$ or underpredicted by as much as a factor of 5, depending on when during the period 1950 to 1956 the tank was filled. Because of its relatively short half-life, the error range for ${ }^{106} \mathrm{Ru}$ is even larger.

Model estimates for tanks filled with REDOX waste generated from 1952 to 1957 could be overpredicting the longer half-lived radionuclides by a factor of 2.2 $(1 / 0.45=2.2)$ or underpredicting them by a factor of 2.4 . ${ }^{241} \mathrm{Am}$ and ${ }^{244} \mathrm{Cm}$ are exceptions in REDOX waste tanks where the inventories could be overpredicted by factors of 20 or greater and underpredicted by factors of up to 4.6 , depending on when the tank was filled.

Tanks receiving P2 waste during the period 1963 to 1967 could be overpredicted by factors of 6 and underpredicted by factors of 2, depending on when the tanks were filled. The ${ }^{244} \mathrm{Cm}$ in these same tanks could be overpredicted by up to a factor of 50 ! 
The uncertainty ranges listed in Table C-1 are presented as an example of the degree of uncertainty present in model predictions for all waste types. For any single waste type some tanks will receive waste that is predicted erroneously low; some tanks will receive waste that is predicted erroneously high; while some tanks will surely receive waste where the "average" concentration is representative of the true concentration.

These uncertainties related to the HDW model's waste concentration averaging method may represent the potential limits of model improvement since to modify the model to use a more detailed set of defined waste compositions (e.g., a separate composition for every quarter or year) may be too large an undertaking.

\section{C3.0 MODEL LIMITATIONS FROM RADIONUCLIDE DECAY METHOD}

The method used to evaluate errors associated with waste concentration averaging has also revealed other model limitations regarding radionuclides which are daughters of parent nuclides such as $\mathbf{U}, \mathrm{Pu}$ and $\mathrm{Np}$ that are significantly separated during fuel reprocessing. The uranium, plutonium, and neptunium decay daughters, ${ }^{226} \mathrm{Ra},{ }^{227} \mathrm{Ac},{ }^{228} \mathrm{Ra},{ }^{229} \mathrm{Th},{ }^{231} \mathrm{~Pa}$, and ${ }^{232} \mathrm{Th}$, are overpredicted by as much as a factor of 50 in the HDW model. This is a direct result of the HDW model performing the processing separations after the decay to $1 / 1 / 1994$, rather than before at the time of fuel separation. Conversely, the ${ }^{233} \mathrm{U}$ that builds in from decay of ${ }^{237} \mathrm{~Np}$ is removed along with the rest of the uranium in the HDW model, resulting in a ${ }^{233} \mathrm{U}$ prediction low by a factor of 84 . Likewise, a low prediction results for ${ }^{238} \mathrm{Pu}$, except to a much lesser extent. The correction for ${ }^{241} \mathrm{Am}$ build-in from ${ }^{241} \mathrm{Pu}$ decay appears to be reasonable, with a ratio of 1.05. However, the ${ }^{243} \mathrm{Am}$ build-in from ${ }^{243} \mathrm{Cm}$ is underpredicted by the HDW model. This appears to be caused by the HDW model applying the ${ }^{241}$ Am buildin correction factor to both ${ }^{241} \mathrm{Am}$ and ${ }^{243} \mathrm{Am}$.

These errors are a result of a model simplifying compromise that was designed into the interface between the DKPRO code and the HDW model when radionuclide capability was being built into the model in 1996 . At that time it was decided to predecay the fuel activity file (generated by the DKPRO code) to the date $1 / 1 / 94$ to avoid having to build decay functions for all radionuclides in the HDW model. It was recognized that daughters of extracted parent nuclides (most importantly ${ }^{241} \mathrm{Am}$ the daughter of ${ }^{241} \mathrm{Pu}$ ) would be misrepresented unless a backdecay correction was built into the HDW model. Accordingly, the HDW model has been equipped with a correction calculation for ${ }^{241} \mathrm{Am}$ but not for other daughter radionuclides such as ${ }^{226} \mathrm{Ra}$, ${ }^{227} \mathrm{Ac},{ }^{228} \mathrm{Ra},{ }^{229} \mathrm{Th},{ }^{231} \mathrm{~Pa}$, and ${ }^{232} \mathrm{Th}$. The need to correct the $1 / 1 / 94$ decay calculations for ${ }^{226} \mathrm{Ra},{ }^{227} \mathrm{Ac},{ }^{228} \mathrm{Ra},{ }^{229} \mathrm{Th},{ }^{231} \mathrm{~Pa}$, and ${ }^{232} \mathrm{Th}$ was thought unnecessary. This is because the need for inventory data on these particular nuclides is in the 10,000 year future; and 
HNF-3273

Revision 0

the future in-growth is determined more by the inventory of their parents than their $1 / 1 / 94$ values.

The most important result coming from this simplified decay method is the error for ${ }^{233} \mathbf{U}$, resulting in model inventory predictions low by a factor of 84 .

\section{C4.0 REFERENCES}

Agnew, S. F., J. Boyer, R. A. Corbin, T. B. Duran, J. R. Fitzpatrick, K. A. Jurgensen, T. P. Ortiz, and B. L. Young, 1997, Hanford Tank Chemical and Radiochemical Inventories: HDW Model Rev, 4, LA-UR-96-3860, Los Alamos National Laboratory, Los Alamos, New Mexico.

Wootan, D. W., 1998, Evaluation of Averaging Radionuclide Inventories by Waste Type in the Hanford Defined Waste Model, Letter Report FDNW-RJP-98-027, R. J. Puigh to J. W. Cammann, Fluor Daniel Northwest, Inc., Richland, Washington. 
HNF-3273

Revision 0

This page intentionally left blank.

C-8 
HNF-3273

Revision 0

\section{APPENDIX D}

\section{HANFORD DEFINED WASTE MODEL UNCERTAINTY EFFECTS- RADIONUCLIDE SOURCE TERMS AND WASTE TRANSACTIONS}


HNF-3273

Revision 0

This page intentionally left blank. 
HNF-3273

Revision 0

\section{APPENDIX D}

\section{HANFORD DEFINED WASTE MODEL UNCERTAINTY EFFECTS-RADIONUCLIDE SOURCE TERMS AND WASTE TRANSACTIONS}

The Hanford Defined Waste (HDW) model's (Agnew et al. 1997) main radionuclide source term is the historical Fuel Activity Data File generated by the DKPRO code (a newly created Fortran code). This file defines the curies of $46 \mathrm{key}$ radionuclide in each of 1276 batches of Hanford reactor fuel; processed through the various separations plants from 1944 through 1989. The DKPRO calculation's are based on a set of ORIGEN2 code (Wittekind 1989) runs which predict discharged fuel activity for a series of fixed fiel exposure levels and fuel types. The result is expressed in curies per metric ton uranium (Ci/MTU). The objective of this section is to determine the accuracy of these fuel activity values as a source term for waste inventory modeling, and to determine the uncertainty effect on waste inventory estimates.

\section{D1.0 SOURCE TERM UNCERTAINTY EFFECTS}

The uncertainty in the ORIGEN2 code prediction of Hanford fuel activities was studied recently by.Wootan (1998). Since code predictions could not be compared to analyzed fuel samples or waste samples (due to the lack of analytical data for all 46 radionuclides), the approach taken was to adjust input parameters for the ORIGEN2 code over a range typical of parameter uncertainty. Two cases were typically run. The first case used "reference" parameter values which were the basis for the HDW model, Rev 4 output. The second case used "updated" parameter values which represent newer data for nuclide properties or a more exacting analysis of average cross-section sets for Hanford reactors. The following parameter types were updated:

- Neutron capture cross sections for actinides and selected activation products

- Definition of fuel and cladding impurity values (i.e., the "target" concentration for activation product generation)

- Fission product half-life values

- Fission product yield values. 
Each parameter type was adjusted individually to determine the magnitude of it's effect on global inventories or on inventories related to smaller batches of fuel. These effects are discussed below.

\section{D1.1 EFFECT OF NEUTRON CAPTURE CROSS SECTION UNCERTAINTIES}

To assess the effects of uncertainties in cross section data sets, the MCNP ${ }^{1}$ code was used to derive cross section values representative of single pass reactor fuel elements, and these results were compared to reference ORIGEN2 calculations. The same single pass reactor fuel MCNP model was also used to evaluate the adequacy of the ORIGEN2 library cross sections for selected activation products. A revised total radionuclide inventory was recalculated using the new single pass reactor cross sections. Table D-1 shows the ratio of the revised total radionuclide inventory to the reference calculated inventory.

These results show that the amount of change in radionuclide inventory varies slightly with the processing plant due to the amount of single pass reactor fuel processed in each plant. The amount of ${ }^{14} \mathrm{C},{ }^{59} \mathrm{Ni}$, and ${ }^{63} \mathrm{Ni}$ increases by up to 50 percent due to the higher capture cross sections. The amount of ${ }^{113 \mathrm{~m}} \mathrm{Cd}$ and ${ }^{154} \mathrm{Eu}$ decreases by about 13 percent due to smaller capture cross sections. Smaller differences in other fission products are likely due to changes in the relative proportion of fission's from ${ }^{235} \mathrm{U},{ }^{238} \mathrm{U}$, and ${ }^{239} \mathrm{Pu}$, with corresponding changes in the fission product yields for sensitive isotopes. For the actinides, the main changes are an increase in the inventories of ${ }^{240} \mathrm{Pu},{ }^{241} \mathrm{Pu},{ }^{242} \mathrm{Pu}$, and ${ }^{241} \mathrm{Am}$ due to higher neutron capture cross sections.

The accuracy of either of these two code runs to model the production of $\mathrm{Pu}$ and it's ${ }^{240} \mathrm{Pu}$ isotopic assay was tested by comparing results to plutonium conversion equations for both natural and enriched single pass reactor fuel for different reactors (Roblyer 1994). The plutonium production from the conversion equations reveals a 10 percent range of values among the different fuel and reactor types. A similar range of 10 percent or less is found for the ${ }^{240} \mathrm{Pu}$ content. Both the reference single pass reactor (SPR) ORIGEN2 cross sections and the MCNP based SPR cross sections predict the plutonium production within the range of the variation by reactor type. However, the reference ORIGEN 2 cross sections underpredict the ${ }^{240} \mathrm{Pu}$ content by about 30-35 percent, while the MCNP cross sections are within 10 percent of the conversion equation values.

1 MCNP $=$ Monte Carlo N-Particle transport code. 
Table D-1. Radionuclide Inventory Comparison For Single Pass Reactor Cross Section Changes.

\begin{tabular}{|c|c|c|c|c|c|}
\hline \multirow[t]{2}{*}{ Radioisotope } & \multirow{2}{*}{$\begin{array}{l}\text { Ratio }= \\
\text { T Plant }\end{array}$} & \multicolumn{4}{|c|}{$\begin{array}{l}\text { Inventory with Modified Single Pass Reactor Cross Sections } \\
\text { Inventory with Original Single Pass Reactor Cross Sections }\end{array}$} \\
\hline & & B Plant & REDOX & PUREX & Total \\
\hline $\mathrm{H} 3$ & 0.980 & 0.980 & 0.989 & 0.992 & 0.991 \\
\hline $\mathrm{C} 14$ & 1.634 & 1.634 & 1.581 & 1.477 & 1.500 \\
\hline $\mathrm{CO60}$ & 1.198 & 1.197 & 1.163 & 1.052 & 1.058 \\
\hline NI59 & 1.269 & 1.269 & 1.253 & 1.238 & 1.242 \\
\hline NI63 & 1.448 & 1.448 & 1.427 & 1.401 & 1.408 \\
\hline SE79 & 0.980 & 0.980 & 0.983 & 0.983 & 0.983 \\
\hline SR90 & 0.998 & 0.998 & 0.994 & 0.992 & 0.992 \\
\hline Y90 & 0.998 & 0.998 & 0.993 & 0.992 & 0.993 \\
\hline ZR93 & 0.997 & 0.998 & 0.995 & 0.995 & 0.995 \\
\hline NB93* & 0.998 & 0.998 & 0.995 & 0.995 & 0.995 \\
\hline TC99 & 1.001 & 1.001 & 1.002 & 1.002 & 1.002 \\
\hline RU106 & 1.004 & 1.039 & 1.061 & 1.000 & 1.000 \\
\hline CD113* & 0.821 & 0.821 & 0.846 & 0.877 & 0.871 \\
\hline SN126 & 0.896 & 0.896 & 0.917 & 0.925 & 0.923 \\
\hline SB125 & 0.854 & 0.857 & 0.892 & 0.990 & 0.989 \\
\hline I129 & 0.985 & 0.984 & 0.996 & 0.998 & 0.997 \\
\hline CS134 & 0.796 & 0.789 & 0.845 & 0.997 & 0.997 \\
\hline CS137 & 1.000 & 1.001 & 1.002 & 1.002 & 1.002 \\
\hline BA137* & 1.002 & 1.002 & 1.004 & 1.003 & 1.004 \\
\hline SM151 & 1.024 & 1.024 & 1.059 & 1.062 & 1.060 \\
\hline EU152 & 0.824 & 0.826 & 0.866 & 0.913 & 0.907 \\
\hline EU154 & 0.779 & 0.779 & 0.814 & 0.896 & 0.888 \\
\hline EU155 & 1.077 & 1.086 & 1.164 & 1.086 & 1.091 \\
\hline RA226 & 1.002 & 1.002 & 1.003 & 1.003 & 1.003 \\
\hline RA228 & 1.330 & 1.331 & 1.123 & 1.000 & 1.000 \\
\hline $\mathrm{AC} 227$ & 0.997 & 0.997 & 0.996 & 1.000 & 1.000 \\
\hline TH229 & 0.792 & 0.792 & 0.798 & 1.000 & 1.000 \\
\hline TH232 & 1.330 & 1.330 & 1.120 & 1.000 & 1.000 \\
\hline $\mathrm{U} 232$ & 0.761 & 0.761 & 0.748 & 1.000 & 1.000 \\
\hline U233 & 0.789 & 0.789 & 0.798 & 1.000 & 1.000 \\
\hline U2234 & 1.002 & 1.002 & 1.004 & 1.004 & 1.003 \\
\hline
\end{tabular}


Table D-1. Radionuclide Inventory Comparison For Single Pass

Reactor Cross Section Changes.

\begin{tabular}{|c|c|c|c|c|c|}
\hline \multirow{2}{*}{$\begin{array}{c}\text { Radioisotope } \\
\mathrm{U} 235 \\
\end{array}$} & \multirow{2}{*}{$\begin{array}{l}\text { Ratio }= \\
0.998 \\
\end{array}$} & \multicolumn{4}{|c|}{$\begin{array}{l}\text { Inventory with Modified Single Pass Reactor Cross Sections } \\
\text { Inventory with Original Single Pass Reactor Cross Sections }\end{array}$} \\
\hline & & 0.998 & 0.996 & 0.996 & 0.997 \\
\hline $\mathrm{U} 236$ & 1.331 & 1.330 & 1.113 & 1.156 & 1.147 \\
\hline U238 & 0.999 & 1.000 & 1.000 & 1.000 & 1.000 \\
\hline NP237 & 0.783 & 0.783 & 0.800 & 0.843 & 0.833 \\
\hline PU238 & 0.912 & 0.912 & 0.922 & 0.949 & 0.945 \\
\hline PU239 & 1.022 & 1.022 & 0.992 & 0.985 & 0.988 \\
\hline PU240 & 1.494 & 1.495 & 1.424 & 1.346 & 1.361 \\
\hline PU241 & 1.287 & 1.283 & 1.207 & 1.121 & 1.129 \\
\hline PU242 & 1.744 & 1.752 & 1.414 & 1.248 & 1.267 \\
\hline AM241 & 1.287 & 1.285 & 1.221 & 1.170 & 1.179 \\
\hline AM243 & 1.541 & 1.547 & 1.132 & 1.065 & 1.071 \\
\hline CM242 & 1.019 & 1.027 & 1.009 & 1.002 & 1.002 \\
\hline CM243 & 1.152 & 1.153 & 1.012 & 1.005 & 1.005 \\
\hline CM244 & 1.328 & 1.332 & 1.020 & 1.007 & 1.008 \\
\hline
\end{tabular}

*Metastable isotope

\section{D1.2 EFFECT OF FUEL AND CLADDING IMPURITY UNCERTAINTIES}

The reference ORIGEN2 runs (the basis of HDW, Rev. 4 inventories) for single pass reactors and $\mathrm{N}$-reactor used fixed settings for fuel and cladding impurity levels. In actuality, however, concentrations of nickel, nitrogen and ${ }^{236} \mathrm{U}$ in the fuel varied significantly from the 1940's to the 1980's. The bias in certain radionuclides introduced by the simplified reference ORIGEN2 setup method has been determined by generating additional ORIGEN2 fuel activity files with modified fuel compositions, reflecting time-dependent impurity levels (Wootan 1998).

Table D-2 shows the ratio of the radionuclide curie inventories in the revised analysis to the inventories in the reference DKPRO calculations (Watrous and Wootan 1997) for the principal radionuclides affected by impurity concentration changes. The net effect of the time dependant nickel impurity concentration change is a reduction in the ${ }^{59} \mathrm{Ni}$ and ${ }^{63} \mathrm{Ni}$ inventories in the fuel processed through $\mathrm{B}, \mathrm{T}$, and REDOX, but an increase in the inventories in the fuel processed through PUREX. Conversely, the net effect of the time dependent nitrogen impurity is an increase in the inventory of ${ }^{14} \mathrm{C}$ in fuel processed through $B$ and $T$ plants, but a reduction in fuel processed through REDOX and PUREX. The time dependant ${ }^{236} \mathrm{U}$ concentration results in a reduction in 
the ${ }^{237} \mathrm{~Np}$ inventory in fuel processed through REDOX and PUREX. The $1.0 \mathrm{ppm}$ of cobalt added to all of the fuel increases the inventory of ${ }^{60} \mathrm{Co}$ by a factor of 2.6 . The $1.0 \mathrm{ppm}$ of chlorine added to the fuel results in the production of approximately 10 Curies of ${ }^{36} \mathrm{Cl}$. [This comparison does not appear in Table $\mathrm{D}-2$ since ${ }^{36} \mathrm{Cl}$ is not one of the identified 46 key radionuclides evaluated in the reference (HDW Rev. 4) analysis.]

Table D-2. Principal Changes in Radionuclide Inventories - Ratio of Curie Inventory Using Time Dependent Impurities to Previous Inventory

\begin{tabular}{|l|l|l|l|l|l|}
\hline Nuclide & T-Plant & B-Plant & REDOX & PUREX & Total \\
\hline${ }^{14} \mathrm{C}$ & 1.283 & 1.284 & 0.801 & 0.445 & 0.534 \\
\hline${ }^{60} \mathrm{Co}$ & 3.178 & 3.163 & 3.064 & 2.566 & 2.593 \\
\hline${ }^{59} \mathrm{Ni}$ & 0.243 & 0.243 & 0.719 & 1.048 & 0.954 \\
\hline${ }^{63} \mathrm{Ni}$ & 0.249 & 0.249 & 0.734 & 1.051 & 0.964 \\
\hline${ }^{237} \mathrm{~Np}$ & 1.000 & 1.000 & 0.729 & 0.905 & 0.872 \\
\hline
\end{tabular}

\section{D1.3 EFFECT OF FISSION PRODUCT HALF-LIFE UNCERTAINTIES}

A previous study (Wootan 1998) investigated the effects of using updated values of selected half lives on the inventory of key radionuclides. The half lives of the radioisotopes ${ }^{79} \mathrm{Se},{ }^{93 \mathrm{~m}} \mathrm{Nb}$, and ${ }^{126} \mathrm{Sn}$ in the ORIGEN2 and DKPRO decay libraries were modified to reflect recent evaluations. New measurements in China of the ${ }^{79} \mathrm{Se}$ halflife indicate a much longer half-life ( $4.8 \mathrm{E} 5$ years and $11.3 \mathrm{E} 5$ years, in separate measurements) than previously used ( $0.65 \mathrm{E} 5$ years). The new half-life value used was taken as the average of these two measurements, with an assigned uncertainty of 40 percent that bounds the two values. A new Chinese measurement of the ${ }^{126} \mathrm{Sn}$ halflife increases that value from 100,000 years to 250,000 years, with an uncertainty of 9.4 percent.

As shown in Table D-3, the net effect of the half-life changes is a reduction by a factor of 0.40 in the curie inventory of ${ }^{126} \mathrm{Sn}$, a reduction by a factor of 0.08 in the inventory of ${ }^{79} \mathrm{Se}$, and a reduction by a factor of 0.93 in the inventory of ${ }^{93 \mathrm{~m}} \mathrm{Nb}$. The actual amount of ${ }^{126} \mathrm{Sn}$ and ${ }^{79} \mathrm{Se}$ in terms of grams of material hardly changes, but the number of curies represented by these amounts changes by the inverse ratio of the new to old half-lives. The uncertainties in the half lives translates directly into uncertainties in Curie inventories for these radioisotopes. The half life uncertainties for the other radioisotopes are 5 percent or less. 
HNF-3273

Revision 0

\section{D1.4 EFFECT OF FISSION PRODUCT YIELD UNCERTAINTIES}

Cumulative fission product yields from ${ }^{235} \mathrm{U}$ fission (ORIGEN2 data library - no uncertainty information given) have been compared with reference values from England (1994) and their stated uncertainties. This comparison shows that the ORIGEN2 prediction of ${ }^{79} \mathrm{Se},{ }^{113 \mathrm{~m}} \mathrm{Cd},{ }^{125} \mathrm{Sb},{ }^{126} \mathrm{Sn},{ }^{129} \mathrm{I}$, and ${ }^{155} \mathrm{Eu}$ production is 10 to 30 percent high. Predicted yields for the other fission products agree within 5 percent.

\section{D1.5 COMPOSITE BIAS}

Table D-3 summarizes "bias factors" for 46 key radionuclides associated with the four adjusted ORIGEN2 input parameters. The bias factors express the ratio of the global curie inventory as calculated with the modified input parameters to the original curie inventory as calculated by the HDW model (Rev. 4). For example, the row of bias factors for ${ }^{14} \mathrm{C}$ means that the updated curie inventory for ${ }^{14} \mathrm{C}$ is 80 percent of the value predicted by the HDW model (Rev. 4) - the result of a 50 percent increase due to adjusted cross sections coupled with a decrease (by a factor of 0.53 ) due to an adjusted target impurity (Nitrogen) concentration in the fuel. Footnote symbols in the "Other Factor" column indicate that there are additional sources of uncertainty in the global inventory. 
HNF-3273

Revision 0

Table D-3. Bias in Global Inventory Values Due to Updated ORIGEN2 Parameters.

\begin{tabular}{|c|c|c|c|c|c|c|}
\hline \multirow[t]{2}{*}{$\begin{array}{l}\text { Radio- } \\
\text { isotope }\end{array}$} & Ratio $=$ & \multicolumn{3}{|c|}{$\begin{array}{l}\text { Inventory with Modified ORIGEN2 Parameters } \\
\text { Inventory with Original ORIGEN2 Parameters }\end{array}$} & \multicolumn{2}{|c|}{ Other Factors } \\
\hline & $\begin{array}{c}\text { Cross } \\
\text { section bias }\end{array}$ & $\begin{array}{c}\text { Fuel } \\
\text { impurity } \\
\text { bias }\end{array}$ & Half-life bias & Fission yield bias & Notes & $\begin{array}{c}\text { Composite } \\
\text { bias }\end{array}$ \\
\hline $\mathrm{H} 3$ & 0.991 & & & & (a) & 0.99 \\
\hline $\mathrm{C} 14$ & 1.500 & 0.53 & & & (b) & 0.80 \\
\hline Co60 & 1.058 & 2.6 & & & & 2.75 \\
\hline Ni59 & 1.242 & 0.95 & & & & 1.18 \\
\hline Ni63 & 1.408 & 0.96 & & & & 1.35 \\
\hline Se79 & 0.983 & & $0.05-0.11$ & 0.85 & & $\begin{array}{c}0.042- \\
0.092\end{array}$ \\
\hline Sr90 & 0.992 & & & & (c) & 0.99 \\
\hline $\mathrm{Y} 90$ & 0.993 & & & & (c) & 0.99 \\
\hline $\mathrm{Zr93}$ & 0.995 & & & . & & 1.00 \\
\hline $\mathrm{Nb93*}$ & 0.995 & & 0.93 & & & 1.00 \\
\hline $\mathrm{Tc} 99$ & 1.002 & & & & (d) & 1.00 \\
\hline Ru106 & 1.000 & & & & & 1.00 \\
\hline Cd113* & 0.871 & & & 0.76 & & 0.66 \\
\hline SN126 & 0.923 & & $0.36-0.44$ & 0.78 & & $0.26-0.32$ \\
\hline SB125 & 0.989 & & & 0.86 & & 0.85 \\
\hline $\mathrm{I} 129$ & 0.997 & & & 0.76 & (e) & 0.76 \\
\hline CS134 & 0.997 & & & & & 1.00 \\
\hline CS137 & 1.002 & & & & $(f)$ & 1.00 \\
\hline BA137* & 1.004 & & & & (f) & 1.00 \\
\hline SM151 & 1.060 & & & & & 1.06 \\
\hline EU152 & 0.907 & & & & & 0.91 \\
\hline EU154 & 0.888 & & & & & 0.89 \\
\hline EU155 & 1.091 & & & 0.89 & & 0.97 \\
\hline RA226 & 1.003 & & & & (g) & 1.00 \\
\hline RA228 & 1.000 & & & & (h) & 1.00 \\
\hline $\mathrm{AC} 227$ & 1.000 & & : & & (i) & 1.00 \\
\hline TH229 & 1.000 & & & & (j) & 1.00 \\
\hline TH232 & 1.000 & & & & (k) & 1.00 \\
\hline
\end{tabular}


Table D-3. Bias in Global Inventory Values Due to Updated ORIGEN2 Parameters.

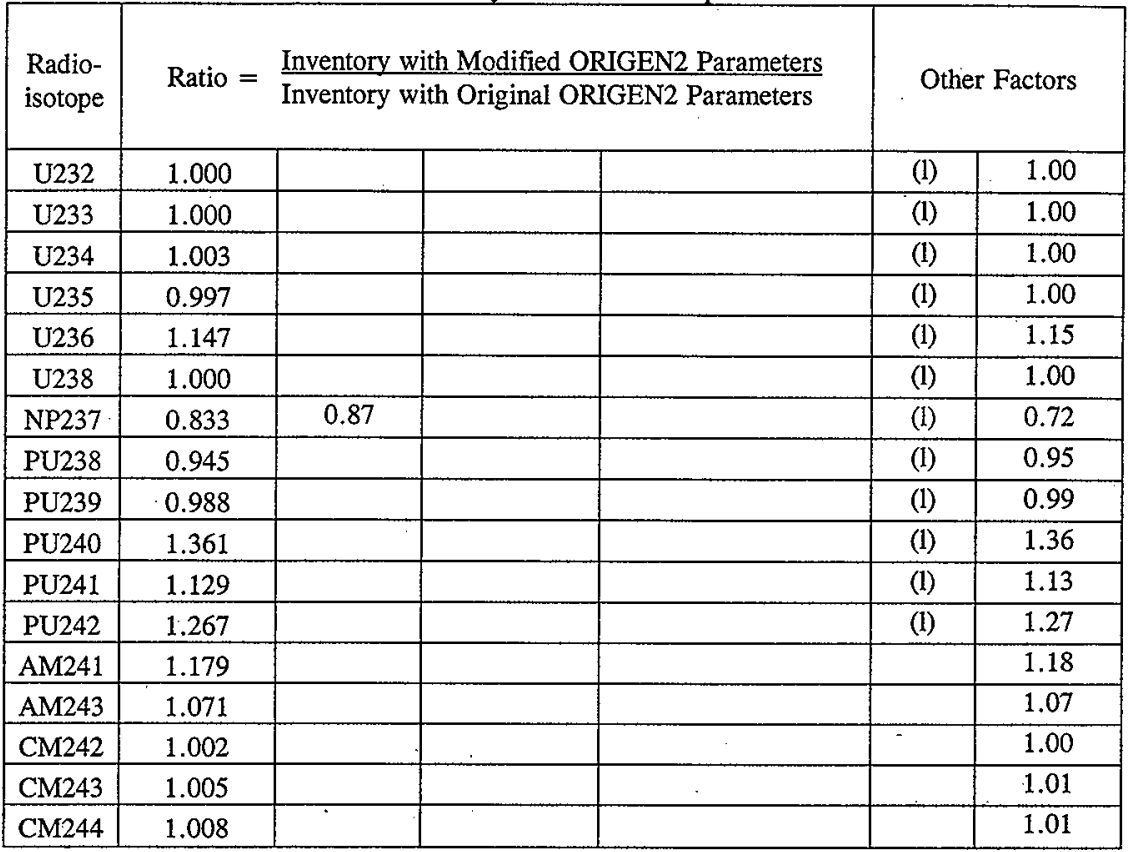

(a)The HDW model assumes $100 \%$ of tritium in fuel is routed to tank waste. Due to losses to atmosphere and condensate, actual tank inventories are significantly less.

(b)Additional uncertainty may exist, associated with losses of $\mathrm{C}-14$ to atmospheric emissions. The HDW modeI assumes $100 \%$ is routed to tank waste.

(c)The HDW global inventory for Sr-90 may be biased low by 14 percent due to internal assumptions accounting for the quantity of Sr-90 separated in B-Plant and routed to capsules, offsite, plant residuals and solid wastes.

(d) The HDW global inventory for ${ }^{93} \mathrm{Tc}$ may be biased high by about 32 percent due to it's not accounting for the fractional separation of $\mathrm{Tc}$ (to the uranium product stream) in TBP, PUREX and REDOX processes.

(e) Additional uncertainty may exist, associated with losses of ${ }^{129} \mathrm{I}$ to atmospheric emissions from fuel dissolution operations. The HDW model (Rev. 4) assumes $100 \%$ is routed to tank waste.

(f) The HDW global inventory for ${ }^{137} \mathrm{Cs}$ may be biased slightly high (less than 2 percent) due to internal assumptions accounting for the quantity of $137 \mathrm{Cs}$ separated in B-Plant and routed to capsules, offsite, plant residuals and solid wastes.

(g)The HDW global inventory for ${ }^{226} \mathrm{Ra}$ is biased by factors of $0.03-1.0$ due to decay calculation limitations and depending on waste type.

(h) The HDW global inventory for ${ }^{228} \mathrm{Ra}$ is biased by factors of $0.02-1.0$ due to decay calculation limitations and depending on waste type.

(i) The HDW global inventory for ${ }^{227} \mathrm{Ac}$ is biased by factors of $0.03-1.0$ due to decay calculation limitations and depending on waste type.

(j) The HDW global inventory for ${ }^{229} \mathrm{Th}$ is biased by factors of $0.14-1.0$ due to decay calculation limitations and depending on waste type.

(k) The HDW global inventory for ${ }^{232} \mathrm{Th}$ is biased by factors of $0.01-1.0$ due to decay calculation limitations and depending on waste type.

(I)The HDW global inventory for actinides may be significantly uncertain due to the use of approximate factors which account for extraction losses of $\mathrm{U}, \mathrm{Np}$ and $\mathrm{Pu}$ and assumptions related to the efficiency of $\mathrm{U}$ recovery from Metal Waste sludges. 
HNF-3273

Revision 0

\section{D2.0 EFFECT OF MISSING WASTE TRANSACTION RECORDS}

The historical waste transfer data file or Waste Status Transaction Record Summary (WSTRS) in the HDW model (Agnew et al. 1997) consists of tank fill records with information extracted from Jungfleish (1983) and Anderson (1990), and checked by Ogden Environmental and Los Alamos National Laboratory (LANL) against quarterly summary reports and the Logbook Dataset. The waste transaction records, although largely representative of the waste histories of the tanks, are nevertheless incomplete in that there are a number of unrecorded transactions that have occurred for many tanks. The waste transaction report is a comparison of the tank volume that is calculated based on the fill records with the measured volume for each tank. This comparison is made each quarter to record any unknown waste additions or removals that may have occurred during the quarter. The largest uncertainty in these records concerns records associated with the evaporator campaigns. The volume reductions and continuous transfers of concentrates and condensates that occurred during these campaigns are not very well represented in the waste transaction records. Transactions from the Logbook Dataset were added to the waste transaction records to resolve many unexplained level changes. This unknown transaction resolution was only completed for all unknowns larger than $190 \mathrm{~kL}$ (50 kgal).

There were volume reductions among the S and SX Farm tanks in the 1950's and early 1960 's. These losses have been attributed to REDOX waste self concentration. PUREX process wastes in the A and AX Farm were self concentrating, but unlike the $S$ and SX tanks, it is assumed in the HDW Model that no salt cake was formed by this . concentration process. Sluicing of $\mathrm{A}$ and $\mathrm{AX}$ Farms resulted in many unrecorded transactions. These transactions were resolved in the HDW Model by creating transactions between tanks and the sluicing receivers in the A and AX Farms.

In this study, several examples were found where the HDW Model is not consistent with the process flow sheets and sample data from some tanks. The HDW Model assumes that a substantial bismuth inventory exists in several of the BY Farm tanks (241-BY-104, 241-BY-105, 241-BY-106, 241-BY-107, 241-BY-108, and 241-BY-110). The sample data and process flow sheets, however, indicate that little bismuth was added to these tanks. In another example, the waste transaction records show that tank 241-BY-110 received 1C waste directly from the BiPO4 process. First cycle $(1 \mathrm{C})$ waste contains a substantial amount of bismuth, but the multiple core samples from tank 241-BY-110 indicate that there is very little bismuth in this tank. The sample data suggests that tank 241-BY-110 must have been the third tank in a three tank cascade of 241-BY-107/241-BY-108/241-BY-110. In this case, the waste transaction records are not consistent with the sample data and must be changed to improve the reliability of the HDW Model. 
HNF-3273

Revision 0

Site historical records were reviewed by Ogden Environmental to confirm the reliability of waste transfers in the HDW Model. Ogden confirmed about 60 percent of the waste transfers from the separation plants to the primary receiver tanks, and about 57 percent of the transfers and receipts between tanks. The remaining transfers were created in the HDW Model to match known or suspected transfers and waste inventory or level measurements in the tanks. While many of these transfers may have occurred, small errors in the transaction records can lead to substantial errors in estimating the inventory of trace analytes such as ${ }^{90} \mathrm{Sr}$. These errors are likely to have a substantially larger affect on the accuracy and reliability of the model than one might assume based on the statistical uncertainty criteria in the model (95 percent confidence interval). Based on our results to date, it appears that the sample data can be used together with the HDW Model results to identify and correct certain discrepancies in the waste transaction records. 
HNF-3273

Revision 0

\section{D3.0 REFERENCES}

Agnew, S. F., J. Boyer, R. A. Corbin, T. B. Duran, J. R. FitzPatrick,

K. A. Jurgensen, T. P. Ortiz, and B. L. Young, 1997, Hanford Tank Chemical and Radionuclide Inventories: HDW Model Rev. 4, LA-UR-96-3860, Los

Alamos National Laboratory, Los Alamos, New Mexico.

Anderson, J. D., 1990, A History of the 200 Area Farms, WHC-MR-0132,

Westinghouse Hanford Company, Richland, Washington.

Jungfleisch, F. M., 1983, Supplementary Information for the Preliminary Estimation of Waste Tank Inventories in Hanford Tanks through 1980, SD-WM-TI-058, Rockwell Hanford Operations, Richland, Washtington.

Roblyer, S. P., 1994, Plutonium and Tritium Produced in the Hanford Site Production Reactors, WHC-SD-CP-RPT-014, Westinghouse Hanford Company, Richland, Washington.

Watrous, R. A., and D. W. Wootan, 1997, Activity of Fuel Batches Processed Through Hanford Separations Plants, 1944 Through 1989, HNF-SD-WM-TI-794, Rev. 0., Lockheed Martin Hanford Corporation, Richland, Washington.

Wittekind, W. D., 1989, Software Certification Package for the ORIGEN2 Computer Code, WHC-SD-NR-SWD-006, Rev. 0, Westinghouse Hanford Company, Richland, Washington.

Wootan, D. W., 1998, Contributions to Uncertainty in Hanford Defined Waste Model Inventories from Radionuclide Source Files, Letter Report FDNW-RJP-98-028, R. J. Puigh to J. W. Cammann (September 1998), Fluor Daniel Northwest, Inc, Richland, Washington. 
HNF-3273

Revision 0

This page intentionally left blank. 
HNF-3273

Revision 0

\section{APPENDIX E}

\section{CHEMICAL ANALYTE PREDICTIONS}


HNF-3273

Revision 0

This page intentionally left blank.

E-2 
HNF-3273

Revision 0

APPENDIX E

\section{CHEMICAL ANALYTE PREDICTIONS}

The Hanford Defined Waste (HDW) model (Agnew et al. 1997) is currently being used to distribute most of the radionuclides to Hanford tank waste. While the HDW model appears to generate representative radionuclide profiles for most tanks, these profiles are essentially based on the same set of records that were used to produce the chemical inventory estimates in the HDW model. Because of extensive core sampling, a representative database now exists for many of the chemical analytes in the tank waste. These data have been used to construct templates that represent the composition of common wastes in various tanks. However, these data can be used to test the accuracy of, or to identify deficiencies in, the HDW model for various groups of tanks. The purpose of this exercise is to not only test the accuracy of the HDW model but also identify those areas where the model could be improved for better radionuclide inventory estimates.

Bismuth was chosen as the example analyte because a substantial amount of core sample data exists for this analyte and only a few waste types (or streams) are known to have contained a significant amount of bismuth. These waste streams include the first cycle (1C) and second cycle (2C) wastes from the Bismuth Phosphate process (B and T plants). Because flow sheet records are also available, bismuth can be used as a tie element to estimate the equivalent amount of waste, on a metric tons of uranium (MTU) basis, added to each of $1 \mathrm{C}$ or $2 \mathrm{C}$ waste receivers (tanks 241-T-104, 241-T-107, 241-B-110, and 241-B-111). Bismuth estimates can be a useful basis for judging the reliability of the waste transaction records for the $1 \mathrm{C}$ and $2 \mathrm{C}$ waste receiver.

\section{E1.0 COMPARISON OF THE HDW MODEL TO SAMPLE INVENTORY ESTIMATES FOR BISMUTH}

Best-basis inventory estimates have been developed for all of the single and double-shell tanks at Hanford. Many of these estimates are based on sample derived estimates developed from core sample data. Bismuth results from this sample population are summarized in Table E-1. This table includes only those tanks with a projected inventory of at least 500 kilograms of bismuth ( 30 tanks). These tanks collectively contain about 70 percent of the total bismuth inventory. Table E-1 also provides a summary of the HDW model predictions for these tanks. These predictions are based on two different sets of solubility assumptions (as defined by split factors or fraction precipitated estimates for bismuth). The first set of split factors (Case 1) was derived from the assumed solubility limit for BiPO4 (0.004 moles per liter). The HDW model uses this solubility limit to compute a vector containing the fraction precipitated 
HNF-3273

Revision 0

solids for each HDW type. The standard fraction precipitated vector derived from the $\mathrm{BiPO}_{4}$ solubility limit is shown in Table E-2.

The second set of solubility assumptions is based on using a common split factor for all of the HDW. In essence, this involves shutting off the minimum solubility limit for bismuth and manually entering the chosen split factor in the fraction precipitated matrix of the HDW model. A common value of 0.98 was chosen for Case 2 . With this assumption, approximately 98 percent of the bismuth would be expected to report to the solid phase and only 2 percent to the liquid or supernate phase. In HDW Rev. 4 model, the fraction precipitated solids for $1 \mathrm{C} 1,1 \mathrm{C} 2,2 \mathrm{C} 1$, and $2 \mathrm{C} 2$ are $0.679,0.679$, 0.606 , and 0.241 , respectively. When these factors are increased to 0.98 , one would expect to see a much larger quantity of bismuth assigned to those tanks with a substantial amount of $1 \mathrm{C}$ and $2 \mathrm{C}$ waste (precipitated sludge). These tanks are 241-T-104, 241-T-107, 241-B-110, and 241-B-111. The results for both sets of solubility assumptions are shown in Figure E-1.

Figure E-1. Ratio of HDW Model to Best Basis Inventory Predictions for Bismuth. Case 1 (Standard Fraction Precipitated Estimates) and Case 2 (0.98 Fraction Precipitated Estimates).

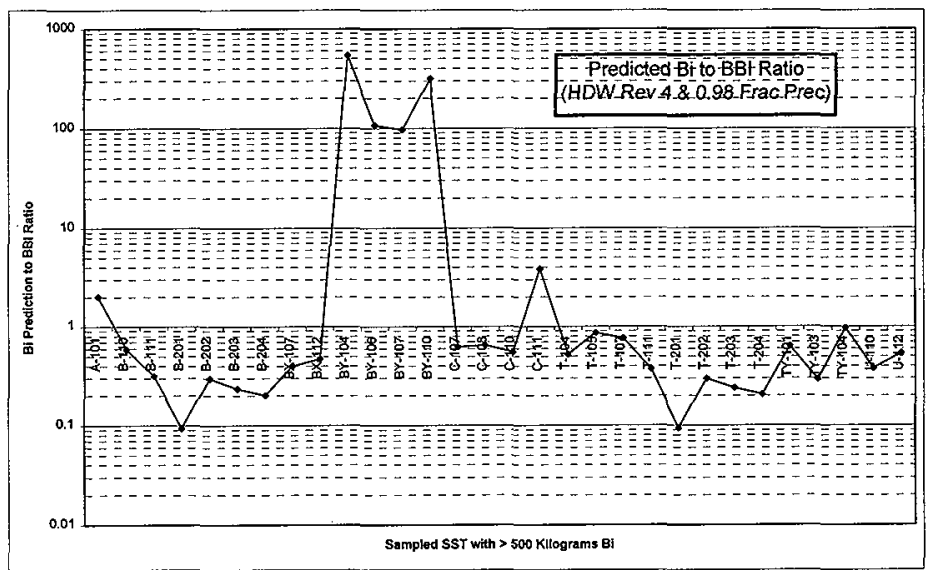


HNF-3273

Revision 0

Table E-1. HDW Model and Best Basis Inventory Predictions for Bismuth. HDW Model Predictions Based on Standard Fraction Precipitated and 0.98 Fraction Precipitated Estimates.

\begin{tabular}{|c|c|c|c|}
\hline Sampled SST & $\begin{array}{c}\text { HDW Rev } 4 \& .98 \\
\text { Frac Prec Bi to BBI } \\
\text { Ratio }\end{array}$ & $\begin{array}{c}\text { HDW Rev } 4 \\
\text { Bi3 + Kilograms }\end{array}$ & BBI Bi, Kilograms \\
\hline A-101 & 2.03 & 768 & 378 \\
\hline B-110 & 0.59 & 13,683 & 23200 \\
\hline $\mathrm{B}-111$ & 0.32 & 6,792 & 21500 \\
\hline $\mathrm{B}-201$ & 0.09 & 343 & 13000 \\
\hline B-202 & 0.30 & 1,187 & 4000 \\
\hline B-203 & 0.23 & 2,197 & 9370 \\
\hline B-204 & 0.20 & 2,153 & 10700 \\
\hline BX-107 & 0.40 & 16,729 & 41900 \\
\hline BX-112 & 0.47 & 6,718 & 14200 \\
\hline BY-104 & 536.70 & 33,973 & 63.3 \\
\hline BY-106 & 107.05 & 27 & 195 \\
\hline BY-107 & 96.60 & 16,423 & 170 \\
\hline BY-110 & 315.13 & 33,089 & 105 \\
\hline $\mathrm{C}-107$ & 0.62 & 10,761 & 17300 \\
\hline C-108 & 0.64 & 1,432 & 2220 \\
\hline $\mathrm{C}-110$ & 0.56 & 9,230 & 16600 \\
\hline C-111 & 3.85 & 1,777 & 462 \\
\hline T-104 & 0.52 & 21,331 & 40800 \\
\hline T-105 & 0.86 & 6,486 & 7500 \\
\hline$T-107$ & 0.76 & 8,441 & 11100 \\
\hline T-111 & 0.37 & 20,856 & 56000 \\
\hline T-201 & 0.09 & 1,230 & 13000 \\
\hline $\mathrm{T}-202$ & 0.30 & 923 & 3111 \\
\hline T-203 & 0.24 & 1,538 & 6430 \\
\hline T-204 & 0.21 & 1,670 & 8130 \\
\hline TY-101 & 0.63 & 12,643 & 19940 \\
\hline TY-103 & 0.29 & 7,955 & 27200 \\
\hline$T Y-104$ & 0.96 & 5,040 & 5240 \\
\hline U-110 & 0.38 & 7,996 & 21000 \\
\hline $\mathrm{U}-112$ & 0.54 & 1,579 & 2940 \\
\hline
\end{tabular}


HNF-3273

Revision 0

Table E-2. Fraction Precipitated Estimates for HDW Rev.4 Model (Case 1) and For 0.98 Fraction Precipitated (Case 2).

\begin{tabular}{|c|c|c|c|c|c|}
\hline $\begin{array}{l}\text { Waste } \\
\text { Type }\end{array}$ & $\begin{array}{l}\text { HDW Rev.4 } \\
\text { Fraction } \\
\text { Precipitated }\end{array}$ & $\begin{array}{l}0.98 \text { Fraction } \\
\text { Precipitated }\end{array}$ & $\begin{array}{l}\text { Waste } \\
\text { Type }\end{array}$ & $\begin{array}{l}\text { HDW Rev.4 } \\
\text { Fraction } \\
\text { Precipitated }\end{array}$ & $\begin{array}{c}0.98 \\
\text { Fraction } \\
\text { Precipitated }\end{array}$ \\
\hline MW1 & 1 & 0.98 & SRR & 1 & 0.98 \\
\hline MW2 & 1 & 0.98 & CSR in & 1 & 0.98 \\
\hline $1 \mathrm{C1}$ & 0.6795 & 0.98 & CSR & 0 & 0.98 \\
\hline $1 \mathrm{C2}$ & 0.6791 & 0.98 & $\mathrm{DE}$ & & 0.98 \\
\hline $2 \mathrm{C} 1$ & 0.6063 & 0.98 & CEM & & 0.98 \\
\hline $2 \mathrm{C2}$ & 0.241 & $0 . \overline{98}$ & NIT & & 0.98 \\
\hline 224 & 0.3363 & 0.98 & $\begin{array}{l}\text { Salt } \\
\text { Slurry }\end{array}$ & 1 & 0.98 \\
\hline UR/TBP & 1 & 0.98 & DW & 1 & 0.98 \\
\hline PfeCN1 & 0.697 & 0.98 & $\mathbf{N}$ & 1 & 0.98 \\
\hline PfeCN2 & 0.697 & 0.98 & $B$ in & & 0.98 \\
\hline TFeCN & 1 & 0.98 & B-SltCk & 0.425 & 0.98 \\
\hline 1CfeCN & 0.715 & 0.98 & T1 in & & 0.98 \\
\hline R1 & 1 & 0.98 & T1-SItCk & 0.2817 & 0.98 \\
\hline R2 & 1 & 0.98 & $R$ in & & 0.98 \\
\hline CWR1 & 1 & 0.98 & RSItCk & 0 & 0.98 \\
\hline CWR2 & 1 & 0.98 & $\mathrm{~T} 2$ in & & 0.98 \\
\hline P1 & 1 & 0.98 & T2-SltCk & 0 & 0.98 \\
\hline P2 & 1 & 0.98 & $B Y$ in & & 0.98 \\
\hline P2' & & 0.98 & BY-SltCk & 0 & 0.98 \\
\hline PL1 & 1 & 0.98 & S1 in & & 0.98 \\
\hline CWP1 & 1 & 0.98 & S1-SitCk & 0 & 0.98 \\
\hline CWP2 & 1 & 0.98 & s2 in & & 0.98 \\
\hline CWZr1 & 1 & 0.98 & S2-SItSIr & 0.559 & 0.98 \\
\hline OWW1 & 0 & 0.98 & A1 in & & 0.98 \\
\hline OWW2 & 0 & 0.98 & A1-SltCk & 0.394 & 0.98 \\
\hline OWW3 & 0 & 0.98 & $A 2$ in & & 0.98 \\
\hline$z$ & 1 & 0.98 & A2-SitSIr & 0 & 0.98 \\
\hline HS & 1 & 0.98 & P3 & 1 & 0.98 \\
\hline TH1 & 1 & 0.98 & PL2 & 1 & 0.98 \\
\hline TH2 & 1 & 0.98 & CWZr2 & 1 & 0.98 \\
\hline AR & 0 & & BP /Cplx & & 0.98 \\
\hline B & 1 & 0.98 & $\begin{array}{c}\mathbf{B P} \\
\text { INCplx } \\
\end{array}$ & & 0.98 \\
\hline \multirow[t]{2}{*}{$\mathrm{BL}$} & 1 & 0.98 & PASF & 1 & 0.98 \\
\hline & & & $\begin{array}{c}\text { sol. limit, } \\
\text { moles/1 }\end{array}$ & 0.004 & 0 \\
\hline
\end{tabular}


This figure shows the ratio of HDW model to best-basis inventory estimate for all of the tanks in the sample population. Data points representing the HDW, Rev. 4 Model are based on solubility derived fraction precipitated estimates, (Case 1) while the alternate data represents a uniform fraction precipitate estimate $(0.98)$ for all Hanford Defined Wastes (Case 2). As shown by this plot, the results are essentially indistinguishable from one another. Fraction precipitated estimates chosen for Case 2 (0.98) have very little effect on the output of the model compared to estimates for Case 1.

This non-linear response is due to other features in the model which limit the distribution of analytes to the solids. In addition to the solids layers defined in the Tank Layering Model (TLM portion of the HDW Model), the HDW Model also defines a set of supernate contributions in the Supernate Mixing Model (SMM portion of the HDW Model). Projected sludge and supernate volumes are used, together with component solubility limits, fraction precipitated estimates, liquid void fraction, solids volume fraction and density estimates to generate a liquid/solids split for each component by waste type. Component contributions are then summed in a linear array to produce the total inventory estimates for the tank. When fraction precipitated estimates are increased, as they were in Case 2, the model continues to allocate each component to the supernate, up to its defined solubility limit, and then to the solids. The solids concentration is directly proportional to the solubility value due to the contribution from interstitial liquid, but inversely proportional to the solids volume fraction for that waste. If the supernate volume is small and solubility limit low, most the material will be allocated to the solids, as in Case 1 from the previous example. When the fraction precipitated estimate is increased, as it was in Case 2, model response may be very small because most of the material has been allocated to the solids and very little remains in the supernate for redistribution to the solids. 
HNF-3273

Revision 0

This page intentionally left blank. 
HNF-3273

Revision 0

\section{E2.0 IMPROVING HDW MODEL PREDICTIONS FOR BISMUTH}

Several other adjustments were made in order to improve the predictive capabilities of the model. These adjustments include modifying the bismuth source terms, the solubility limits and the waste transaction records for certain transfers. The HDW model, for example shows that substantial amount of bismuth resides in the BY Farm (in tanks 241-BY-106, 241-BY-107, 241-BY-108 and 241-BY-110). These tanks were previously included among the ferrocyanide watchlist tanks because of the ferrocyanide treated UR/TBP wastes they contain. Scavenged UR waste was routed to several tanks in the BY Tank Farm in the 200 East Area (241-BY-106, 241-BY-107, 241-BY-108, or 241-BY-110) (Borsheim and Simpson 1991). Some of this sludge was also transferred to tanks 241-BY-104 and 241-BY-105. This sludge, which was derived from BiPO4 metal waste, is known as PFeCN1 and PFeCN2 waste in the HDW Model. According to the BiPO4 flow sheet (Schneider 1951), the metal waste fraction only contained about 642 kilograms of bismuth. The HDW Model, however, indicates that 137,700 kilograms of bismuth exist, mostly in the form of PFeCN1 and PFeCN2 wastes, in tanks 241-BY-104, 241-BY-106, 241-BY-107, 241-BY-108 and 241-BY-110.

Clearly, this is an example where the HDW model predictions are not consistent with the BiPO4 flow sheet, or with sample data from tank 241-BY-110. The tank characterization database for tank 241-BY-110 contains more than 1,180 data points for bismuth, including duplicates, standards and spike recovery samples. All of the analytical samples appear to be at the minimum detection limit for bismuth, including those from fusion analysis and acid dissolution of the core segment and composite samples from cores 103, 107 and 113. The analytical results are consistent with BiPO4 flow sheet and tank transaction records, which show that very little bismuth was added to these tanks. In this case, it appears that the HDW model needs to be revised to better reflect the actual inventory of bismuth in the tanks. When the PFeCN1 and $\mathrm{PFeCN} 2$ bismuth concentrations were reduced to zero, HDW model results were found to be consistent with sample results for tanks 241-BY-104 and 241-BY-106, but not with sample data from tanks 241-BY-107, 241-BY-108 and 241-BY-110. These discrepancies are important because they highlight potential problems with the model or problems that have occurred in developing the Best-Basis Inventory (BBI) estimates for these tanks.

According to the BBI, tank 241-BY-107 currently contains 170 kilograms of bismuth. This estimate is based on the composition of BY salt cake because analytical results for the core composites were found to be at the analytical detection limit for bismuth (less than 2,000 micrograms per gram based on fusion analysis of the two core composite samples). In addition to salt cake, UR, PFeCN1 and PFeCN2 wastes, tank 241-BY-107 also received a small amount of $1 \mathrm{C}$ waste, which contained several thousand kilograms of bismuth. If the bismuth concentration is assumed to be at the analytical detection limit, the projected inventory could be as high as 3,170 kilograms. 
This value is generally consistent with the BiPO4 flow sheet estimate of $9,800 \mathrm{~kg}$ for the 241-BY-107/241-BY-108/241-BY-110 cascade, and also appears to be a better match for the HDW Model derived estimate of 1,493 kilograms of bismuth. This example is of interest because it shows how the HDW model can be used to improve the quality of the Best-Basis Inventory estimates for certain analytes measured at the analytical detection limit.

A parallel situation is also apparent for tank 241-BY-108. The majority of the bismuth analytical data appears to be at the analytical detection limit but these values were used to estimate the BBI for this tank to be less than 644 kilograms. The HDW model currently estimates an inventory of only 6 kilograms of bismuth in this tank. This discrepancy highlights one of the potential problems with the HDW Model, namely the accurate identification of sludge layers in various tanks. Tanks 241-BY-107 and 241-BY-108 were operated as a cascade during the receipt of $1 \mathrm{C}$ waste in 1952 . In the HDW Model, it is assumed that none of the $1 \mathrm{C}$ waste was carried over to the second tank in the cascade (241-BY-108). Sample results, however, suggest otherwise indicating a small but measurable amount of bismuth laden $1 \mathrm{C}$ waste in 241-BY-108.

Tank transaction records show tank $241-\mathrm{BY}-110$ received about $2,755 \mathrm{~kL}$ of $1 \mathrm{C}$ waste in 1951 and 1952. In the HDW Model, this transfer is assumed to be a direct transfer from B-plant. Based on the projected amount of bismuth in the $1 \mathrm{C}$ waste, some 6,871 kilograms of bismuth should have been added to this tank and other downstream tanks in the cascade. The HDW Model generated a prediction of 2,300 kilograms of bismuth in this tank. Analytical results, however, show that only about 50 to 200 kilograms of bismuth were added to this tank, based on the analytical detection limit of acid dissolution samples from three core composites. In this case, there appears to be a significant discrepancy between the HDW model and sample results for tank 241-BY-110.

The HDW model relies extensively on the tank inventory records developed by Anderson, especially for undocumented transfers that occurred in the late 1940's and early 1950's (Anderson 1990). For tank 241-BY-110, Anderson shows that the initial transfer of $1 \mathrm{C}$ waste occurred during the fourth quarter of 1951. This period corresponds to the time frame when tanks 241-BY-107 and 241-BY-108 were also being filled with $1 \mathrm{C}$ waste. However, the low bismuth inventory in tank 241-BY-110 suggests that this tank may have been operated as the third tank in this cascade. As the third tank in the cascade, 241-BY-110 would have received very little bismuth from $1 \mathrm{C}$ waste. In this case, the waste transaction records used by the HDW model are not consistent with sample results and thus may be in error for this tank.

Several parameters were subsequently adjusted, including chemical source term estimates, to improve the fit between the model and sample based estimates for the bismuth. The results are shown in Figure E-2 (with a corrected sample value for 241-BY-107). This fit was obtained by increasing the amount of bismuth in $1 \mathrm{C} 1$ waste 


\section{Revision 0}

(from 0.012 to 0.018 moles/liter) and by doubling the amount of bismuth in 224 waste (from 0.006 to 0.012 moles/liter). As mentioned before, the amount of bismuth in the $\mathrm{PFeCN} 1$ and PFeCN2 wastes was also reduced to zero. Finally, the solubility limit for $\mathrm{BiPO} 4$ was reduced from 0.004 to $0.001 \mathrm{moles} / \mathrm{liter}$. These changes are considered to be reasonable in light of the high bismuth inventories found in the 224 waste receivers (B-200 and T-200 series of tanks), the absence of bismuth in PFeCN1 and PFeCN2 wastes and high bismuth inventories found in several of the $1 \mathrm{C}$ waste receivers. Otherwise, only the standard HDW model values were used to produce the results in Figure E-2. This figure shows two separate correlations. The first one, represented by the light gray squares, shows the ratio of HDW rev.4 model to Best Basis Inventory (BBI) estimate, while second one (diamond data points) shows the improved fit between the modified HDW model and BBI. This fit appears to be reasonably good for most tanks except BY-110 and C-111. Table E-2 provides a summary of the tank inventory estimates and HDW model to BBI ratios used in Figure E-2. 
HNF-3273

Revision 0

Figure E-2. Ratio of HDW Rev. 4 Model to Best Basis Inventory Estimates for Bismuth (square data points) and Modified HDW Model to Best Basis Inventory Estimates (diamond shaped data points).

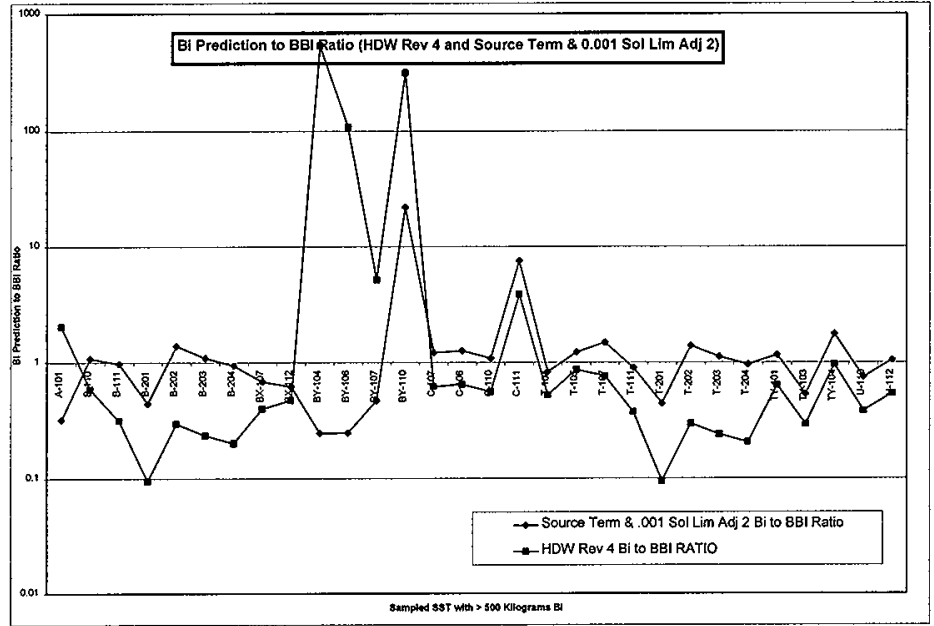


HNF-3273

Revision 0

Table E-2. HDW Rev.4 Model and Best Basis Inventory Estimates Together with Modified HDW model Results for Figure E-2.

\begin{tabular}{|c|r|c|c|c|c|}
\hline $\begin{array}{c}\text { SST } \\
\text { Tanks }\end{array}$ & $\begin{array}{c}\text { HDW } \\
\text { Rev 4 } \\
\text { Model, } \\
\text { Kg }\end{array}$ & $\begin{array}{c}\text { Best } \\
\text { Basis } \\
\text { Ingentory } \\
\text { Kg }\end{array}$ & $\begin{array}{c}\text { HDW Rev 4 to } \\
\text { BBI RATIO }\end{array}$ & $\begin{array}{c}\text { Modified HDW } \\
\text { Model } \\
\text { Kg }\end{array}$ & $\begin{array}{c}\text { Modified HDW } \\
\text { Model to BBI } \\
\text { Ratio }\end{array}$ \\
\hline A-101 & 768 & 378 & 2.03 & 121 & 0.32 \\
\hline B-110 & 13,683 & 23200 & 0.59 & 25075 & 1.08 \\
\hline B-111 & 6,792 & 21500 & 0.32 & 20884 & 0.97 \\
\hline B-201 & 343 & 13000 & 0.09 & 5754 & 0.44 \\
\hline B-202 & 1,187 & 4000 & 0.30 & 5548 & 1.39 \\
\hline B-203 & 2,197 & 9370 & 0.23 & 10275 & 1.10 \\
\hline B-204 & 2,153 & 10700 & 0.20 & 10068 & 0.94 \\
\hline BX-107 & 16,729 & 41900 & 0.40 & 28625 & 0.68 \\
\hline BX-112 & 6,718 & 14200 & 0.47 & 8819 & 0.62 \\
\hline BY-104 & 33,973 & 63.3 & 536.70 & 16 & 0.25 \\
\hline BY-106 & 27 & 195 & 107.05 & 48 & 0.25 \\
\hline BY-107 & 16,423 & 3170 & 5.18 & 1493 & 0.47 \\
\hline BY-110 & 33,089 & 105 & 315.13 & 2300 & 21.91 \\
\hline C-107 & 10,761 & 17300 & 0.62 & 21029 & 1.22 \\
\hline C-108 & 1,432 & 2220 & 0.64 & 2797 & 1.26 \\
\hline C-110 & 9,230 & 16600 & 0.56 & 18038 & 1.09 \\
\hline C-111 & 1,777 & 462 & 3.85 & 3473 & 7.52 \\
\hline T-104 & 21,331 & 40800 & 0.52 & 33730 & 0.83 \\
\hline T-105 & 6,486 & 7500 & 0.86 & 9198 & 1.23 \\
\hline T-107 & 8,441 & 11100 & 0.76 & 16495 & 1.49 \\
\hline T-111 & 20,856 & 56000 & 0.37 & 50135 & 0.90 \\
\hline T-201 & 1,230 & 13000 & 0.09 & 5754 & 0.44 \\
\hline T-202 & 923 & 3111 & 0.30 & 4315 & 1.39 \\
\hline T-203 & 1,538 & 6430 & 0.24 & 7192 & 1.12 \\
\hline T-204 & 1,670 & 8130 & 0.21 & 7808 & 0.96 \\
\hline TY-101 & 12,643 & 19940 & 0.63 & 23170 & 1.16 \\
\hline TY-103 & 7,955 & 27200 & 0.29 & 14448 & 0.53 \\
\hline TY-104 & 5,040 & 5240 & 0.96 & 9216 & 1.76 \\
\hline U-110 & 7,996 & 21000 & 0.38 & 15626 & 0.74 \\
\hline U-112 & 1,579 & 2940 & 0.54 & 3087 & 1.05 \\
\hline & & & & & \\
\hline
\end{tabular}

The fit for 241-BY-110 is mostly affected by the assumption that 241-BY-110 was used as a primary receiver of $1 \mathrm{C}$ waste from B-plant. Sample results, however, suggest that 241-BY-110 was used as a downstream receiver (third tank in a three tank cascade). If this is true, the waste transaction records could be easily changed so the model results would fall in line with the sample data for this tank. Tank 241-C-111 was also used as the second tank in a cascade receiving $1 \mathrm{C}$ waste. In this case, the 
HNF-3273

Revision 0

model assigns a disproportionately large amount of waste to the second tank in the cascade (241-C-111). Sample results from the 241-BY-107/241-BY-108 and 241-T-104/241-T-105 cascades show that about 15 percent of the $1 \mathrm{C}$ waste carried over to the second tank in the cascade. The HDW model assumes that about 23 percent of the $1 \mathrm{C}$ waste carried over to the downstream receiving tank. However, for the 241-C-110/241-C-111 cascade, the carryover only amounts to 2.7 percent of the incoming waste, based on the analytical results for bismuth. Apparently, for reasons that are not fully understood, waste settling properties and carryover efficiencies were not necessarily uniform across all of the cascade tanks. If this discrepancy is corrected for the 241-C-110/241-C-111 cascade, model predictions should also become more closely aligned with sample results from tank $241-\mathrm{C}-111$.

This bismuth trial included 30 single-shell tanks (SSTs) with a sample-based inventory of at least 500 kilograms of bismuth each. The adjusted HDW model provided estimates within $+/-50$ percent of the sample inventory for 73 percent of the tanks, and estimates within $+/-100$ percent of the sample inventory for 93 percent of the tanks.

In a recent comparison between HDW Rev. 3 model predictions and samplebased estimates, HDW model predictions were found to be in statistical agreement with 40 to 50 percent of the analytes in the sample tank population (17 tanks). This comparison once again highlights potential inconsistencies in the HDW model, but also shows, for certain analytes, the model can be used to judge the internal consistency of our analytical results and to augment the current database. This study was performed by PNNL (Hartley et al. 1996).

\section{E3.0 COMPARISON OF HDW MODEL TO SAMPLE INVENTORY ESTIMATES FOR SR-90}

In a related study, HDW model predictions were also compared to sample derived ${ }^{90} \mathrm{Sr}$ estimates in 47 single-shell tanks. This group represents 31.5 percent of the tanks and 44.6 percent of the ${ }^{90} \mathrm{Sr}$ inventory in the SST farms $(19,152,410$ out of $42,958,300 \mathrm{Ci}$ of ${ }^{90} \mathrm{Sr}$ in the SSTs). The initial results are shown in Figure E-3. This figure provides two different sets of estimates. The first set, which is presented as the ratio of HDW model to best basis inventory, was produced by using the model's standard solubility limit for ${ }^{90} \mathrm{Sr}(0.034 \mathrm{Ci} /$ liter $)$. In this plot, the tanks are arranged in order of increasing ratio (with a ratio of 1.0 representing a perfect fit between model and sample results) and the data points being plotted as small squares. The second set of estimates is based on a revised solubility limit of $0.01 \mathrm{Ci} /$ liter for ${ }^{90} \mathrm{Sr}$. This comparison is useful because it shows that HDW model predictions will not necessarily improve simply changing the solubility limit for ${ }^{90} \mathrm{Sr}$. 

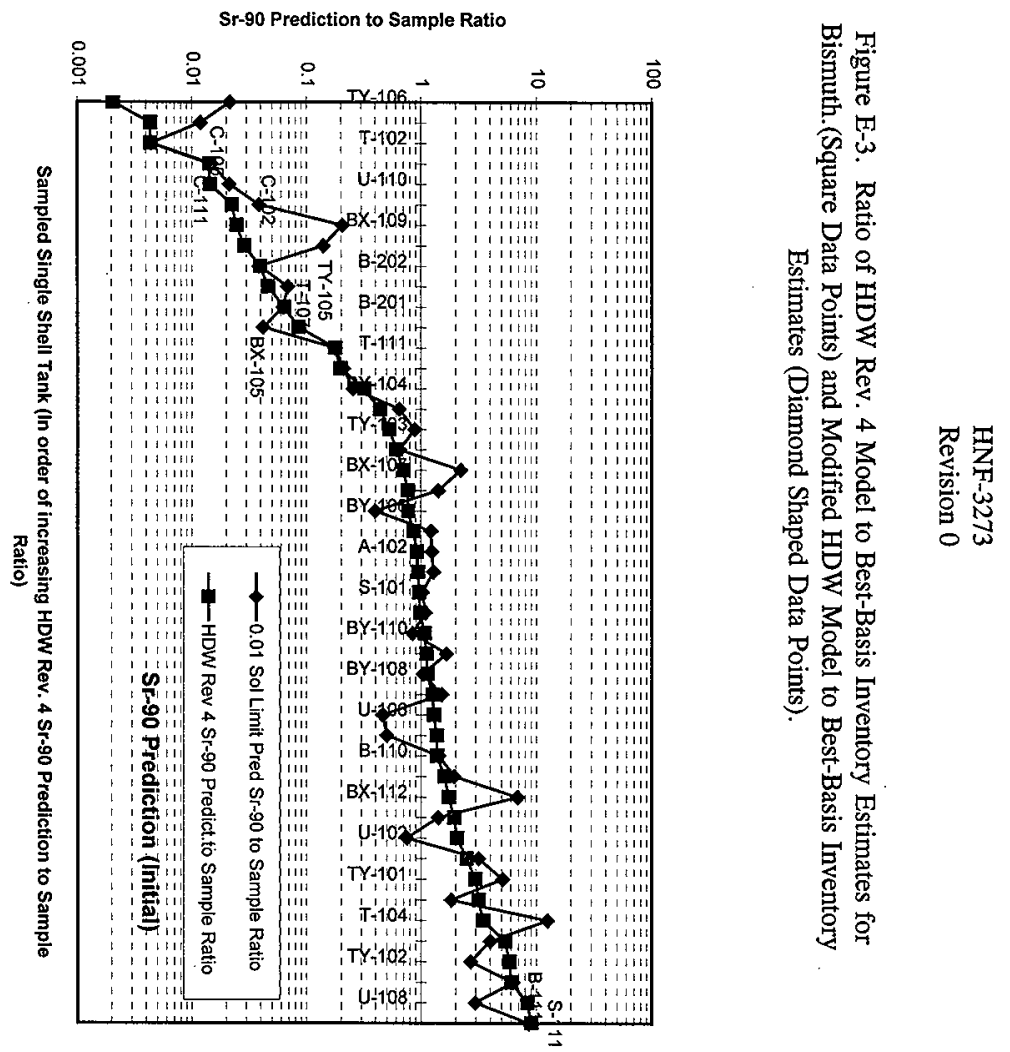
HNF-3273

Revision 0

This page intentionally left blank.

E-16 
HNF-3273

Revision 0

\section{E4.0 IMPROVING HDW MODEL PREDICTIONS FOR SR-90}

When the solubility limit is changed, the "set frac" subroutine (or marco) in the model recalculates the liquid/solids distribution for each analyte by waste type. This produces a new set of fraction precipitated estimates in the model. The model also allows one to individually adjust the fraction precipitated estimates for each waste type, rather than relying on a common solubility limit for all wastes. The source terms in the model can be adjusted, both terms relating to the distribution of radionuclides between wastes or terms relating to the volume of sludge or supernate from each waste. With these adjustments, the model can be systematically changed to improve the potential fit with tank sample data from target tank population. The final results of this exercise are shown in Figure E-4. Table E-4 provides the HDW model and adjusted HDW model values and Best Basis Inventory estimates displayed in Figure E-4. 
HNF-3273

Revision 0

Figure E-4. Ratio of HDW Rev.4 Model to Best Basis Inventory Estimates for Sr-90

(Square Data Points) and Revised HDW Model to Best-Basis Inventory Estimates (Diamond Shaped Data Points).

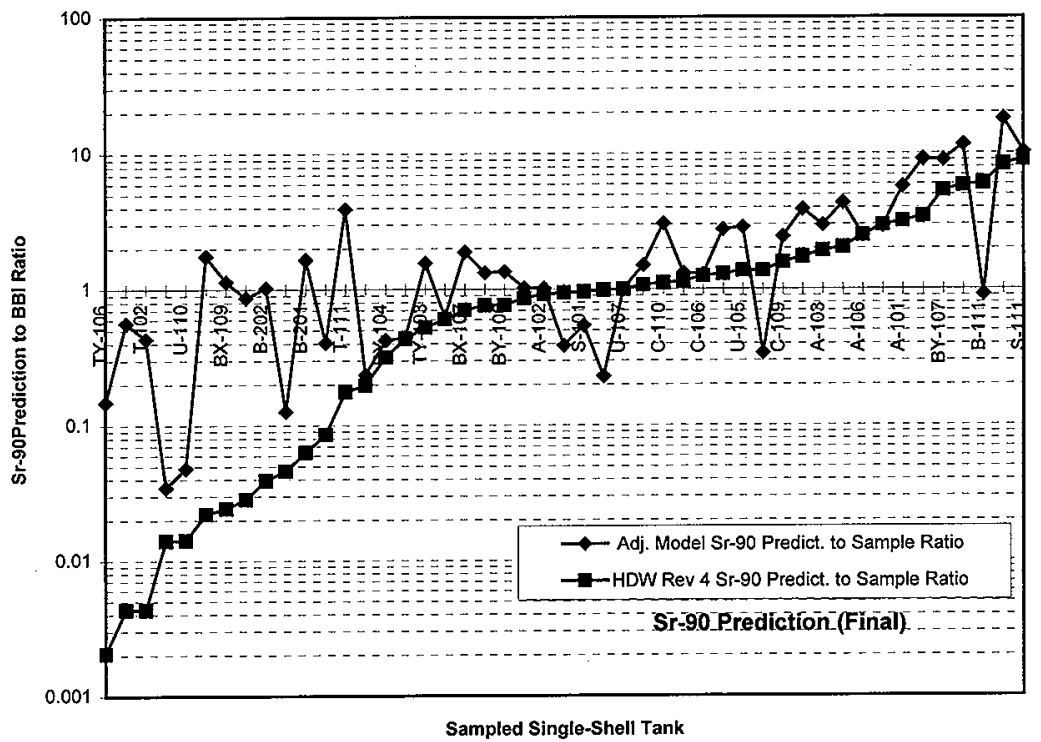

E-18 
HNF-3273

Revision 0

Table E-4. Ratios of HDW Rev.4 Model to Best-Basis Inventory and

Revised HDW Model to Best-Basis Inventory Estimates for St-90

\begin{tabular}{|c|c|c|c|c|c|}
\hline $\begin{array}{l}\text { Sampled Single } \\
\text { Shell Tank }\end{array}$ & $\begin{array}{l}\text { HDW Rev } 4 \\
\text { Sr-90 Estimate } \\
\text { Ci }\end{array}$ & $\begin{array}{c}\text { Revised Model Sr-90 } \\
\text { Estimate } \\
\mathrm{Ci}\end{array}$ & $\begin{array}{c}\text { Sample } \\
\text { Sr-90 Estimate } \\
\mathrm{Ci}\end{array}$ & $\begin{array}{c}\text { Revised Model to } \\
\text { Sample } \\
\text { Sr-90 Ratio }\end{array}$ & $\begin{array}{l}\text { HDW Rev } 4 \text { to Sample } \\
\text { Sr-90Ratio }\end{array}$ \\
\hline$T Y-106$ & 19 & 1,388 & 9,420 & 0.15 & 0.002 \\
\hline C-105 & 1,581 & 205,507 & 365,000 & 0.56 & 0.004 \\
\hline T-102 & 133 & 13,290 & 30,690 & 0.43 & 0.004 \\
\hline C-111 & 16,046 & 39,579 & $1,140,000$ & 0.035 & 0.014 \\
\hline $\mathrm{U}-110$ & $4, \overline{847}$ & 16,378 & 340,000 & 0.048 & 0.014 \\
\hline $\mathrm{C}-102$ & $4, \overline{044}$ & 321,527 & 182,000 & 1.77 & 0.022 \\
\hline BX-109 & $4 \overline{859}$ & 226,806 & 199,000 & 1.14 & 0.024 \\
\hline TY-105 & $7, \overline{283}$ & 221,139 & 256,000 & 0.86 & 0.028 \\
\hline $\mathrm{B}-202$ & 18 & 460 & 449 & 1.03 & 0.039 \\
\hline$T-107$ & 4,925 & 13,544 & 107,000 & 0.13 & 0.046 \\
\hline$\overline{\mathrm{B}-201}$ & $\overline{18}$ & 477 & 287 & 1.66 & 0.064 \\
\hline $8 X-105$ & 2,217 & 10,538 & 26,000 & 0.41 & 0.085 \\
\hline $\bar{T}-111$ & 1,929 & 42,744 & 10,900 & 3.9 & 0.18 \\
\hline $\mathrm{C}-112$ & 245,501 & 292,972 & $1,250,000$ & 0.23 & 0.20 \\
\hline$\overline{B Y-104}$ & 279,983 & $3 7 \longdiv { 3 1 0 }$ & 884,000 & 0.42 & 0.32 \\
\hline$\overline{C-107}$ & 731,274 & 744,457 & $1,680,000$ & 0.44 & 0.44 \\
\hline TY-103 & 49,578 & 147,943 & 94,300 & 1.57 & 0.53 \\
\hline $\mathrm{C}-103$ & $1,198,918$ & $1,241,701$ & $1,980,000$ & 0.63 & 0.61 \\
\hline BX-107 & 13,087 & 35,127 & 18,600 & 1.89 & 0.70 \\
\hline TY-104 & 24,240 & 42,159 & 31,800 & 1.33 & 0.76 \\
\hline BY-106 & 380,000 & 668,771 & 496,000 & 1.35 & 0.77 \\
\hline C-104 & 534,115 & 636,461 & 624,000 & 1.02 & 0.86 \\
\hline A-102 & 124,029 & 136,704 & 135,000 & 1.01 & 0.92 \\
\hline S-107 & 379,796 & 156,008 & 404,000 & 0.39 & 0.94 \\
\hline S-101 & 500,920 & 285,428 & 525,000 & 0.54 & 0.95 \\
\hline S-104 & 539,937 & 125,975 & 549,000 & 0.23 & 0.98 \\
\hline BY-110 & 281,690 & 395,199 & 263,000 & 1.50 & 1.07 \\
\hline $\mathrm{C}-110$ & $5, \overline{386}$ & 14,811 & 4,860 & 3.05 & 1.11 \\
\hline BY-108 & 221,717 & 255,161 & 195,000 & 1.31 & 1.14 \\
\hline C-106 & $5,969,308$ & $6,138,664$ & $4,770,000$ & 1.29 & 1.25 \\
\hline U-106 & $\overline{136,769}$ & 291,600 & 106,000 & 2.75 & 1.29 \\
\hline $\mathrm{U}-105$ & 210,413 & 442,532 & 154,000 & 2.87 & 1.37 \\
\hline B-110 & 184,588 & 45,605 & 135,000 & 0.34 & 1.37 \\
\hline$\overline{C-109}$ & 349,522 & $\overline{537,763}$ & 221,000 & 2.43 & 1.58 \\
\hline BX-112 & 8,509 & 19,097 & 4,920 & 3.9 & 1.73 \\
\hline A-103 & 284,512 & 438,825 & 148,000 & 2.97 & 1.92 \\
\hline $\mathrm{U}-102$ & 164,999 & 349,657 & 81,000 & 4.3 & 2.04 \\
\hline A-106 & $2,072,538$ & $2,071,991$ & 834,000 & 2.48 & 2.49 \\
\hline TY-101 & 59,511 & 58,480 & 20,100 & 2.91 & 2.96 \\
\hline A-101 & 480,939 & 871,412 & 152,000 & 5.7 & 3.2 \\
\hline$T-104$ & 19,541 & 51,220 & 5,660 & 9.0 & 3.5 \\
\hline BY-107 & 160,822 & 269,483 & 30,100 & 9.0 & 5.3 \\
\hline$T Y-102$ & 9,995 & 19,917 & 1,720 & 11.6 & 5.8 \\
\hline B-111 & $1,594,017$ & 240,987 & 264,000 & 0.91 & 6.0 \\
\hline U-108 & 244,616 & 528,359 & 29,400 & 18.0 & 8.3 \\
\hline $\mathrm{S}-111$ & 460,413 & 523,046 & 51,200 & 10.2 & 9.0 \\
\hline
\end{tabular}


HNF-3273

Revision 0

HDW model predictions in Figure E-4 were improved in a variety of ways. Fraction precipitated estimates were varied by waste type for some tanks to improve the fit with sample data. Sometimes, this involved choosing a compromise value that would collectively minimize the deviation for a group of tanks. Radionuclide distribution source terms were also increased for some of the coating wastes, including CWR1, CWP1 and CWP2, to increase the amount of ${ }^{90} \mathrm{Sr}$ in the coating waste receivers (tanks 241-C-102, 241-C-105, 241-C-107, and 241-C-111). The original values in the HDW model call for 0.4 percent of the radionuclides being distributed to the coating waste. Due to the high sample inventories in the coating waste receivers, these values were increased to 2 percent, 4 percent and 1 percent, respectively, for CWR1, CWP1 and CWP2 wastes. While these ratios may not be the optimum choice, they had a positive effect on reducing deviations between model and sample predictions for the coating waste tanks. Table E-5 provides a list of the original fraction precipitated estimates by waste type in HDW Rev. 4 together with the set of estimates developed from this study and a third set of estimates developed from fundamental consideration of chemistry conditions in the tanks (Solubility Case 3 estimates, see Section 5.1). 
HNF-3273

Revision 0

Table E-5. Fraction Precipitated Estimates for Sr-90 Based on HDW Rev.4 Model, Revised

HDW Model and Basic Chemistry Conditions (Solubility Case 3 Estimates).

\begin{tabular}{|c|c|c|c|c|c|c|c|}
\hline Waste Type & $\begin{array}{l}\text { HDW } \\
\text { Rov.4 } \\
\text { Model }\end{array}$ & $\begin{array}{l}\text { Revised HDW } \\
\text { Model }\end{array}$ & $\begin{array}{c}\text { Chemisty } \\
\text { Conditions } \\
\text { (Case } 3 \\
\text { Estimates) }\end{array}$ & Waste Type & $\begin{array}{c}\text { HDW Rev.4 } \\
\text { Model }\end{array}$ & $\begin{array}{c}\text { Revised HDW } \\
\text { Model }\end{array}$ & $\begin{array}{l}\text { Chemistry } \\
\text { Conditions } \\
\text { (Case } 3 \\
\text { Estimates) }\end{array}$ \\
\hline$\overline{M W 1}$ & 0 & 1 & 0.98 & CSR & 0 & & 0.98 \\
\hline MW2 & 0 & 1 & 0.98 & $\mathrm{DE}$ & & 1 & 0.98 \\
\hline$\overline{1 C 1}$ & 0 & 0.2 & 0.98 & CEM & & 1 & 0.98 \\
\hline $1 \mathrm{C2}$ & 0 & 0.2 & 0.98 & NIT & & 1 & 0.98 \\
\hline $2 \mathrm{C1}$ & 0 & 0.8 & 0.98 & Salt Slurry & 1 & . & \\
\hline $2 \mathrm{C2}$ & 0 & 0.8 & 0.98 & DW & 1 & 1 & 0.98 \\
\hline 224 & 0 & 0.9 & 0.98 & $\mathbf{N}$ & 1 & 1 & 0.98 \\
\hline URЛTBP & 0 & 0.92 & 0.98 & B-SitCk & 0 & 0 & \\
\hline PFeCN1 & 0.98 & 0.98 & 0 & T1-SitCk & 0 & 0 & \\
\hline PFeCN2 & 0.98 & 0.98 & 0 & RSItCk & 0 & 0 & \\
\hline TFeCN & 0.98 & 0.98 & 0 & T2-SItCk & 0.7197 & 0.719 & \\
\hline ICFeCN & 0.55 & 0.55 & 0 & BY-SItCk & 0.01437 & 0.294 & \\
\hline R1 & 0.55 & 0.1 & 0.98 & S1-SitCk & 0.7877 & 0.788 & \\
\hline $\mathbf{R 2}$ & 0.875 & 0.963 & 0.98 & S2-SItSlr & 0.697 & 0.697 & \\
\hline CWR1 & 0 & 0 & 0.98 & A1-SItCk & & 0.683 & 0.683 \\
\hline CWR2 & 0 & 0 & 0.98 & A2-SitSir & 0.54 & 0.54 & \\
\hline P1 & 0.88 & 0.965 & 0.98 & P3 & 0.986 & 0.996 & 0.98 \\
\hline P2 & 0.949 & 0.1 & 0.98 & PL2 & 0 & & 0.98 \\
\hline P2' & 0.997 & 0.997 & 0.98 & CWZr2 & 0 & 0 & 0.98 \\
\hline PL1 & 0 & & 0.98 & BP/Cplx & & & 0 \\
\hline CWP1 & 0 & 0.98 & 0.98 & BP/Ncplx & & & 0 \\
\hline CWP2 & 0 & 0.98 & 0.98 & PASF & 1 & 1 & 0.98 \\
\hline $\mathrm{CWZr1}$ & 0 & 0 & 0.98 & $\begin{array}{l}\text { sol.limit, } \\
\text { moles/l }\end{array}$ & $3.40 \mathrm{E}-02$ & $0.00 \mathrm{E}+00$ & \\
\hline OWWI & 0 & 1 & 0.98 & & & & \\
\hline OWW2 & 0 & 1 & 0.98 & & & & \\
\hline OWw3 & 0 & 1 & 0.98 & & & & \\
\hline $\mathbf{Z}$ & 0 & 0.98 & 0.98 & & & & \\
\hline HS & 0.758 & 0.929 & 0 & & & & \\
\hline TH1 & 0 & 0 & 0.98 & & & & \\
\hline TH2 & 0.106 & 0.737 & 0.98 & & & & \\
\hline AR & 0.921 & 0.976 & 0.98 & & & & \\
\hline $\mathbf{B}$ & 0.549 & 0.867 & 0.98 & & & & \\
\hline$\overline{B L}$ & 0.619 & 0.888 & 0.98 & & & & \\
\hline SRR & 0.666 & 0.902 & 0 & & & & \\
\hline
\end{tabular}

For those tanks where the model to sample deviations were substantial, the extent of this departure from sample data clearly exceeded the $95 \%$ confidence intervals defined in HDW Rev. 4. In other words, the $95 \% \mathrm{CI}$ in the HDW Model does not truly represent the wide range of variability found in the Sr-90 tank population. 
Four of the tanks with unusually high model predictions contain $1 \mathrm{C} 1$ and $1 \mathrm{C} 2$ wastes (241-BX-112, 241-C-109, 241-C-110, and 241-104). This suggests that a better fit might be obtained if the assumed 10 percent split for $\mathrm{BiPO} 4$ radionuclides is reduced to about 3 percent for the $1 \mathrm{C} 1 / 1 \mathrm{C} 2$ waste. The adjusted model predictions for tank 241-T-111 also appear to be excessively high. As a $2 \mathrm{C} 1 / 2 \mathrm{C} 2$ waste receiver, the ${ }^{90} \mathrm{Sr}$ inventory in tank 241-T-111 is not consistent with the amount in tanks 241-B-110 and 241-B-111, but these latter tanks also received a small amount of high-level PUREX (P2) waste. Obviously, more needs to be done to calibrate the effect of P2 waste. The remaining tanks in this population mostly contain salt cake wastes. Because salt cake waste generally contains only a small amount of ${ }^{90} \mathrm{Sr}$, there may be other features in the model that tend to exaggerate the ${ }^{90} \mathrm{Sr}$ inventory in the salt cake receivers. This problem could be caused by errors in the waste transaction records. Certain features in the SMM portion of the HDW model could also lead to unusually high predictions. These discrepancies need to be studied in more detail before any conclusions can be reached regarding the reliability of the model for the salt cake laden tanks.

Chemistry based fraction precipitated estimates (Solubility Case 3) in Table E-5 produced slightly better results than those in the revised HDW model. Both sets produced a two fold reduction in scatter compared to HDW, Rev.4.

Sample data can also be used to identify other areas of improvement in the HDW model. The HDW model ${ }^{90} \mathrm{Sr}$ estimate is 10 times higher than the sample derived estimate for tank 241-S-111. The waste transaction records indicate this tank was used as the second tank in a REDOX waste cascade from 1952 to 1957 . As the second tank in the cascade, the HDW model has assigned an inventory of $250 \mathrm{~kL}$ (66 kgal) of R1 sludge to this tank, compared to an inventory of $336.8 \mathrm{~kL}$ ( $89 \mathrm{kgal}$ ) of such sludge in the primary receiver (tank 241-S-110). The 1996 core sample from tank 241-S-111 (core 149), however, shows that all of the waste consists of salt cake, wet salt, moist salt or dry salt at the bottom of the tank. The only sludge layer that was found is one from segment 4, close to the top of the eleven segment core. According the normal chronology of such deposits, this sludge layer must have been added at some later date, and should not consist of R1 waste as alleged in the HDW model. This observation is consistent not only with the physical evidence from the core, but also with the ${ }^{90} \mathrm{Sr}$ results obtained from the core composite. 


\section{E5.0 IDENTIFIED LIMITATIONS IN THE HDW MODEL}

To investigate the potential for improving tank-by-tank inventory predictions, the HDW Model was compared to sample based estimates for bismuth and ${ }^{90} \mathrm{Sr}$. The bismuth trial included 30 SSTs with a sample-based inventory of at least 500 kilograms of bismuth each. These tanks collectively contain about 70 percent of the total bismuth inventory at Hanford. The HDW Model was adjusted to improve the fit between model and sample based estimates for these tanks. The adjusted HDW model provided estimates within $+/-50$ percent of the sample inventory for 73 percent of the tanks, and estimates within $+/-100$ percent of the sample inventory for 93 percent of the tanks. A similar study was also performed for 47 single-shell tanks with sample derived ${ }^{90} \mathrm{Sr}$ inventories (best basis inventories). The results show that the adjusted HDW model provided estimates within $+/-100$ percent of the sample estimate for 66 percent of the tanks, and estimates within $+1-200$ percent of the sample estimate for 80 percent of the tanks ( 38 out of 47 tanks in the sample tank population). Thus, approximately 80 percent of the tanks had predicted inventories within a factor of three of the sample derived estimates. For those tanks where the model to sample deviations were high, these deviations clearly exceeded the 95 percent confidence intervals defined in HDW Rev. 4. In other words, the 95 percent $\mathrm{CI}$ in HDW, Rev. 4 does not truly represent the wide range of variability found in the ${ }^{90} \mathrm{Sr}$ tank population

There are a number of potential deficiencies in the HDW model. One limitation involves the accurate identification of all sludge layers in the tanks. This may be a generic problem for many tanks. One way to reduce the possible extent of this error is to cross check the HDW model TLM (Tank Layering Model) profile against core sample profiles from those tanks that have been core sampled. The second source of error involves the distribution of waste to the second or third tanks in a cascade. The distribution assumptions in the model need to be checked against the sample data for the downstream tanks in the cascade. The third source of error involves the composition of such waste in the downstream receiver tanks. The HDW model assumes that these wastes have the same composition profile. Since various components settle at different rates, depending on the solubility and size of precipitates that are formed, the downstream tanks probably contain a sludge that is different in composition from the sludge in the primary receiver tanks. For some radionuclides, such as ${ }^{90} \mathrm{Sr}$, carrier precipitation processes in the presence of ferric iron may be more important in the primary settling tank than in one of the downstream tanks where less iron is expected in the waste. Co-precipitation with iron could bias the expected distribution pattern for ${ }^{90} \mathrm{Sr}$. If organic complexants are present, a significant fraction of the ${ }^{90} \mathrm{Sr}$ might not precipitate even in the presence of iron. Chemistry conditions in the tank can have an important affect on the behavior of trace radionuclides. For this reason, one should always try to calibrate both the model and underlying assumptions in the model with sample data from the target tank population. 
The HDW Model can be used in a variety of ways to rationalize the distribution of trace radionuclides, to test the consistency of sample based estimates, or to test the validity and accuracy of the waste transaction records for certain tanks. The model can also be adjusted to minimize possible discrepancies between model and sample derived estimates. With such adjustments, the model can be used to produce more reliable predictions for those tanks with common waste types that have not been sampled. Since many of these adjustments can be also made for analytes where the sample data exists, it should be possible to tailor the model output for groups of radionuclides that exhibit common chemistry behavior. For example, ${ }^{90} \mathrm{Sr}$ could be used to simulate the behavior of insoluble radionuclides, such as the actinides, ${ }^{154 / 155} \mathrm{Eu}$ could be used for the semisoluble radionuclides; and ${ }^{137} \mathrm{Cs}$ could be used to simulate the behavior of soluble radionuclides. This approach would presumably lead to a better distribution of the radionuclides and significantly improved tank inventory predictions. 
HNF-3273

Revision 0

\section{E7.0 REFERENCES}

Agnew, S. F., J. Boyer, R. A. Corbin, T. B. Duran, J. R. FitzPatrick, K. A. Jurgensen, T. P. Ortiz, and B. L. Young, 1997, Hanford Tank Chemical and Radionuclide Inventories: HDW Model Rev. 4, LA-UR-96-3860, Los Alamos National Laboratory, Los Alamos, New Mexico.

Anderson, J. D., 1990, A History of the 200 Area Farms, WHC-MR-0132, Westinghouse Hanford Company, Richland, Washington.

Borsheim, G. L., and B. C. Simpson, 1991, An assessment of the Inventories of the Ferrocyanide Watchlist Tanks, WHC-SD-WM-ER-133, Rev. 0, Westinghouse Hanford Company, Richland, Washington.

Hartley, S. A., et al., 1996, A Comparison of Historical Tank Content Estimate (HTCE) Model, Revision 3, and Sample-Based Estimates of Hanford Waste Tank Contents, Pacific Northwest National Laboratory, Richland, Washington.

Schneider, K. L., 1951, Flow Sheets and Flow Diagrams of Precipitation Separations Process, HW-23043, Hanford Atomic Products Operations, Richland, Washington. 
HNF-3273

Revision 0

This page intentionally left blank. 


\section{DISTRIBUTION SHEET}

\begin{tabular}{|c|c|c|c|c|c|}
\hline \multirow[b]{2}{*}{ Distribution } & \multirow{2}{*}{\multicolumn{3}{|c|}{ Models and Inventory }} & \multicolumn{2}{|l|}{ Page 1 of 1} \\
\hline & & & & \multicolumn{2}{|c|}{ Date $\quad 10 / 27 / 98$} \\
\hline \multirow{2}{*}{\multicolumn{4}{|c|}{$\begin{array}{l}\text { Project Title/Work Order } \\
\text { HNF-3273, Rev. O, "Hanf } \\
\text { Improvements" }\end{array}$}} & \multicolumn{2}{|c|}{ EDT No. EDT-622490 } \\
\hline & & & & \multicolumn{2}{|c|}{ ECN No. N/A } \\
\hline \multicolumn{2}{|l|}{ Name } & $\begin{array}{c}\text { Text } \\
\text { With } \\
\text { A11 } \\
\text { Attach. }\end{array}$ & Text Only & $\begin{array}{l}\text { Attach.' } \\
\text { Appendix } \\
\text { Only }\end{array}$ & $\begin{array}{c}\text { EDT/ECN } \\
\text { Only }\end{array}$ \\
\hline
\end{tabular}

COGEMA

S. L. Lambert

R3-75 X

U. S. Department of Energy -

Richland Field office

W. LiOU

$57-54$

S7-54

A $0-21$

J. F. Thompson

N. C. Welliver

DOE/RL Reading Room

$\mathrm{H} 2-53$

$x$

Fluor Daniel Hanford

T. R. PauTy

D. J. Washenfelder

$57-40$

S7 -40

$X$
$X$
$X$
$X$

Lockheed Mart in Hanford Corp.

J. W. Cammann

R. W. Harmsen

M. J. Kupfer

R. R. Thompson

R. A. Watrous

T.C.S.R.C.

$\begin{array}{ll}\text { R2 }-11 & X \\ \text { R3 }-75 & X \\ \text { R3-75 } & \text { X } \\ \text { R2 }-12 & X \\ \text { R3-75 } & \text { X } \\ \text { R1-10 } & \text { X }\end{array}$

Lockheed Martin Services, Inc.

Central Files

B1-07 $\quad X$ 